\title{
UNCERTAINTY IN CURRENCY MISPRICING
}

Kenneth Clements (Corresponding author),

Business School, The University of Western Australia.

35 Stirling Highway, Crawley WA 6009, Australia. Phone: +61 86488 2898. E-mail:

Ken.Clements@uwa.edu.au.

Yihui Lan,

Business School, The University of Western Australia

yihui.lan@uwa.edu.au

Jiawei Si,

Business School, The University of Western Australia

jiawei.si@uwa.edu.au

\section{Abstract}

Declaring a currency to be mispriced is fraught with uncertainties. In this paper, these uncertainties are explicitly recognized in a model of pricing a homogeneous commodity around the world. This allows for a common driver of prices, due to a base-currency effect, and country-specific factors that lead to departures from absolute purchasing power parity on account of income differences, local taxes and charges, etc. This approach leads to estimates of currency mispricing whose significance can be tested in the usual way. Using Big Mac prices, we show that the approach has advantages over the popular Big Mac Index to currency valuation.

JEL Classifications: F31, C43

Keywords: Currency Mispricing, Purchasing Power Parity, Stochastic Index Numbers, Equilibrium Exchange Rates 


\section{INTRODUCTION}

In 1972, just prior to the collapse of the Bretton-Woods system of fixed exchange rates, the US dollar cost about 40 British pence. By 1985, the dollar had appreciated to 90 pence, but in September 2015 it had fallen back to 65 pence. Should these substantial currency movements be a concern for policy makers? How do we assess whether these movements are "excessive", or "rational" and reflect economic fundamentals? Is the Chinese RMB still undervalued? Despite the notorious volatility of currency values in the short run and their long-run swings, it is now widely accepted that exchange rates revert back to equilibrium over the long run, so that departures from equilibrium signal temporary misalignment. Exchange rate misalignment is commonly blamed for various domestic and global economic problems, including the loss of international competitiveness, global imbalances, and hindered recovery from the global financial crisis.

Exchange-rate mispricing is unobservable and has to be estimated on the basis of an equilibrium rate. There are a number of approaches to estimating the equilibrium rate and, hence, misalignment. ${ }^{1}$ One of the most prominent is purchasing power parity (PPP), whereby the exchange rate is the ratio between prices at home and abroad. ${ }^{2}$ But even here there can be considerable scope for disagreement and uncertainties. For example, what price should be used in PPP calculations? Price indexes are frequently used, but this entails the additional complication that the underlying baskets should be identical in the two countries, a requirement rarely met in practice. ${ }^{3}$

The Big Mac Index (BMI), published by The Economist magazine, uses hamburger prices as the basis for equilibrium exchange rates. Its advantage lies in the ingredients of a Big Mac hamburger being approximately the same globally and the ready availability of its price in many countries. Therefore, the BMI largely avoids the identical-baskets problem.

\footnotetext{
1 In addition to Purchasing Power Parity, other approaches to equilibrium exchange rates (EERs) include the Fundamental EER (FEER) of Wren-Lewis (1992) and Williamson (1994), the Behavioural EER (BEER) by Edwards (1989), the Natural Real Exchange Rate (NATREX) by Stein (1995a, 1995b), the new open economy macroeconomic (NOEM) approach (Obstfeld and Rogoff, 1995), the Permanent EER (PEER) by Clark and MacDonald (2004), etc. The International Monetary Fund employs related concepts (see, e. g., Lee, et. al, 2008). These models have their own advantages and disadvantages and differ in the formulation of the EER, time frame and the way exchange rate dynamics are modelled. For recent reviews, see Rogoff (2009) and Manzur (2017).

${ }^{2}$ Empirical evidence on the validity of PPP has been controversial (see, e.g. Taylor and Taylor, 2004 and Manzur, 2008). Research on PPP has been voluminous, with recent studies including Arize et al. (2015), Bahmani-Oskooee and Ranjbar (2016), Chortareas and Kapetanios (2009), Dong and Nam (2013), Hall et al. (2013), Jiang et al. (2015), Sarno and Valente (2006), Taylor (2013) and Zhou and Kutan (2011).

${ }^{3}$ The data derived from surveys conducted by the International Comparison Program (ICP) are widely used in PPP-based studies. For example, Frankel (2006), Cheung et al. (2007, 2010) and Coudert and Couharde (2007), among others, use these data to measure the undervaluation of the Chinese Renminbi. For details of the most recent rendition of the ICP data, see World Bank (2015). Cheung and Fujii (2014) find that ICP data revisions can lead to substantial changes in the estimates of exchange rate misalignment.
} 
Cumby (1996) and Ong $(1997,2003)$ are among the first to investigate the performance of the BMI; see Clements et al. (2012) for a review.

Under the BMI, the equilibrium exchange rate equates the cost of a Big Mac hamburger in the two countries, so that deviations from absolute parity are identified as currency mispricing. In this paper, we improve on the BMI in two ways. First, we allow for the substantial bias in the BMI. According to the BMI, the currencies of some countries are continuously over- or under-valued for lengthy periods of time. ${ }^{4}$ It is widely known that Big Mac prices are heavily influenced by a range of country-specific factors, including taxes, labour costs and the cost of non-tradable inputs such as electricity and rents. This means that Big Mac prices are cheaper in poorer countries than in richer ones, so that currencies of lowincome countries appear undervalued and vice versa, along the lines of the BalassaSamuelson productivity-bias hypothesis. ${ }^{5}$ Rather than allowing these long-term factors to represent sustained departures from parity, we incorporate them in a more realistic pricing model. When the long-term deviations from parity are removed, in essence the exchange rate becomes proportional to the price ratio, which amounts to relative parity. There is also an analogous time effect, whereby in a given year, there are common shocks to markets that affect all currencies. As all BMI currencies have the US dollar as their base, this most likely reflects common shocks to the US economy and/or shifts in sentiment away from/towards the US dollar.

Our second improvement is to recast mispricing as an econometric estimation problem that explicitly recognizes the inherent uncertainties involved in valuing a currency. In view of the substantial scope for disagreement regarding the valuation of currencies, focusing on confidence intervals and other uncertainty measures of mispricing, rather than simple point estimates, would seem beneficial. This innovation draws on the stochastic approach to index numbers, which treats the measurement of inflation as a signal-extraction problem: Inflation is the common component that has to be extracted from the noisy prices of individual goods. ${ }^{6}$

The structure of the paper is as follows. Sections 2 and 3 set out a simple model that leads to stochastic measures of currency mispricing. As this involves the extension of the BMI to eliminate bias (over countries and years) and the application of an econometric framework to allow for uncertainty, we call the new index the "enhanced" BMI (EBMI).

\footnotetext{
${ }^{4}$ For example, as shown below, on the basis of the BMI, the Australian dollar was undervalued for at least 15 consecutive years up to 2010 .

5 Since 2012, The Economist has published an "adjusted" BMI to take into consideration income differences between countries. This is an attempt to deal with the issue of systematic departures from parity. As far as we are aware, no studies have evaluated the performance of the adjusted index, possibly because of its short life.

${ }^{6}$ For details of the stochastic approach, see, for example, Clements et al. (2006), Diewert (2005) and Selvanathan and Rao (1994).
} 
Sections 4 and 5 apply the framework to 24 currencies over the last two decades, compare the EBMI to the BMI and analyse the degree of predictability of future currency movements. Section 6 contains concluding comments.

\section{A GLOBAL PRICING MODEL}

Suppose MacDonald's is opening its first store in a country. How might it price hamburgers? A reasonable starting point might be to look at the price of hamburgers in the US and the other country, and then make appropriate adjustments for local conditions. These adjustments could include using an appropriate exchange rate to convert from US dollars to the domestic currency, as well as allowing for differences in local costs and the impact of any impediments to international trade that give rise to a wedge between local and US prices. The exchange rate could reflect the longer term and recognize systematic under- or over-valuation of currencies. These considerations can be summarized in the following simple pricing model:

$$
\mathrm{p}_{\mathrm{it}}=\mathrm{p}_{\mathrm{t}}^{*}+\tilde{\mathrm{s}}_{\mathrm{it}}+\beta_{\mathrm{i}}+\mathrm{u}_{\mathrm{it}}
$$

Here, $\mathrm{p}_{\mathrm{it}}$ is the logarithm of the domestic-currency price of a Big Mac in country i for year $t$, $\mathrm{p}_{\mathrm{t}}^{*}$ is the price in the US in terms of US dollars (also in logs), $\tilde{\mathrm{s}}_{\mathrm{it}}$ is the appropriate exchange rate (the domestic-currency cost of one US dollar, in logs); $\beta_{\mathrm{i}}$ is a country-specific effect; and $\mathrm{u}_{\mathrm{it}}$ is a random term measuring the effects of omitted factors.

According to this model, the local price is the sum of four factors:

$\mathrm{p}_{\mathrm{it}}=$ head-office price in \$US + conversion to domestic currency + country effect + everything else.

These factors can be explained as follows:

- $\quad$ Head-office price $(\mathrm{HO}), \mathrm{p}_{\mathrm{t}}^{*}$ : The HO price is the price of a Big Mac in the US.

- Currency conversion factor, $\tilde{\mathrm{s}}_{\mathrm{it}}$ : The HO price needs to be converted from dollars to the currency of country $i$ by adding the log of the appropriate exchange rate $\tilde{s}_{i t}$ (an increase implies a depreciation of the domestic currency). Due to the possibility of currency misalignment, the exchange rate $\tilde{\mathrm{s}}_{\mathrm{it}}$ is not necessarily the observed rate and is defined as $\tilde{s}_{i t}=s_{i t}+\alpha_{t}$, where $s_{i t}$ is the actual rate and $\alpha_{t}$ is an adjustment factor, common to all countries, that measures the under or overvaluation of the dollar. If, for example, the dollar were under-valued, then using the actual rate to convert the HO price from dollars to domestic currency terms, $s_{i t}+p_{t}^{*}$, would give too low a value as the starting point for local pricing - perhaps so low to be unprofitable. In such a case, 
the required adjustment factor $\alpha_{t}>0$. This adjustment factor can vary from year to year, according to developments in currency markets. But as $\alpha_{t}$ refers to the value of the dollar, the base currency, the adjustment factor affects prices in all non-US countries equiproportionally. Thus, we could call $\tilde{\mathrm{s}}_{\mathrm{it}}$ the "true" exchange rate, with $\alpha_{t}=\tilde{s}_{i t}-s_{i t}$ the deviation of the true value from the actual rate. If purchasing power parity held in absolute form, then $\alpha_{t}=0$. As $\alpha_{t}$ is the deviation from the perspective of the non-US countries, it is convenient to switch signs and refer to $-\alpha_{t}$ as the departure from parity for the dollar: The dollar is thus undervalued if $-\alpha_{t}<0$, and overvalued if $-\alpha_{t}>0$.

- Country effect, $\beta_{\mathrm{i}}$ : This allows for the impacts of local costs, transport costs and all other barriers to trade that prevent domestic prices fully reflecting US prices.

- Everything else, $\mathrm{u}_{\mathrm{it}}$ : There are many forces other than head office effects, currency values and country effects that determine prices. These might include discounting as a marketing strategy in a certain period, changes in the competitive environment faced by the local producer, one-off weather conditions that may influence costs and/or demand for hamburgers in the country, and so on. These effects are included in the random term $\mathrm{u}_{\mathrm{it}}$, which is taken to have an expectation of zero.

Using $\tilde{s}_{\mathrm{it}}=\mathrm{s}_{\mathrm{it}}+\alpha_{\mathrm{t}}$, equation (1) becomes $\mathrm{p}_{\mathrm{it}}=\mathrm{p}_{\mathrm{t}}^{*}+\mathrm{s}_{\mathrm{it}}+\alpha_{\mathrm{t}}+\beta_{\mathrm{i}}+\mathrm{u}_{\mathrm{it}}$, or $\mathrm{p}_{\mathrm{it}}-\mathrm{p}_{\mathrm{t}}^{*}-\mathrm{s}_{\mathrm{it}}=\alpha_{\mathrm{t}}+\beta_{\mathrm{i}}+\mathrm{u}_{\mathrm{it}}$. Define country i's deviation from absolute parity as

$$
\mathrm{q}_{\mathrm{it}}=\log \left(\frac{\mathrm{P}_{\mathrm{it}}}{\mathrm{S}_{\mathrm{it}} \mathrm{P}_{\mathrm{t}}^{*}}\right)=\mathrm{p}_{\mathrm{it}}-\mathrm{p}_{\mathrm{t}}^{*}-\mathrm{s}_{\mathrm{it}},
$$

where uppercase letters are antilogs of their lowercase counterparts, so that equation (1) can be expressed as

$$
\mathrm{q}_{\mathrm{it}}=\alpha_{\mathrm{t}}+\beta_{\mathrm{i}}+\mathrm{u}_{\mathrm{it}}, \quad \mathrm{i}=1, \ldots, \mathrm{n} \text { countries; } \mathrm{t}=1, \ldots, \mathrm{T} \text { years. }
$$

If $\mathrm{q}_{\mathrm{it}}>0$, prices in country $\mathrm{i}$ are too high relative to those of the US and according to the original BMI, the currency is overvalued, and vice versa. In what follows, we use model (2) to enhance this "raw" measure of mispricing.

\section{STOCHASTIC MISPRICING}

In equation (2), $-\alpha_{t}$ is the under- or over-valuation of the US dollar, so that detrended mispricing, $\mathrm{q}_{\mathrm{it}}-\alpha_{\mathrm{t}}=\beta_{\mathrm{i}}+\mathrm{u}_{\mathrm{it}}$, has the expectation of $\beta_{\mathrm{i}}$. As countries vary greatly in economic size, an equally-weighted approach would not be a satisfactory representation of 
this heterogeneity. To make things representative, let $\mathrm{w}_{\mathrm{i}}$ be the weight to be accorded to country $i$ that reflects its relative economic size, with $\sum_{i=1}^{n} w_{i}=1$. The weighted least-squares estimators of $\alpha_{\mathrm{t}}$ and $\beta_{\mathrm{i}}$, subject to the identification constraint $\sum_{\mathrm{i}=1}^{\mathrm{n}} \mathrm{w}_{\mathrm{i}} \beta_{\mathrm{i}}=0$, are (Clements and Izan, 1987)

$$
\hat{\alpha}_{t}=\sum_{i=1}^{n} w_{i} q_{i t}, \quad \hat{\beta}_{i}=\sum_{t=1}^{T} \phi_{t}\left(q_{i t}-\hat{\alpha}_{t}\right),
$$

where $\phi_{\mathrm{t}}=\left(1 / \theta_{\mathrm{t}}^{2}\right) / \sum_{\mathrm{t}=1}^{\mathrm{T}}\left(1 / \theta_{\mathrm{t}}^{2}\right)$ and $\theta_{\mathrm{t}}^{2}=\Sigma_{\mathrm{i}=1}^{\mathrm{n}} \mathrm{w}_{\mathrm{i}}\left[\mathrm{q}_{\mathrm{it}}-\hat{\alpha}_{\mathrm{t}}-(1 / \mathrm{T}) \Sigma_{\mathrm{i}=1}^{\mathrm{n}}\left(\mathrm{q}_{\mathrm{it}}-\hat{\alpha}_{\mathrm{t}}\right)\right]^{2}$ is a type of weighted residual sum of squares. Thus, the estimated common component of the $n$ currencies, $\hat{\alpha}_{t}$, is a weighted average of the raw mispricings, $\mathrm{q}_{1 \mathrm{t}}, \ldots, \mathrm{q}_{\mathrm{nt}}$. The weights are the shares of each country in the world economy, $w_{1}, \ldots, w_{n}$. The country effect, $\hat{\beta}_{i}$, is a weighted average over all $\mathrm{T}$ years of the de-trended mispricing for currency $\mathrm{i}$, $\mathrm{q}_{\mathrm{i} 1}-\alpha_{1}, \ldots, \mathrm{q}_{\mathrm{iT}}-\alpha_{\mathrm{T}}$. To interpret the weights $\phi_{\mathrm{t}}$ in $\hat{\beta}_{\mathrm{i}}$, note that $1 / \theta_{\mathrm{t}}^{2}$ is a measure of goodness-of-fit of the model in year $t$, while $\sum_{t=1}^{\mathrm{T}}\left(1 / \theta_{t}^{2}\right)$ is the same measure for all years combined. Accordingly, as the weight $\phi_{\mathrm{t}}$ is the proportion of the overall goodness-of-fit attributable to year $t, \hat{\beta}_{\mathrm{i}}$ accords more weight to years in which the model more accurately reflects observed mispricing. The sampling variances are $\operatorname{var}\left(\hat{\alpha}_{t}\right)=\theta_{t}^{2} /(n-1)$, $\operatorname{var}\left(\hat{\beta}_{\mathrm{i}}\right)=\left(1 / \mathrm{w}_{\mathrm{i}}-1\right) \sum_{\mathrm{t}=1}^{\mathrm{T}}\left(1 / \theta_{\mathrm{t}}^{2}\right) /(\mathrm{n}-1)$, which also have simple interpretations.

As the error term in equation (2) has a zero-mean, $\mathrm{E}\left(\mathrm{q}_{\mathrm{it}}\right)=\alpha_{t}+\beta_{\mathrm{i}}$, which accords with relative PPP in an expected value sense. That is, the nominal exchange rate is proportional to the ratio of prices, $E\left(S_{i t}\right)=A_{i t}\left(P_{i t} / P_{t}^{*}\right)$, where $A_{i t}=\exp \left(-\alpha_{t}-\beta_{i}\right)$. The error term in equation (2) thus represents the departure from relative parity and the proportional deviation is

$$
\frac{S_{i t}-E\left(S_{i t}\right)}{E\left(S_{i t}\right)}=\frac{e^{-\alpha_{t}-\beta_{i}-u_{i t}}\left(P_{i t} / P_{t}^{*}\right)}{e^{-\alpha_{t}-\beta_{i}}\left(P_{i t} / P_{t}^{*}\right)}-1=e^{-u_{i t}}-1 \approx u_{i t} .
$$

This constitutes a new measure of mispricing, which is adjusted for both the time and the country effects. ${ }^{7}$ We dub this index the "enhanced" BMI (EBMI). ${ }^{8}$

\footnotetext{
${ }^{7}$ Earlier research has also considered that PPP is a time-dependent equilibrium. See, e.g., Manzur and Ariff (1995) who carry out PPP tests based on Divisia indices calculated from deviations of the exchange rate and prices from their respective time effects, and Westerlund and Blomquist (2013) who incorporate a time-specific common factor in panel PPP tests.

8 Our EBMI is different from the "adjusted" index published by The Economist since 2012, as mentioned above. The "adjusted" index takes account of criticisms that Big Macs are cheaper in poorer countries where the
} 
To estimate the EBMI for currency $\mathrm{j}$ in year $\tau$, we add the term $\gamma$ to model (2)

(4)

$$
\mathrm{q}_{\mathrm{j \tau}}=\mathrm{a}_{\tau}+\mathrm{b}_{\mathrm{j}}+\gamma+\varepsilon_{\mathrm{j \tau}},
$$

where $a_{t}$ and $b_{i}$ are the corresponding currency conversion and country effects and $\varepsilon_{i t}$ is a disturbance term. Equation (4) applies for currency $\mathrm{j}$ and year $\tau$ only, while (2) refers to all other pairs of currencies and years. Defining $\delta_{\mathrm{pq}}$ as the Kronecker delta $\left(\delta_{\mathrm{pq}}=1\right.$ if $\mathrm{p}=\mathrm{q}, 0$ otherwise $)$, these two equations can be combined as

$$
\mathrm{q}_{\mathrm{it}}=\mathrm{a}_{\mathrm{t}}+\mathrm{b}_{\mathrm{i}}+\delta_{\mathrm{ij}} \delta_{\mathrm{t \tau}} \gamma+\varepsilon_{\mathrm{it}}, \quad \mathrm{i}=1, \ldots, \mathrm{n} ; \mathrm{t}=1, \ldots, \mathrm{T},
$$

where $a_{t}=\alpha_{t}, t \neq \tau, b_{i}=\beta_{i}, i \neq j$. The weighted least-squares estimate of the EBMI, $\gamma$ is approximately equal to the estimated error term in model (2) for $\mathrm{i}=\mathrm{j}$ and $\mathrm{t}=\tau$, viz., $\mathrm{q}_{\mathrm{j} \tau}-\hat{\alpha}_{\tau}-\hat{\beta}_{\mathrm{j}}$; see Appendix A1 of the online supplementary appendix for details. It is also shown in the online supplementary appendix that the exact expressions for the estimators are

$$
\begin{aligned}
& \hat{a}_{t}=\left\{\begin{array}{cc}
\hat{\alpha}_{t} & \text { when } t \neq \tau \\
\hat{\alpha}_{\tau}+\frac{1}{\left(1-\phi_{\tau}\right)\left(1-1 / \mathrm{w}_{\mathrm{j}}\right)}\left(\mathrm{q}_{\mathrm{j} \tau}-\hat{\alpha}_{\tau}-\hat{\beta}_{\mathrm{j}}\right) & \text { when } \mathrm{t}=\tau
\end{array}\right. \\
& \hat{b}_{\mathrm{i}}=\left\{\begin{array}{cc}
\hat{\beta}_{\mathrm{i}}+\frac{1}{\left(1-1 / \phi_{\tau}\right)\left(1-1 / \mathrm{w}_{\mathrm{j}}\right)}\left(\mathrm{q}_{\mathrm{j} \tau}-\hat{\alpha}_{\tau}-\hat{\beta}_{\mathrm{j}}\right) & \text { when } \mathrm{i} \neq \mathrm{j} \\
\hat{\beta}_{\mathrm{i}}+\frac{1}{\left(1-1 / \phi_{\tau}\right)}\left(\mathrm{q}_{\mathrm{j} \tau}-\hat{\alpha}_{\tau}-\hat{\beta}_{\mathrm{j}}\right) & \text { when } \mathrm{i}=\mathrm{j}
\end{array}\right. \\
& \hat{\gamma}=\frac{1}{\left(1-\phi_{\tau}\right)\left(1-\mathrm{w}_{\mathrm{j}}\right)}\left(\mathrm{q}_{\mathrm{j} \tau}-\hat{\alpha}_{\tau}-\hat{\beta}_{\mathrm{j}}\right) .
\end{aligned}
$$

Here, $\hat{\alpha}_{t}, \hat{\beta}_{i}, \phi_{\tau}$ and $\theta_{t}^{2}$ are as defined in and below equation (3). The sampling variance of the estimated EBMI is $\operatorname{var}(\hat{\gamma})=\theta_{\tau}^{2} /\left[\mathrm{w}_{\mathrm{j}}\left(1-\mathrm{w}_{\mathrm{j}}\right)\left(1-\phi_{\tau}\right)(\mathrm{n}-1)\right]$.

\section{ESTIMATED MISPRICING}

Big Mac prices are available for each year between 1994 and 2014 in 24 currencies. ${ }^{9}$ Figure 1 gives the information on the distribution of the original BMI, or raw mispricing, in logarithmic terms, that is, $\mathrm{q}_{\mathrm{ct}}$ for each year (100 times $\mathrm{q}_{\mathrm{ct}}$ is the approximate percentage

labour costs are lower and vice versa. The underlying model is $\mathrm{P}_{\mathrm{i}} / \mathrm{S}_{\mathrm{i}}=\delta+\lambda G D \mathrm{P}_{\mathrm{i}}+\mathrm{e}_{\mathrm{i}}$, where $\mathrm{P}_{\mathrm{i}}, \mathrm{S}_{\mathrm{i}}$ and $\mathrm{GDP}_{\mathrm{c}}$ are the Big Mac price, the exchange rate and GDP per capita in country $\mathrm{i}$. The Economist calculates the adjusted Big Mac index as $\left(\hat{\mathrm{P}}^{*} / \hat{\mathrm{P}}_{\mathrm{i}}\right)\left(\mathrm{P}_{\mathrm{i}} / \mathrm{P}^{*}\right)-1$, where $\hat{\mathrm{P}}^{*}=\hat{\delta}+\hat{\lambda} \mathrm{GDP}^{*}$ and $\hat{\mathrm{P}}_{\mathrm{i}}=\mathrm{S}_{\mathrm{i}}\left(\hat{\delta}+\hat{\lambda} \mathrm{GDP}_{\mathrm{i}}\right)$ are the fitted prices in the US and country $i$, with $\hat{\delta}$ and $\hat{\lambda}$ being the estimated intercept and slope.

${ }^{9}$ The data are from The Economist (2015). 
deviation). The means and medians are negative in all years, suggesting that the US dollar is over-valued in the whole period. The interquartile range varies from 38 to 65 percent, which is substantial. The dollar is least over-valued in 1995, when the mean $\mathrm{q}_{\mathrm{i}, 1995}$ is -7 percent.

\section{Country and Time Effects}

We initially estimate model (5) with the mispricing parameter $\gamma$ omitted, so that it reverts to model (2). The weights are each country's share in the total trade of the 24-country group and since they vary over time, we divide the 21 -year period into four sub-periods, with six years in the first sub-period and five years in each of the subsequent sub-periods, and use the mean shares. ${ }^{10}$ Figure 2 presents the estimates of the country components of mispricing, $\hat{b}_{i}$. As can be seen, the largest are for those countries with historically strong currencies, Switzerland, Denmark and Sweden, while China, Hong Kong and Malaysia are at the other end. In general, currencies of developed countries in Europe have the largest $\hat{b}_{i}$, while those of developing countries/areas in the far-east have the smallest. There is only a moderate amount of variation between sub-periods, but this is mostly confined to currencies of countries in the middle of the figure, such New Zealand, Australia and Argentina. ${ }^{11}$

Figure 3 presents the estimates of $\hat{a}_{t}$ in the form of a fan chart. The width of the error band varies over time, reflecting how changes in the underlying uncertainty of currency markets: The two-standard-error band ranges from something of the order of 10 percentage points in some years to less than half that in others. Since $-\hat{a}_{t}$ represents mispricing of the US dollar, that currency is not significantly different from parity if the two-standard-error band includes zero. Figure 3 shows this is the case for 1994 and 1996. In all other years except 1995, the estimates of $-\hat{a}_{t}$ are positive, suggesting that the US dollar has been systematically overvalued in most years. This pattern can be compared with that of the raw BMI in Figure 1, where the dots refer to the unweighted means. In broad terms, the patterns in the two figures are similar. ${ }^{12}$

Next, we estimate $\gamma$, mispricing of currency $\mathrm{j}$ in year $\tau$, which is the EBMI. In the previous section this mispricing referred to the specific pair $(\mathrm{j}, \tau)$ only. To investigate

\footnotetext{
${ }^{10}$ Total trade is the sum of current-price exports and imports of goods in US dollars, from the IMF (2015). For details of the data, see Appendix A2 of the online supplementary.

${ }^{11}$ Interestingly, these three are commodity exporters. There is a similar pattern for Brazil, also a commodity exporter.

${ }^{12}$ We have carried out some sensitivity analysis by using two other sets of weights, those based on GDP with (i) market exchange rates used to convert to US dollars, and (ii) PPP exchange rates from the World Economic Outlook published by the International Monetary Fund. Although there are changes, in the main, the results are not overly sensitive to the choice of weights. When trade weights are used (the case reported above), the overvaluation of the dollar lies between that from the other two other cases. For details, see Appendix A2 of the online supplementary appendix A2.
} 
possible mispricing of each currency and in each years, we estimate model (5) n $\cdot \mathrm{T}$ times, by successively setting the currency index $\mathrm{j}$ to $1, \ldots, \mathrm{n}$ and the year index $\tau=1, \ldots \mathrm{T}$. Figure 4 contains a fan chart of the estimated EBMI for the 24 currencies in 2014 . The point estimates are in the range of -20 to 20 percent, except for the Argentina peso that is undervalued by 57 percent. About one-half of the currencies are significantly mispriced in this year. A comparison of the ranking of countries in Figures 2 and 4 reveals there is little or no relationship between mispricing, as measured by the EBMI, and the country component of raw mispricing $\left(\right.$ the $\left.\hat{b}_{\mathrm{i}}\right){ }^{13}$

\section{Comparison with the Raw Index}

The raw Big Mac Index is $\mathrm{q}_{\mathrm{it}}=\log \left[\mathrm{P}_{\mathrm{it}} /\left(\mathrm{S}_{\mathrm{it}} \mathrm{P}_{\mathrm{t}}^{*}\right)\right]$. The estimated EBMI of equation (6) is $\hat{\gamma}=\left(\mathrm{q}_{\mathrm{j} \tau}-\hat{\alpha}_{\tau}-\hat{\beta}_{\mathrm{j}}\right) /\left[\left(1-\phi_{\tau}\right)\left(1-\mathrm{w}_{\mathrm{j}}\right)\right]$, which is the raw BMI stripped of the year and country effects, $\mathrm{q}_{\mathrm{j} \tau}-\hat{\alpha}_{\tau}-\hat{\beta}_{\mathrm{j}}$ scaled by $1 /\left[\left(1-\phi_{\tau}\right)\left(1-\mathrm{w}_{\mathrm{j}}\right)\right]$. As $\phi_{\mathrm{t}}$ and $\mathrm{w}_{\mathrm{i}}$ are both positive fractions, $1 /\left[\left(1-\phi_{\tau}\right)\left(1-\mathrm{w}_{\mathrm{j}}\right)\right] \approx 1 /\left(1-\phi_{\tau}-\mathrm{w}_{\mathrm{j}}\right) \approx 1+\phi_{\tau}+\mathrm{w}_{\mathrm{j}}>1$. Other things equal, larger year and county effects lead to a lower value of the adjusted index, and vice versa. Figure 5 presents histograms of the BMI and EBMI for all $\mathrm{n} \cdot \mathrm{T}$ observations. The raw index clearly exhibits substantially more dispersion: Its standard deviation of 36 percent is more than twoand-one-half times larger that of the EBMI of 14 percent.

Figure 6 compares the evolution of two indices for Australia. According to the raw BMI, the Australian dollar was undervalued for 15 years up to 2009, whereas the EBMI more reasonably fluctuates around zero. For some years, the contrast is stark. Take as an example 2004, arguably the beginning of the Millennium Commodity Boom, from which Australia, as a commodity exporter, was a huge beneficiary. In this year, the Australian dollar was undervalued by about 20 percent on the basis of the BMI, but the EBMI declares it to be overvalued by almost the same amount. This overvaluation is more plausible for a commodity currency at the start of a boom, such as the \$A in that year. The BMI is a lagging indicator as it signals the \$A first became overvalued as late as 2012, when the Millennium Boom was ending. ${ }^{14}$

\footnotetext{
${ }^{13}$ The rank correlation is -0.25 .

${ }^{14}$ The difference between the two indices is approximately the sum of the estimated year and country effects, $\hat{a}_{t}+\hat{b}_{i}$. Hence, in Figure 6 the two almost coincide in 2010, when $\hat{a}_{2010}$ almost offsets $\hat{b}_{A U}$. For comparisons of the two indices for each of the 24 currencies, see Appendix A3 of the online supplementary appendix.
} 
Figure 7 is a scatter plot of the two indices and as can be seen, there is no noticeable relationship between them. The majority of points lie below the 45-degree line, so the raw BMI is smaller than the EBMI, on average. It is also clear that there is greater dispersion along the vertical axis relative to the horizontal, again indicating the lower variance of the EBMI.

\section{PREDICTING FUTURE CURRENCY MOVEMENTS}

An over- (under-) valued currency should subsequently depreciate (appreciate). Does this in fact occur? And if it does, how long does it take for the mispricing to disappear? These issues are investigated in this section. ${ }^{15}$

In Figure 8, we plot the future change in the BMI over a h-year horizon $\Delta_{\mathrm{h}} \mathrm{q}_{\mathrm{i}, \mathrm{t}+\mathrm{h}}=\mathrm{q}_{\mathrm{i}, \mathrm{t}+\mathrm{h}}-\mathrm{q}_{\mathrm{i}, \mathrm{t}}$ against the current EBMI $\hat{\gamma}_{\mathrm{it}}$. We use a rolling window of five years so that the EBMI is based only on past information of the most up-to-date kind. The figure also contains the regression line corresponding to

$$
\Delta_{\mathrm{h}} \mathrm{q}_{\mathrm{i}, \mathrm{t}+\mathrm{h}}=\mathrm{k}_{0}^{(\mathrm{h})}+\mathrm{k}_{1}^{(\mathrm{h})} \hat{\gamma}_{\mathrm{it}}+\mathrm{e}_{\mathrm{it}}^{(\mathrm{h})},
$$

where $\mathrm{k}_{0}^{(\mathrm{h})}$ and $\mathrm{k}_{1}^{(\mathrm{h})}$ are coefficients for horizon $\mathrm{h}$ and $\mathrm{e}_{\mathrm{it}}^{(\mathrm{h})}$ is a disturbance. In this context, ordinary least-squares estimates are unbiased but the standard errors are incorrect due to the two special characteristics of our data: Overlapping observations and clustering by year and country. We thus first transform the data to put them on a non-overlapping basis, following Britton-Jones et al. (2011). We then apply Thompson's (2011) clustering approach to the transformed data to obtain robust standard errors that are adjusted for correlation across years and countries.

Under the purchasing power parity hypothesis, deviations are temporary and over time, the rate returns to equilibrium. If, for example, the currency is currently undervalued, a future appreciation is to be expected, so that $q_{i, t+h}$ would increase relative to $q_{i t}$. The h-year subsequent change is $\Delta_{h} q_{i, t+h}=\left(p_{i, t+h}-p_{i t}\right)-\left(p_{t+h}^{*}-p_{t}^{*}\right)-\left(s_{i, t+h}-s_{i t}\right)$, so that $\Delta_{h} q_{i, t+h}>0$ would mean either inflation at home, an appreciation of the nominal rate (a fall in s), or any combination of the two. Measuring mispricing by $\hat{\gamma}_{\text {it }}$ means that the points in Figure 8 should mostly lie in the second and fourth quadrants and the regression line have a negative slope.

\footnotetext{
${ }^{15}$ For analyses along similar lines, see Cumby (1996) and Clements et al. (2012).
} 
Although there is considerable randomness, these predictions seem to be mostly borne out in the figure, especially as the forecast horizon lengthens. ${ }^{16}$

There is a further implication of pricing model (4). That model implies that the h-year change in $\mathrm{q}_{\mathrm{it}}$ is

$$
\Delta_{h} \mathrm{q}_{\mathrm{i}, \mathrm{t}+\mathrm{h}}=\mathrm{a}_{\mathrm{t}+\mathrm{h}}-\mathrm{a}_{\mathrm{t}}+\gamma_{\mathrm{i}, \mathrm{t}+\mathrm{h}}-\gamma_{\mathrm{it}}+\varepsilon_{\mathrm{i}, \mathrm{t}+\mathrm{h}}-\varepsilon_{\mathrm{it}},
$$

so the currency effect drops out. Suppose that PPP holds h years into the future, that is $\gamma_{\mathrm{i}, \mathrm{t}+\mathrm{h}}=0$. Equation (8) then takes the form of (7) with the slope coefficient $\mathrm{k}_{1}^{(\mathrm{h})}=-1$, the intercept $\mathrm{k}_{0}^{(\mathrm{h})}$ now varying with time and equal to $\mathrm{a}_{\mathrm{t}+\mathrm{h}}-\mathrm{a}_{\mathrm{t}}$, and the disturbance $\mathrm{e}_{\mathrm{i}, \mathrm{t}+\mathrm{h}}=\varepsilon_{\mathrm{i}, \mathrm{t}+\mathrm{h}}-\varepsilon_{\mathrm{it}}$. In Figure 8, for simplicity, the h-year change in the year effect is taken to be a constant. Figure 9 is a fan-chart of the estimated slopes and as can be seen, the slopes are all negative and mostly decrease with the horizon. The 95-percent confidence interval (based on robust standard errors) always includes the value of -1 for horizons greater than 5 years, which could be taken as an estimate of the long run for PPP. ${ }^{17}$ As PPP is usually thought to refer to the long run, a five-year adjustment period is not implausible. ${ }^{18}$

Next, we compare the predictive properties of the EBMI with those of the BMI. Panel A of Table 1 reproduced the estimates of model (7) from Figure 8, while panel B contains similar regressions with the BMI replacing the EBMI. Compared to the BMI, for each horizon, the slope coefficient for the EBMI is closer to -1 . As the -1 value means full adjustment to current mispricing, this result points to the advantage of the EBMI. What if we use a linear combination of the two methods? Panel $\mathrm{C}$ reveals this approach has some benefit as the estimated BMI weight is of the order of one-half, which means that the optimal predictor is an unweighted average of the EBMI and the BMI. It is also noteworthy that the slope coefficients are now even closer to the PPP value of -1 .

Finally, panel A of Figure 10 contains the root-mean-squared errors (RMSEs) of the three prediction methods. For all horizons, the EBMI and the average prediction are quite similar with RMSEs usually in the range of about 20-25 percent, while that of the BMI is about 15 points higher at around 40 percent. When the overlapping observations are dropped (panel B), there is more variability, but the results are qualitatively similar. Figure 11 shows

\footnotetext{
${ }^{16}$ Cumby (1996) and Clements et al. (2012) also make a similar conclusion along this line. Though not mentioned in these papers, simple algebra shows that if sampling implications are ignored, the regression slope coefficient over the $h$-year horizon $(h>1)$ is approximately $h$ times that of the 1-year horizon regression.

${ }^{17}$ We also experimented with separate intercepts for each year. Qualitatively, the results for the slope are almost the same.

${ }^{18}$ Note that if the disturbances in model (4), $\varepsilon_{\mathrm{it}}$, are serially uncorrelated, then the h-year differences in (8), $\varepsilon_{\mathrm{i}, \mathrm{t}+\mathrm{h}}-\varepsilon_{\mathrm{it}}$, will not be. While this is ignored, any serial correlation declines as the horizon increases, that is, as PPP becomes more likely to hold.
} 
the sensitivity of the results for the weighted average by varying the weights: As the weight accorded to the BMI increases, the quality of the weighted average prediction almost always deteriorates.

In summary, the EMBI is an imperfect measure, but it seems to do a reasonable job predicting future currency movements, especially over the longer term. While the EBMI dominates the BMI, the BMI still has some predictive value when averaged with the EBMI.

\section{CONCLUDING COMMENTS}

Understanding the valuation of currencies is a significant intellectual challenge and of great importance for policy, the efficient functioning of financial markets and the financial management of international companies. In view of the volatility of exchange rates, measures of the over-/under-valuation of currencies should come with considerable scepticism. There will always be debate (disputation?) regarding the underlying theory - Purchasing Power Parity (PPP), the Fundamental Equilibrium Exchange Rate, the Behavioural Equilibrium Exchange Rate and the Natural Real Exchange Rate are popular models that all have their own strengths and weaknesses, supporters and detractors. Even once a model is agreed upon, there is the further issue of uncertainty of the numerical values of parameters, which usually have to be estimated econometrically. Notwithstanding the difficulties, there is still a strong demand for these measures from financial markets, importers and exporters, and policy makers.

In this paper, we explicitly acknowledged at least some of the inherent uncertainties in currency valuation by using an approach in which mispricing is stochastic. Mispricing has a probability distribution, the dispersion of which reflects the extent to which the underlying model adequately describes the data. We use a weak version of PPP theory (the "relative" version) in the form of a model of the price of a homogeneous product (Big Mac hamburgers) in different countries. Departures from the model signal currency misalignment and our approach means that it is possible to test if this is significantly different from zero. We dub this new measure the "extended Big Mac Index". The results indicate substantial differences from the conventional Big Mac Index of The Economist magazine.

We conclude with a recapitulation of our approach to currency mispricing that can be summarized in seven elements:

1. Absolute parity: We start with the Big Mac Index (BMI) that uses absolute PPP with the exchange rate equalising the dollar price of a Big Mac hamburger in the home country with that in the US. That is, if $P_{i t}$ and $P_{t}^{*}$ are the prices for year $t$ in country $i$ 
and the US respectively, then $\mathrm{P}_{\mathrm{it}} / \mathrm{S}_{\mathrm{it}}=\mathrm{P}_{\mathrm{t}}^{*}$, where $\mathrm{S}_{\mathrm{it}}$ is the exchange rate (the domestic-currency cost of the dollar). The BMI uses the observed rate to measure currency mispricing as the proportionate departure from parity, $\left(\mathrm{P}_{\mathrm{it}} / \mathrm{S}_{\mathrm{it}}-\mathrm{P}_{\mathrm{t}}^{*}\right) / \mathrm{P}_{\mathrm{t}}^{*}$. For reasons of convenience, we use a logarithmic formulation of the deviation from parity, $\log \left(\mathrm{P}_{\text {it }} / \mathrm{S}_{\mathrm{it}} \mathrm{P}_{\mathrm{t}}^{*}\right) \approx\left(\mathrm{P}_{\text {it }} / \mathrm{S}_{\mathrm{it}}-\mathrm{P}_{\mathrm{t}}^{*}\right) / \mathrm{P}_{\mathrm{t}}^{*}$. If $\mathrm{q}_{\mathrm{it}}=\log \left(\mathrm{P}_{\mathrm{it}} / \mathrm{S}_{\mathrm{it}} \mathrm{P}_{\mathrm{t}}^{*}\right)$, then parity holds when $\mathrm{q}_{\mathrm{it}}=0$.

2. Relative parity: As the BMI is known to systematically under or over value certain currencies for sustained periods, it is a biased measure of mispricing. Thus, we debias the BMI for each currency by subtracting its average deviation from parity.

3. Dollar shocks: As the US dollar is the base currency, fluctuations in the dollar that represent departures from parity impart shocks of the opposite sign to all other currencies. We measure mispricing of the dollar in a given year by averaging over currencies the departures form parity in that year.

4. The extended Big Mac Index: The new measure of mispricing is the extended BMI (EBMI). This accounts for currency and dollar effects -- to be denoted by bias ${ }_{\mathrm{i}}$ and (\$US mispricing) $)_{\mathrm{t}}$, respectively -- that represent systematic departures from absolute parity. Accordingly,

Mispricing of currency $\mathrm{i}$ in year $\mathrm{t}=$

$$
\mathrm{k}_{\mathrm{it}} \cdot\left[\mathrm{q}_{\mathrm{it}}-\text { bias }_{\mathrm{i}}+(\text { SUS mispricing })_{\mathrm{t}}\right] \text {, with } \mathrm{k}_{\mathrm{it}}=\frac{1}{\left(1-\phi_{\mathrm{t}}\right)\left(1-\mathrm{w}_{\mathrm{i}}\right)} \text {. }
$$

As this is in logarithmic terms, multiplication by 100 is the percentage mispricing.

5. The scaling factor: The terms $\phi_{t}$ and $\mathrm{w}_{\mathrm{i}}$ in the scaling factor $\mathrm{k}_{\mathrm{it}}$ are positive fractions, so $\mathrm{k}_{\mathrm{it}} \approx 1+\phi_{\mathrm{t}}+\mathrm{w}_{\mathrm{i}}>1$. The fraction $\phi_{\mathrm{t}}$ is the relative importance of year $\mathrm{t}$ in the overall period under consideration; if, for example, the residual variance is lower in $\mathrm{t}$, then $\phi_{\mathrm{t}}$ takes a larger value. The fraction $\mathrm{w}_{\mathrm{i}}$ measures the relative size of country $\mathrm{i}$ in the world economy. Accordingly, $\mathrm{k}_{\mathrm{it}}$ increases with the importance of the year in question and the share of world economy accounted for by the country under consideration. Currency mispricing is thus proportional to the BMI after allowing for currency biases and base-currency shocks.

6. Hypothesis testing: Precise expressions are given in the paper for each of the terms above, as well as their standard errors. This means that the significance of any mispricing, and its components, can be investigated. 
7. Predicting exchange rates: If, for example, $\mathrm{EBMI}_{\mathrm{it}}>0$, then domestic prices are too high, the currency is over-valued and can be expected to adjust in the future either by a nominal depreciation or higher inflation, or by some combination of the two. The EBMI was found to predict future exchange rates better than the BMI. There is also some evidence in favour of averaging the two indexes.

Acknowledgements

We thank Haiyan Liu for excellent research assistance. For helpful comments, we would like to thank an anonymous referee. This research was financed in part by the ARC and BHP. All errors are our own.

\section{Disclosure}

The authors do not have any financial interests or benefits that will arise from the direct applications of this research.

\section{REFERENCES}

Arize, A. C., J. Malindretos, and D. Ghosh (2015). "Purchasing Power Parity-Symmetry and Proportionality: Evidence from 116 Countries." International Review of Economics and Finance 37: 69-85.

Bahmani-Oskooee, M., and O. Ranjbar (2016). "Quantile Unit Root Test and PPP: Evidence from 23 OECD Countries.” Applied Economics 1-13.

Britton-Jones, M., A. Neuberger and I. Nolite (2011). "Improved Inference in Regression with Overlapping Observations." Journal of Business Finance and Accounting 38: 65783.

Cheung, Y-W., M. D. Chinn and E. Fujii (2007). "The Overvaluation of Renminbi Undervaluation." Journal of International Money and Finance 26: 762-85.

Cheung, Y-W., M. D. Chinn and E. Fujii (2010). "Measuring Renminbi Misalignment: Where do We Stand?" Korea and the World Economy 11: 263-96.

Cheung, Y. W., and E. Fujii (2014). "Exchange Rate Misalignment Estimates-Sources Of Differences.” International Journal of Finance and Economics 19(2): 91-121.

Chortareas, G., and G. Kapetanios (2009). "Getting PPP Right: Identifying Mean-Reverting Real Exchange Rates in Panels." Journal of Banking and Finance 33: 390-404.

Clark, P.B., and MacDonald, R., 2004. "Filtering the BEER: a Permanent and Transitory Decomposition." Global Finance Journal 15: 29-56.

Clements, K. W., and H. Y. Izan (1987). "The Measurement of Inflation: A Stochastic Approach." Journal of Business and Economic Statistics 5: 339-50.

Clements, K. W., H. Y. Izan and E. A. Selvanathan (2006). "Stochastic Index Numbers: A Review." International Statistical Review 74: 235-70.

Clements, K. W., Y. Lan and S. Seah (2012). "The Big Mac Index Two Decades On: An Evaluation of Burgernomics.” International Journal of Finance and Economics 17: 3160.

Coudert, V., and C. Couharde (2007). "Real Equilibrium Exchange Rate in China: Is the Renminbi Undervalued?" Journal of Asian Economics 18: 568-94.

Cumby, R. E. (1996). "Forecasting Exchange Rates and Relative Prices with the Hamburger Standard: Is What You Want What You Get with McParity?" NBER Working Paper 5675 .

Diewert, W. E. (2005). "Weighted Country-Product-Dummy Variable Regressions and Index Number Formulae." Review of Income and Wealth 51: 561-70. 
Dong, W., and D. Nam (2013). "Exchange Rates and Individual Good's Price Misalignment: Evidence of Long-Horizon Predictability." Journal of International Money and Finance 32: 611-636.

Frankel, J. (2006). "On the Yuan: The Choice between Adjustment under a Fixed Exchange Rate and Adjustment under a Flexible Rate." CESifo Economic Studies 52: 246-75.

Hall, S. G., G. Hondroyiannis, A. Kenjegaliev, P. A. V. B. Swamy, and G. S. Tavlas (2013). "Is the Relationship between Prices and Exchange Rates Homogeneous?" Journal of International Money and Finance 37: 411-438.

IMF (2015). International Financial Statistics. Washington DC: International Monetary Fund. Jiang, C., M. Bahmani-Oskooee and T. Chang (2015). "Revisiting Purchasing Power Parity in OECD." Applied Economics 47(40): 4323-4334.

Lee, J., J. D. Ostry, A. Prati, L. A. Ricci and G-M. Milesi-Ferretti (2008). Exchange Rate Assessments: CGER Methodologies. Occasional Paper No. 261. Washington DC: International Monetary Fund.

Manzur, M., ed., (2008). Purchasing Power Parity. Cheltenham, UK: Edward Elgar.

Manzur, M. (2017). "Exchange Rate Economics is Always and Everywhere Controversial." Applied Economics. doi:10.1080/00036846.2017.1313960

Manzur, M., and M. Ariff (1995). "Purchasing Power Parity: New Methods and Extensions." Applied Financial Economics, 5(1): 19-26.

Obstfeld, M., and K. Rogoff. 1995. "Exchange Rate Dynamics Redux." Journal of Political Economy 103: 624-660. doi:10.1086/261997.

Ong, L. L. (1997). "Burgernomics: the Economics of the Big Mac Standard." Journal of International Money and Finance 16: 865-78.

Ong, L. L. (2003). The Big Mac Index: Applications of Purchasing Power Parity. London: Macmillan.

Rogoff, K. (2009). "Exchange Rates in the Modern Floating Era: What do We Really Know?" Review of World Economics 145(1): 1-12.

Sarno, L., and G. Valente (2006). "Deviations from Purchasing Power Parity under Different Exchange Rate Regimes: Do they Revert and, if so, How?" Journal of Banking and Finance 30: 3147-69.

Selvanathan, E. A., and P. Rao (1994). Index Numbers: A Stochastic Approach. Michigan: University of Michigan Press.

Stein, J. L. (1995a). "The Natural Real Exchange Rate of the United States Dollar and the Determination of Capital Flows." In J. L. Stein, P. Reynolds-Allen, Fundamental Determinants of Exchange Rates. Oxford: Oxford University Press.

Stein, J. (1995b). "The Fundamental Determinants of the Real Exchange Rate of the U.S. Dollar Relative to Other G-7 Currencies." IMF Working Paper 95-81.

Taylor, A.M., and M. P. Taylor (2004). "The Purchasing Power Parity Debate." Journal of Economic Perspectives 18: 135-58.

Taylor, M. P., (ed.) (2013). Purchasing Power Parity and Real Exchange Rates. Oxon UK: Routledge.

The Economist (2015). "The Big Mac Index." Available at: http://www.economist.com/ content/big-mac-index. [Accessed 30 November 2015].

Thompson, S. B. (2011). "Simple Formulas for Standard Errors that Cluster by Both Firm and Time." Journal of Financial Economics 99: 1-10.

Westerlund, J., and Blomquist, J. (2013). A modified LLC panel unit root test of the PPP hypothesis. Empirical Economics 44(2): 833-860.

Williamson, J. (1994). Estimating Equilibrium Exchange Rates. Washington DC: Institute for International Economics.

World Bank (2015). Purchasing Power Parities and the Real Size of World Economies: A Comprehensive Report of the 2011 International Comparison Program. Washington DC: International Bank for Reconstruction and Development/World Bank. 
http://siteresources.worldbank.org/ICPEXT/Resources/ICP-2011-report.pdf

Wren-Lewis, S. (1992). "On the Analytical Foundations of the Fundamental Equilibrium Exchange Rate.” In C. P. Hargreaves (ed.) Macroeconomic Modelling of the Long Run. Edward Elgar.

Zhou, S., and A. M. Kutan (2011). "Is the Evidence for PPP Reliable? A Sustainability Examination of the Stationarity of Real Exchange Rates." Journal of Banking and Finance 35: 2479-90. 
Figure 1 Raw Currency Mispricing of 24 Currencies, 1994-2014

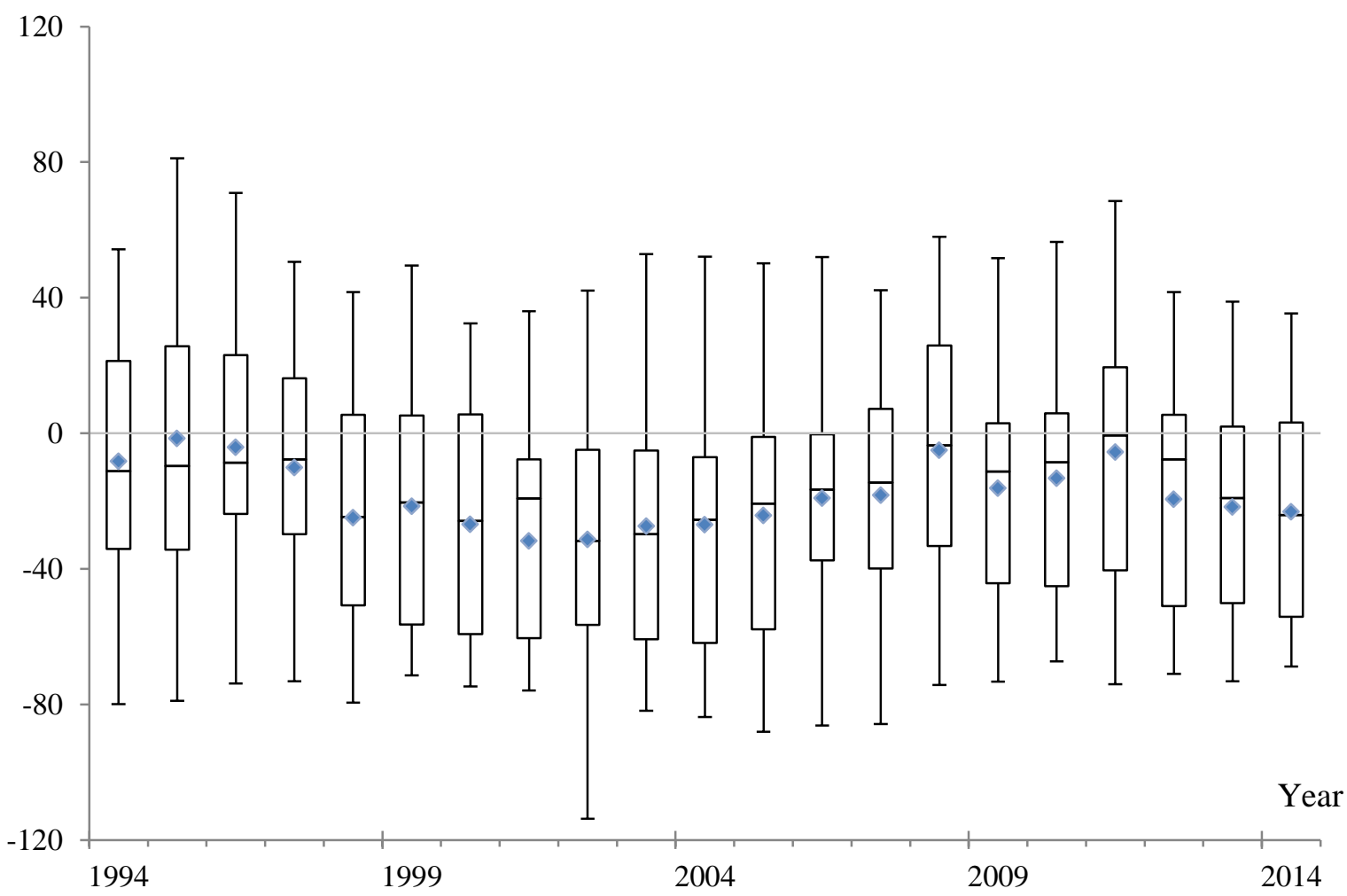

Note: This figure contains boxplots for 24 currencies in each year of the BMI, or raw mispricing, in logarithmic form, that is, $\mathrm{q}_{\mathrm{it}}=\log \left(\mathrm{P}_{\mathrm{it}} / \mathrm{S}_{\mathrm{it}} \mathrm{P}_{\mathrm{t}}^{*}\right)$, where, for year $\mathrm{t}, \mathrm{P}_{\mathrm{it}}$ and $\mathrm{P}_{\mathrm{t}}^{*}$ are the prices of a Big Mac in country $\mathrm{i}$ and the US, respectively; and $S_{i t}$ is the exchange rate (the cost in terms of currency i of $\$ U S 1$ ). If $q_{i t}>0$, prices in country $i$ are too high relative to those of the US and according to the BMI, the currency of $i$ is overvalued, and vice versa. All entries are $\times 100$. 
Figure 2 Country Components of Raw Currency Mispricing in 24 Countries, 1994-2014

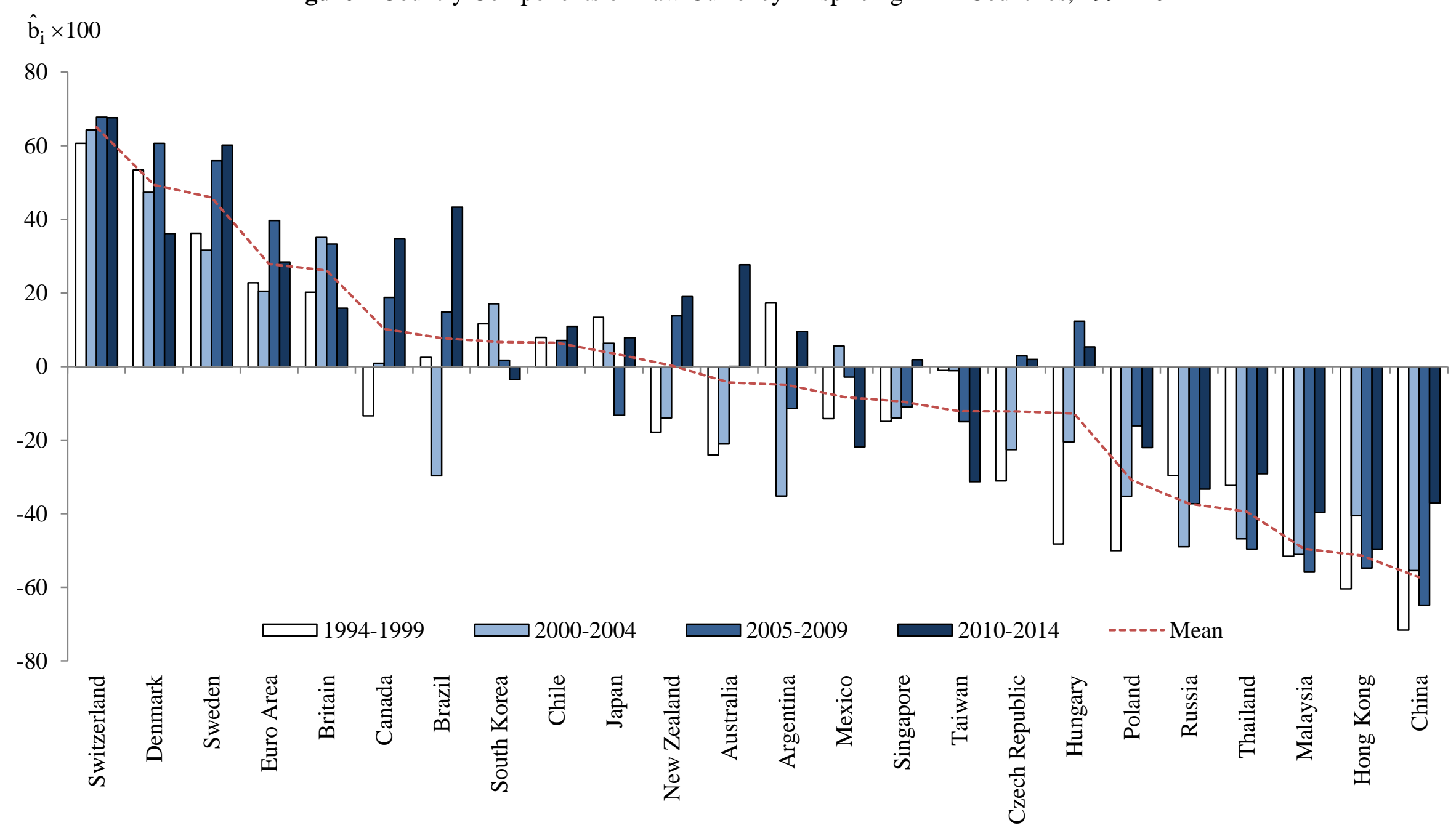

Note: This figure plots estimates of the currency component, $\beta_{i}$, in $q_{i t}=\alpha_{t}+\beta_{i}+u_{i t}, i=1, \ldots, 24$ currencies, $t=1, \ldots, T$ years. Here, $q_{i t}=\log \left(P_{i t} / S_{i t} P_{t}^{*}\right)$ is the BMI or raw mispricing. If $\mathrm{q}_{\mathrm{it}}>0$, the currency is overvalued vis-a-vis the dollar. 
Figure 3 Time Component of Raw Currency Mispricing in 24 Countries, 1994-2014

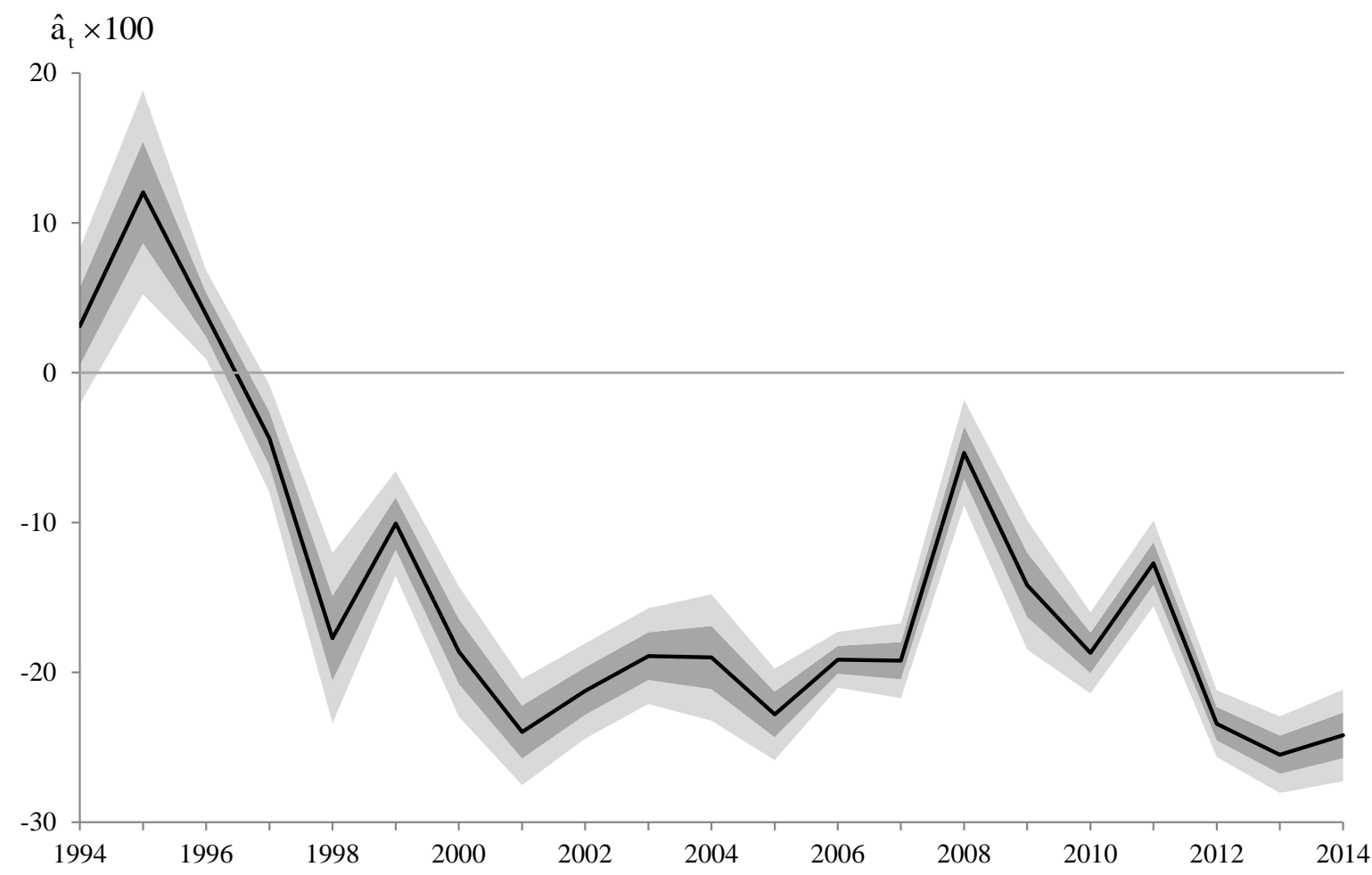

Note: The solid dark line represents the estimated time components, $\alpha_{t}$, in $q_{i t}=\alpha_{t}+\beta_{i}+u_{i t}, i=1, \ldots, 24$ currencies, $\mathrm{t}=1, \ldots, \mathrm{T}$ years. The dark grey band is $+/$ - one standard error, and the light grey band is $+/$ two standard errors. When, for some $t$, the light grey band includes 0 , we are unable to reject Ho: $\alpha_{t}=0$. 
Figure 4 Currency Mispricing, the Enhanced Big Mac Index, 2014

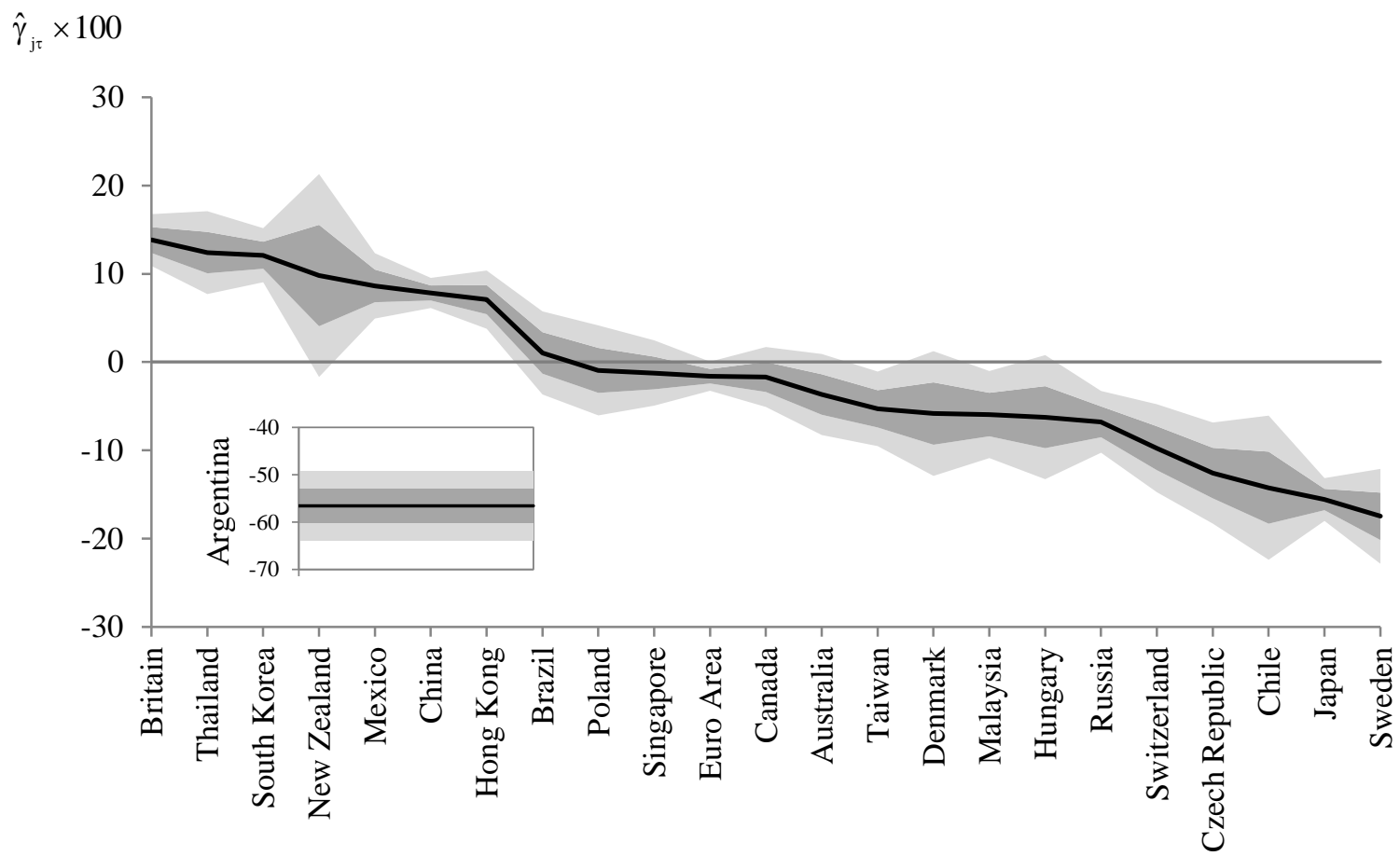

Note: The solid dark line represents the enhanced BMI (EBMI) for each currency in 2014, that is, the estimate of $\gamma$ in $\mathrm{q}_{\mathrm{it}}=\mathrm{a}_{\mathrm{t}}+\mathrm{b}_{\mathrm{i}}+\delta_{\mathrm{ij}} \delta_{\mathrm{tr}} \gamma+\varepsilon_{\mathrm{it}}$, where $\delta_{\mathrm{pq}}$ is the Kronecker delta ( $\delta_{\mathrm{pq}}=1$ if $\mathrm{p}=\mathrm{q}, 0$ otherwise). The dark grey band is the EBMI +/- one standard error, and the light grey band is $+/$ - two standard errors. When, for some currency, the light grey band includes 0 , we are unable to reject $\mathrm{H}_{0}: \gamma=0$. 
Figure 5 Two Measures of Mispricing, 24 Currencies, 1994-2014

\section{A. The BMI}

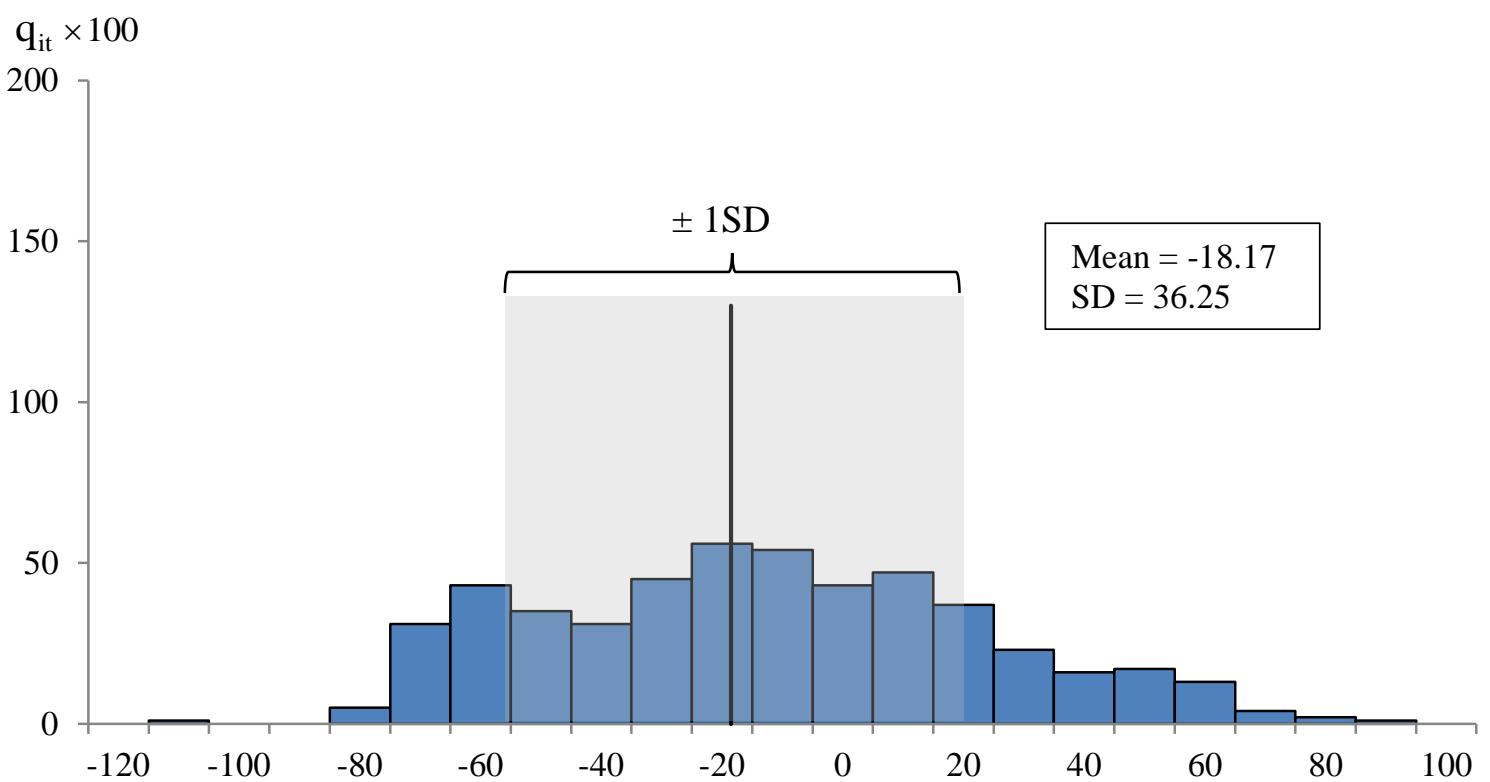

B. The Enhanced BMI

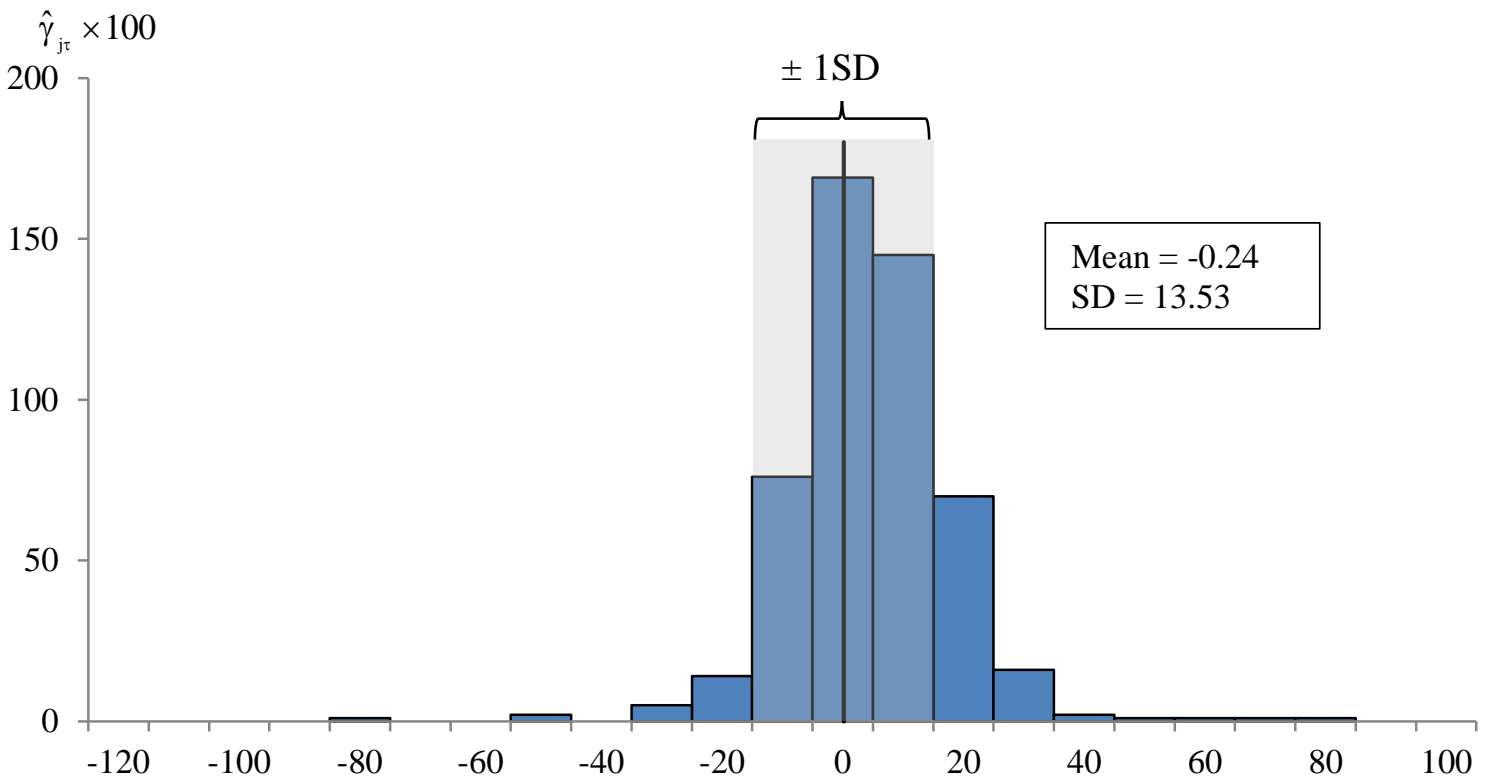

Notes:

1. Panel $\mathrm{A}$ is a histogram of the BMI for all currencies and years. That is, $\mathrm{q}_{\mathrm{it}}=\log \left(\mathrm{P}_{\mathrm{it}} / \mathrm{S}_{\mathrm{it}} \mathrm{P}_{\mathrm{t}}^{*}\right)$ for $\mathrm{i}=1, \ldots, 24$ countries and $t=1994, \ldots, 2014$. For year $t, P_{i t}$ and $P_{t}^{*}$ are the prices of a Big Mac in country $i$ and the US; and $\mathrm{S}_{\mathrm{it}}$ is the exchange rate. According to the BMI, the currency is overvalued if $\mathrm{q}_{\mathrm{it}}>0$ and vice versa.

2. Panel $B$ is a similar histogram for the EBMI, which is the estimate of $\gamma$ in $\mathrm{q}_{\mathrm{it}}=\mathrm{a}_{\mathrm{t}}+\mathrm{b}_{\mathrm{i}}+\delta_{\mathrm{ij}} \delta_{\mathrm{tt}} \gamma+\varepsilon_{\mathrm{it}}$. This equation is estimated $24 \times 21$ times with the subscripts $(\mathrm{j}, \tau)$ successively taking each currency-year pair, $j=1, \ldots, 24, \tau=1994, \ldots, 2014$. 
Figure 6 Two Measures of Mispricing, Australian Dollar

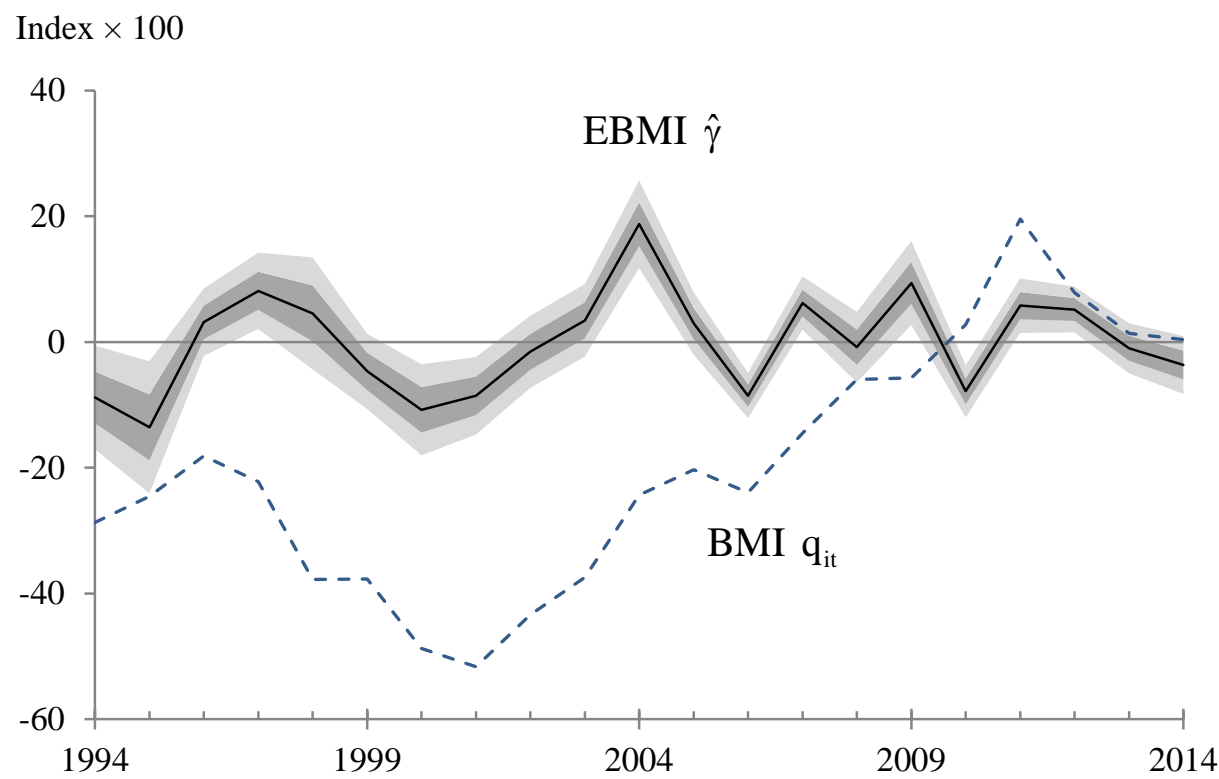

Note: The solid dark line represents the enhanced BMI (EBMI) for Australia. This is the estimate of $\gamma, \hat{\gamma}$, in $\mathrm{q}_{\mathrm{it}}=\mathrm{a}_{\mathrm{t}}+\mathrm{b}_{\mathrm{i}}+\delta_{\mathrm{ij}} \delta_{\mathrm{t} \tau} \gamma+\varepsilon_{\mathrm{it}}$, when the model is estimated 21 times with the subscript pair $(\mathrm{j}, \tau)$ referring to Australia in each year successively; that is, for $\mathrm{j}=$ Australia and $\tau=1, \ldots, 21$ years. The dark grey band is the EBMI +/- one standard error, and the light grey band is +/- two standard errors. When the light grey band includes 0 , we are unable to reject $\mathrm{H}_{0}: \gamma=0$; and when the band includes the BMI, we are unable to reject $\mathrm{H}_{0}: \gamma=$ BMI. 
Figure 7 Scatter Plot of Two Measures of Mispricing, 24 Currencies, 1994-2014

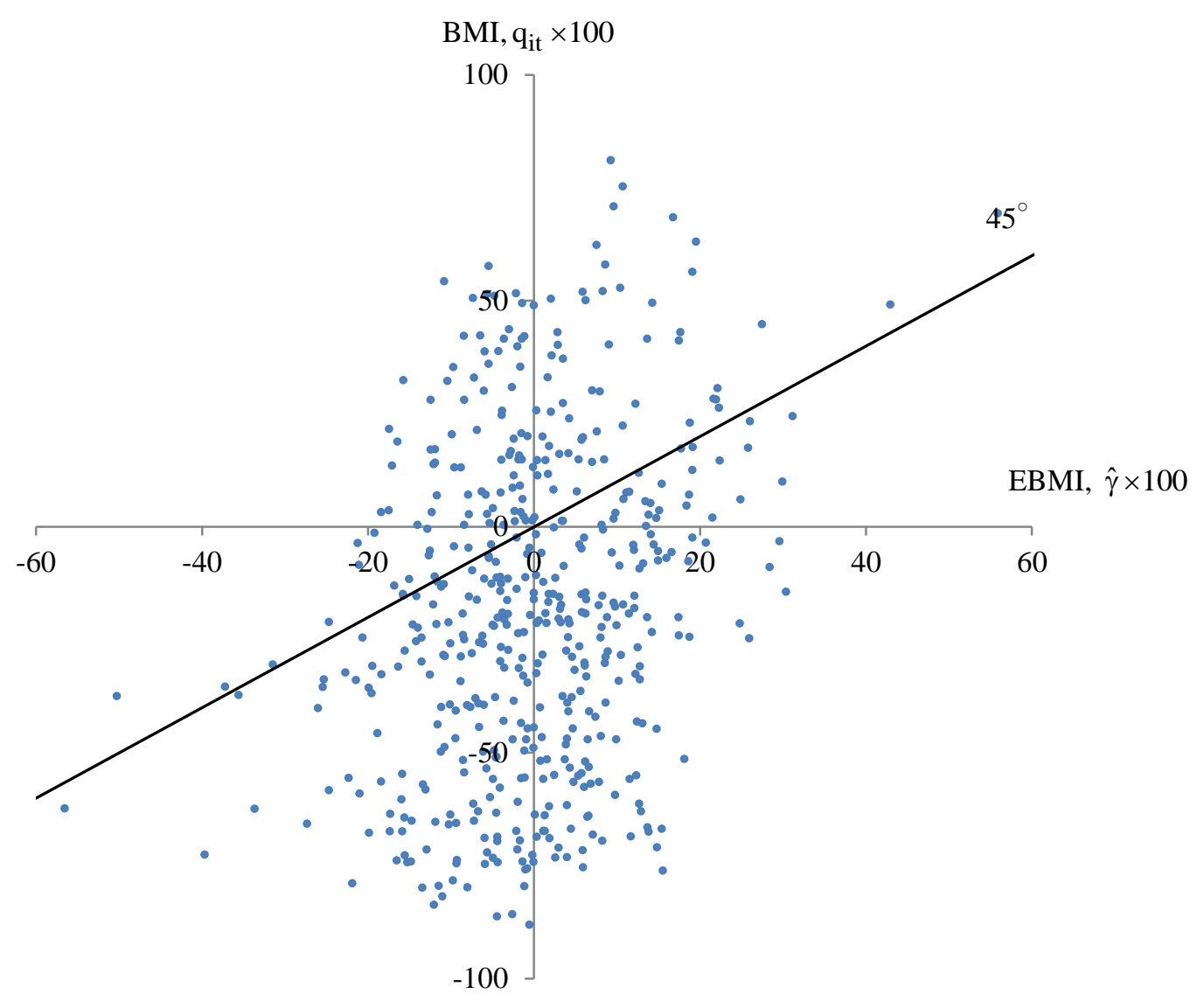

Note: See notes to Figure 5. 
Figure 8 Predictions of Future Currency Movements, 24 Currencies, 1994-2014

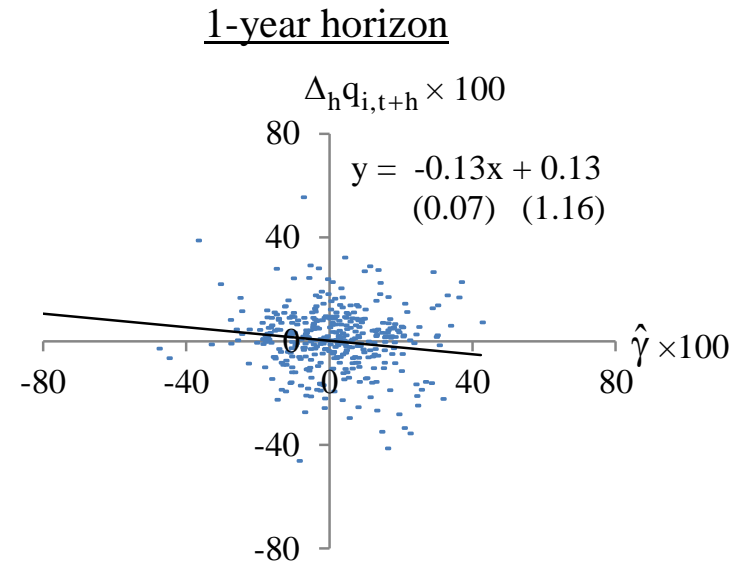

3-year horizon

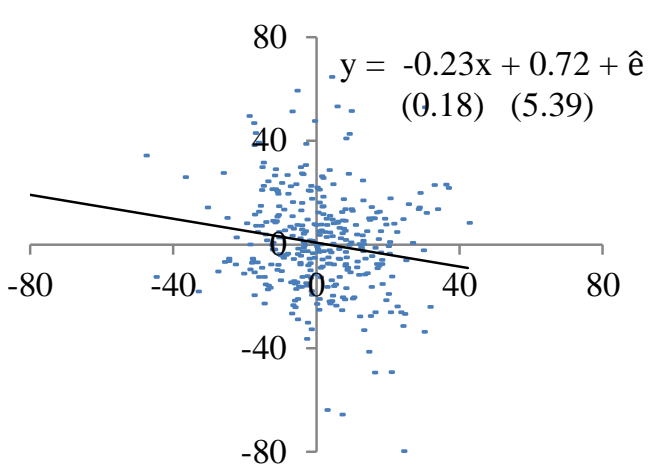

5-year horizon

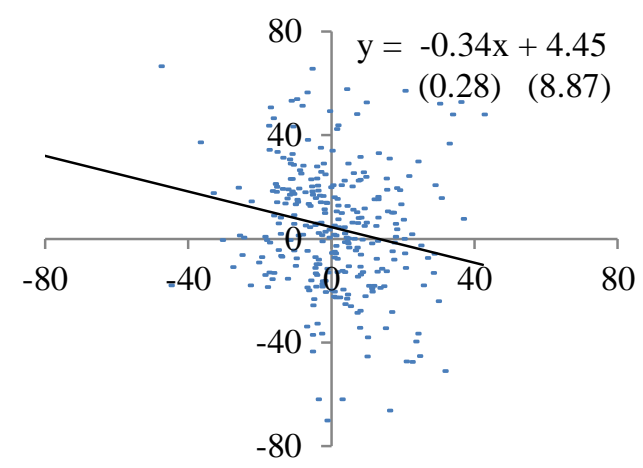

$\underline{7-y e a r ~ h o r i z o n}$

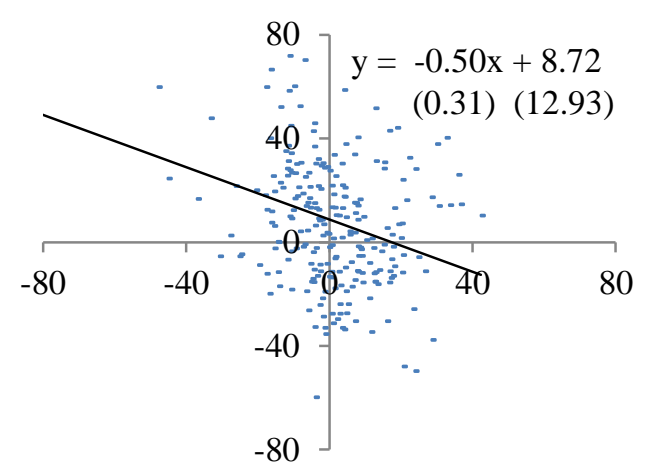

$\underline{2-y e a r ~ h o r i z o n ~}$

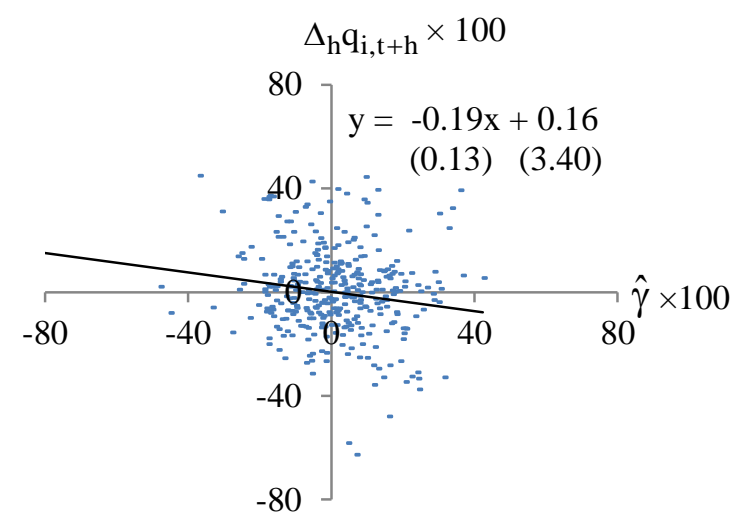

\section{4-year horizon}

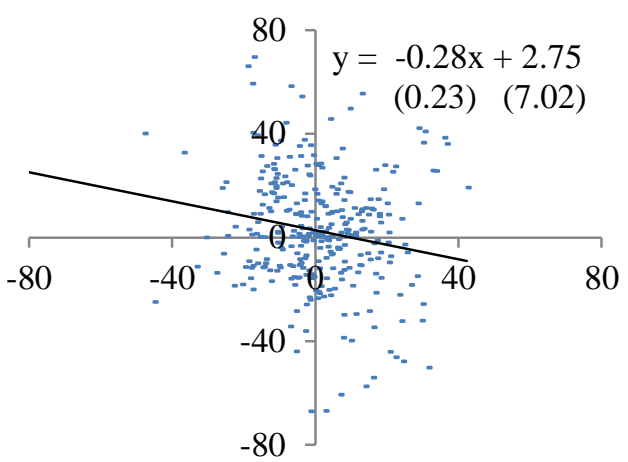

6-year horizon

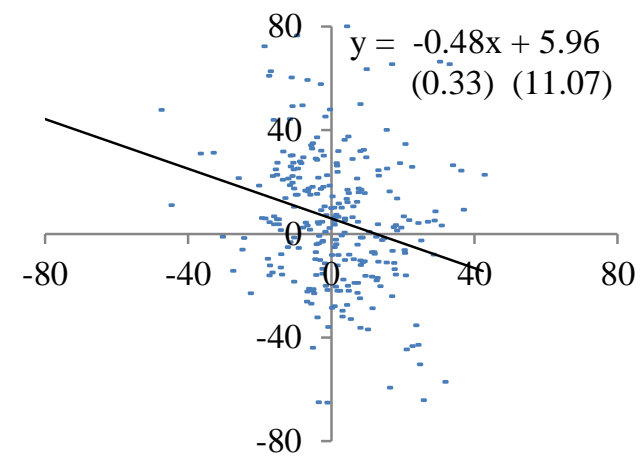

\section{$\underline{8 \text {-year horizon }}$}

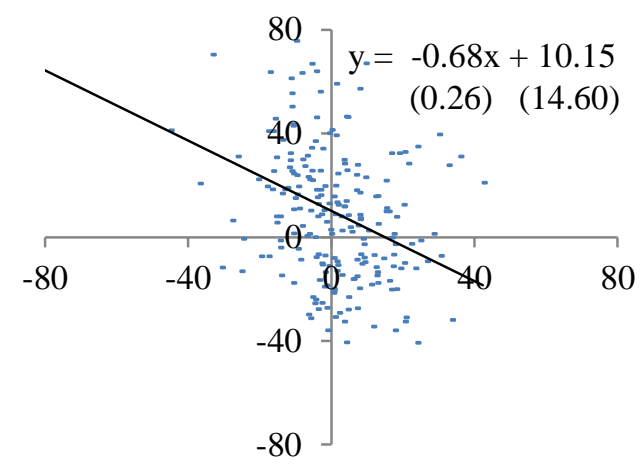

(continued on next page) 
Figure 8 Predictions of Future Currency Movements, 24 Currencies, 1994-2014 (continued)

9-year horizon

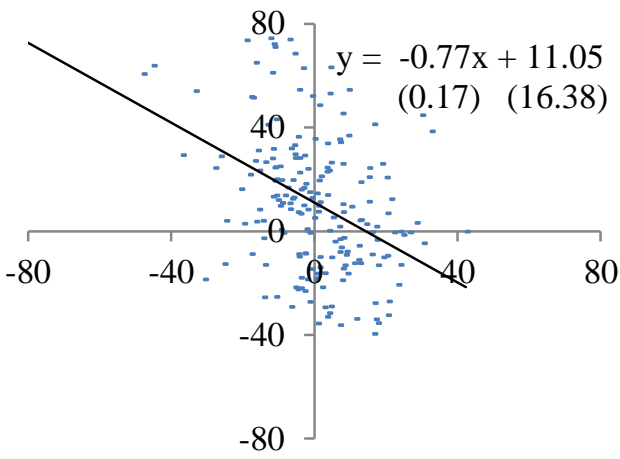

$\underline{10-\text { year horizon }}$

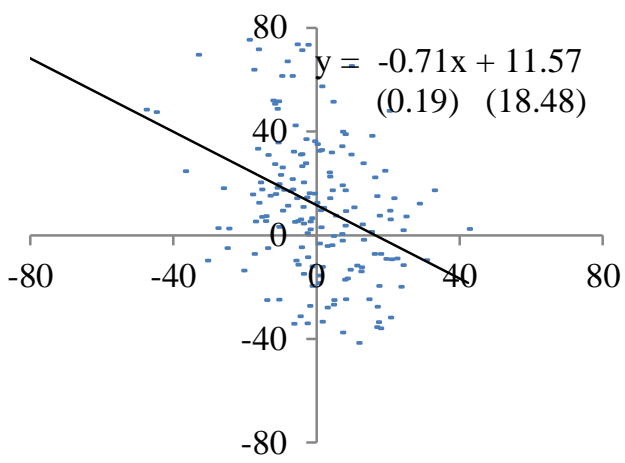

Notes: Each panel of this figure is a scatter plot of changes in the rate from year $t$ to $t+h, \Delta_{h} q_{i, t h}$, with $h$ fixed, against mispricing in $t$, as measured by the EBMI. Robust standard errors are in parentheses. For presentation purposes, observations have been truncated at $[-80,80]$. 
Figure 9 Slope Coefficients for Future Currency Movements

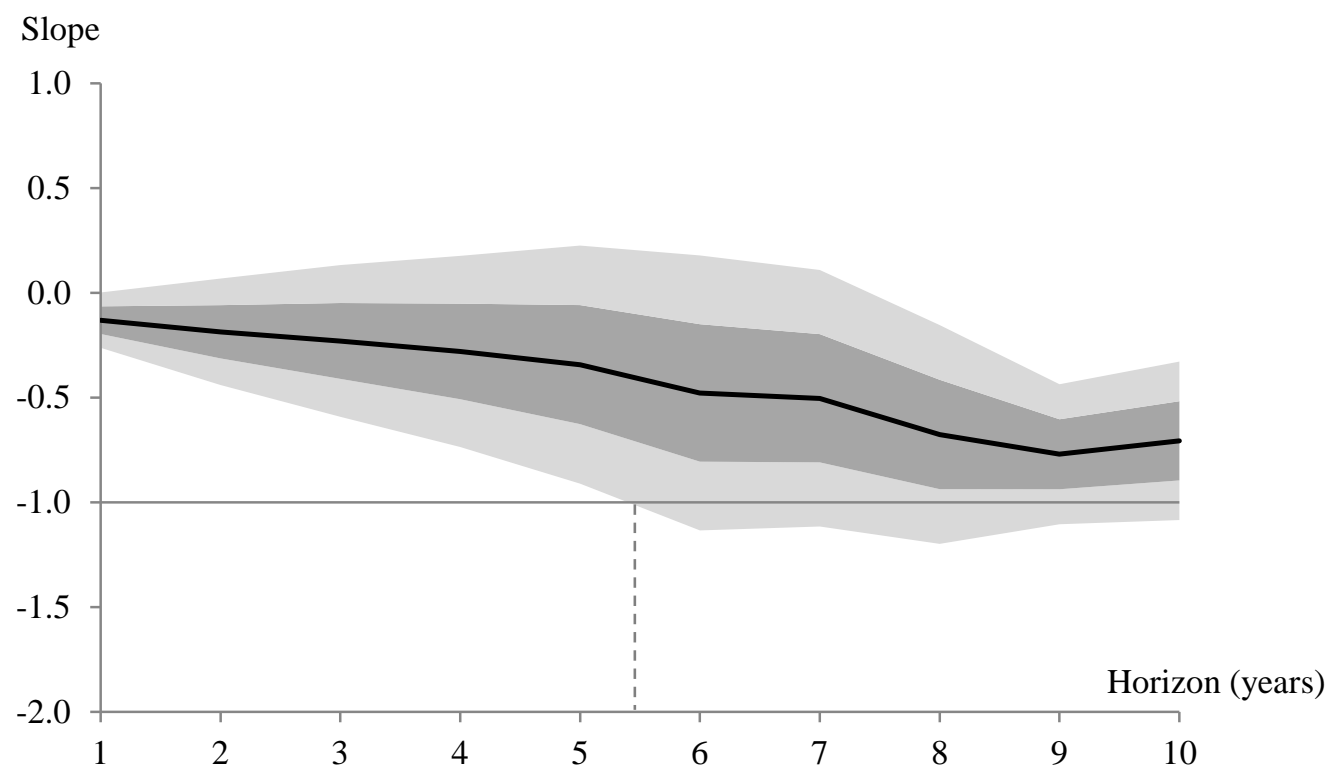

Notes: The solid dark line represents the estimated slope coefficients from Figure 8. The dark grey band is the coefficients $+/$ - one standard error, and the light grey band is $+/$ - two standard errors. Standard errors are robust. 
Figure 10 Quality of Exchange-Rate Predictions

A. With overlapping observations

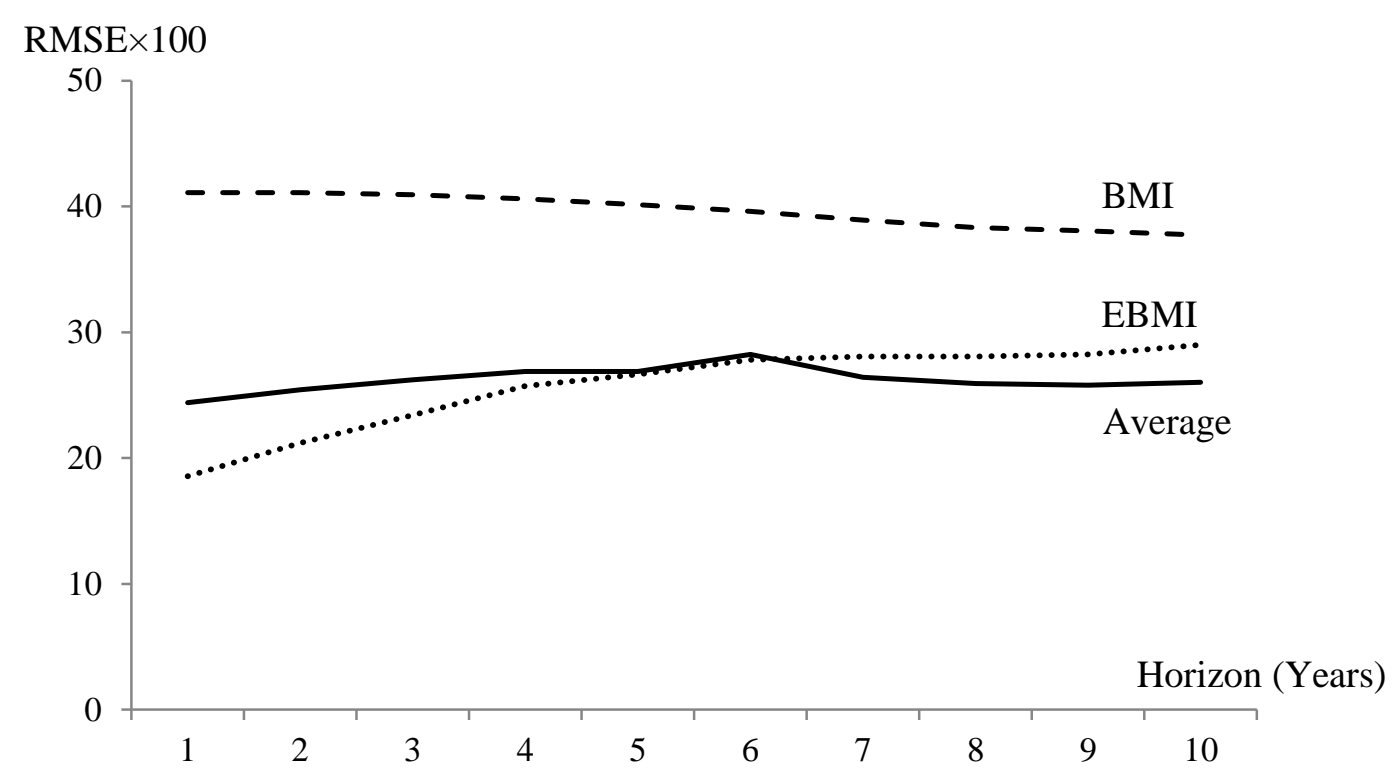

B. Without overlapping observations

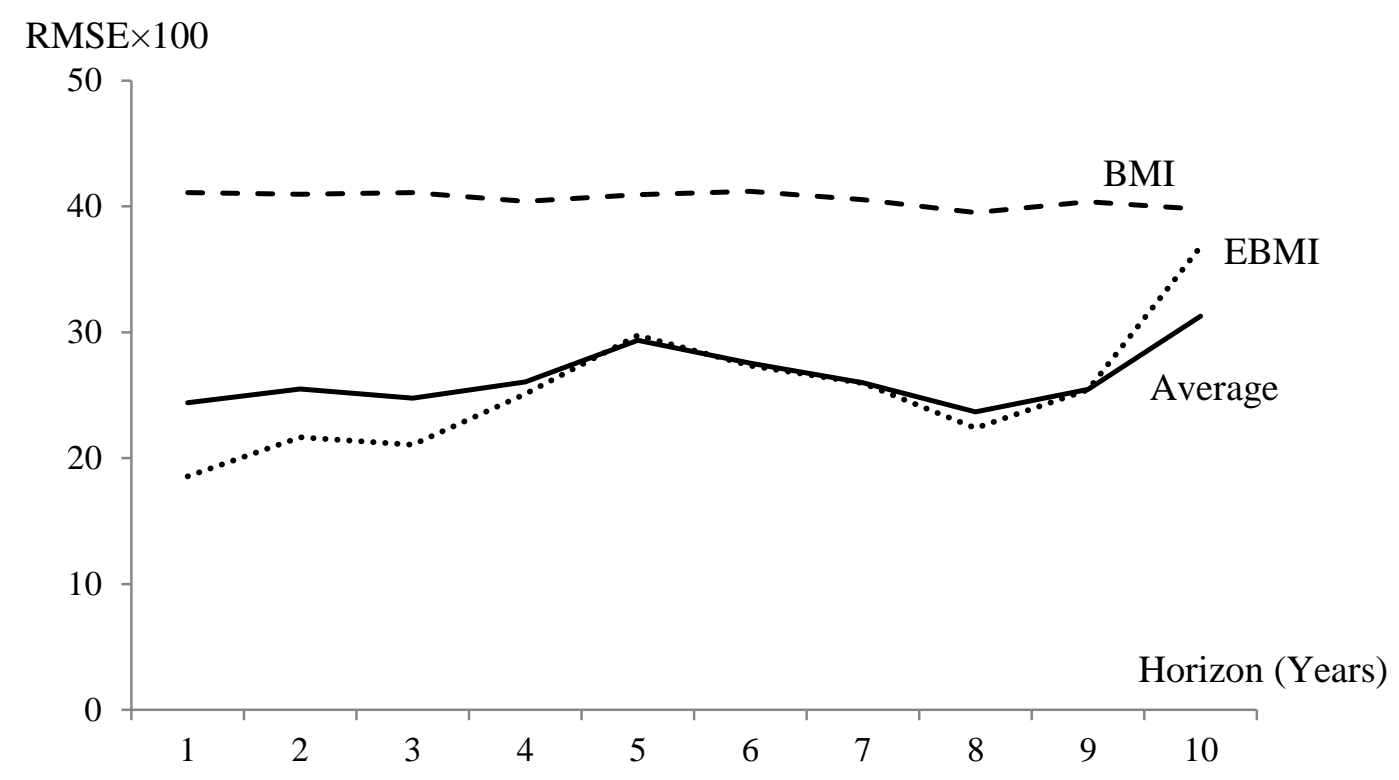

Note: The "average" prediction is the equally weighted average of the BMI and EBMI. 
Figure 11 Sensitivity of Exchange-Rate Predictions

A. With overlapping observations

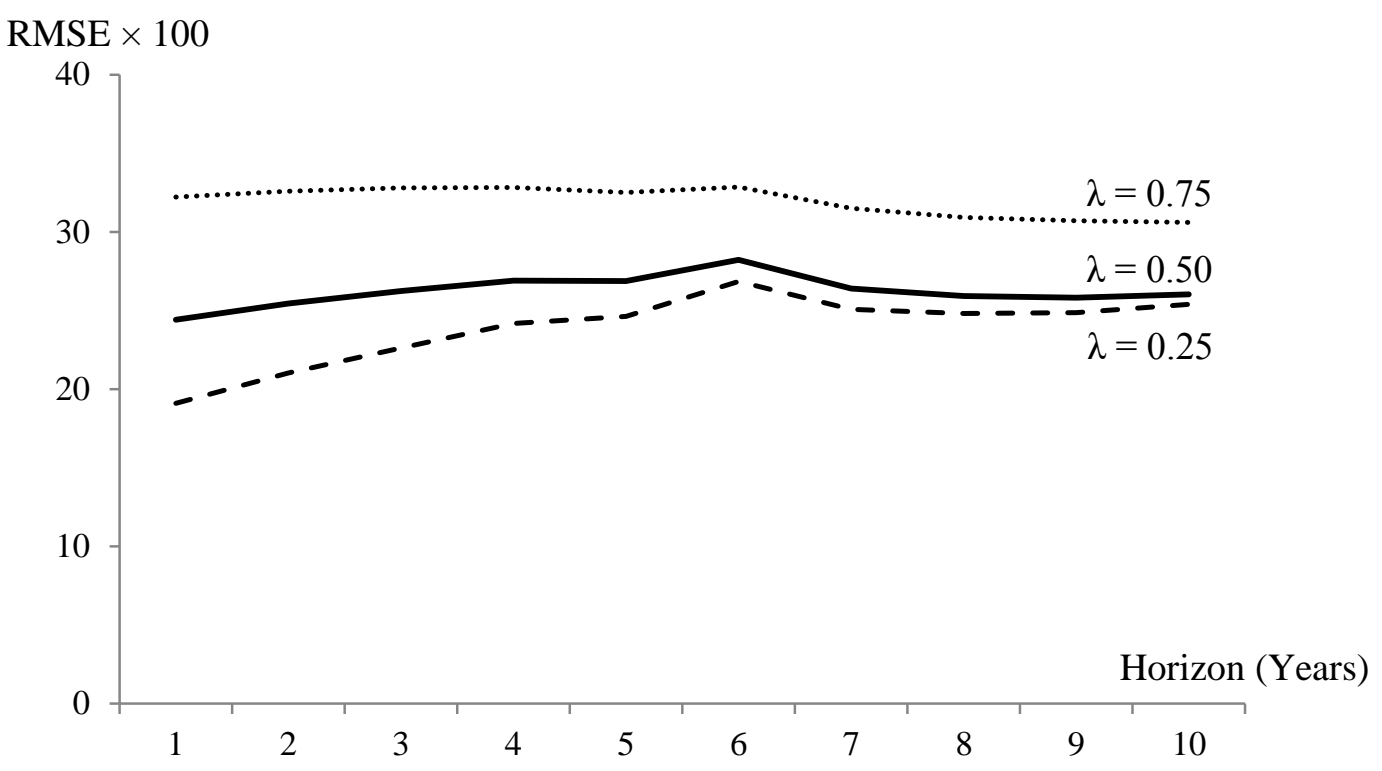

B. Without overlapping observations

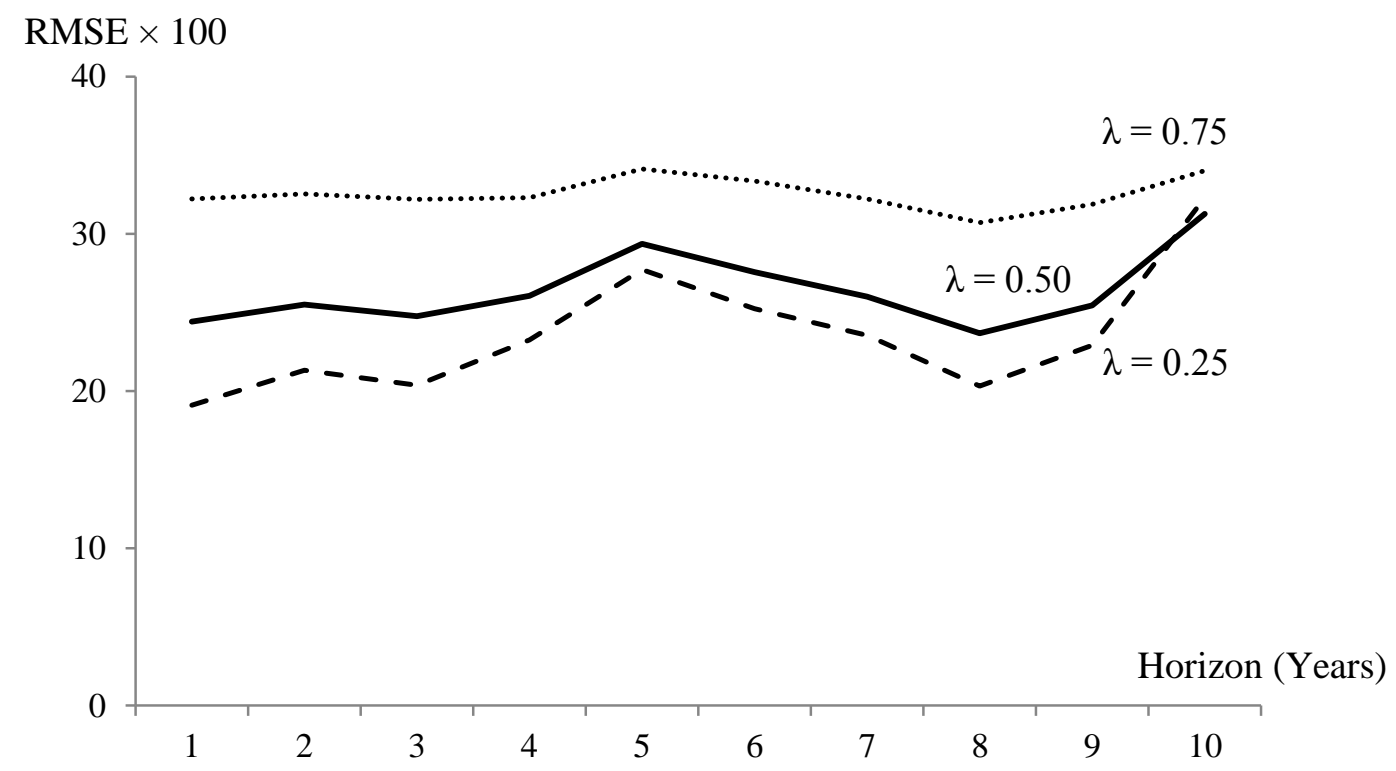

Note: The predictions here are the weighted average of the BMI (which has weight $\lambda$ ) and the EBMI (weight $1-\lambda)$. 
Table 1 Exchange-Rate Predictions

$$
\Delta \mathrm{q}_{\mathrm{i}, \mathrm{t}+\mathrm{h}}=\mathrm{k}_{1}^{(\mathrm{h})}+\mathrm{k}_{1}^{(\mathrm{h})} \mathrm{x}_{\mathrm{it}}+\mathrm{e}_{\mathrm{it}}^{(\mathrm{h})}
$$

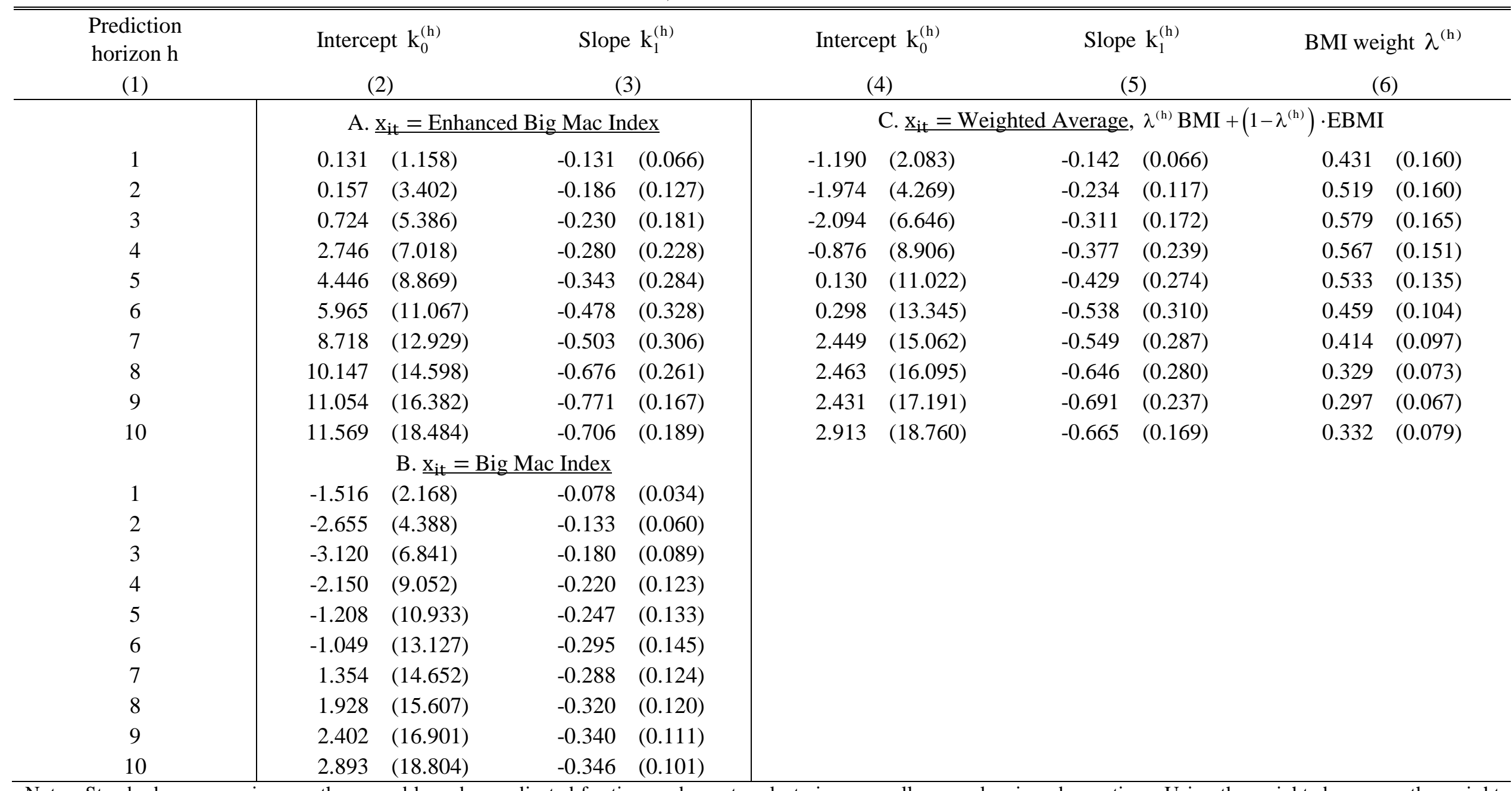

Notes: Standard errors are in parentheses and have been adjusted for time and country clustering, as well as overlapping observations. Using the weighted average, the weight accorded to the BMI for horizon $\mathrm{h}, \lambda^{(\mathrm{h})}$, is estimated from the equation $\Delta \mathrm{q}_{\mathrm{i}, t+\mathrm{h}}=\mathrm{k}_{0}^{(\mathrm{h})}+\mathrm{k}_{1}^{(\mathrm{h})} \cdot\left[\lambda^{(\mathrm{h})} \cdot \mathrm{BMI}_{\mathrm{it}}+\left(1-\lambda^{(\mathrm{h})}\right) \cdot \mathrm{EBMI}_{\mathrm{it}}\right]+\mathrm{e}_{\mathrm{it}}^{(\mathrm{h})}$ in the form $\Delta \mathrm{q}_{\mathrm{i}, \mathrm{t}}=\mathrm{k}_{0}^{(\mathrm{h})}+\mathrm{k}_{1}^{(\mathrm{h})} \cdot \mathrm{EBMI}_{\mathrm{it}}+\mathrm{k}_{1}^{(\mathrm{h})} \lambda^{(\mathrm{h})} \cdot\left(\mathrm{BMI}_{\mathrm{it}}-\mathrm{EBMI}_{\mathrm{it}}\right)+\mathrm{e}_{\mathrm{it}}^{(\mathrm{h})}$, so that $\lambda^{(\mathrm{h})}$ is the ratio of the coefficient of BMI-EBMI to that of EBMI. 


\section{Supplementary Appendix: UNCERTAINTY IN CURRENCY MISPRICING}

by

Kenneth W Clements, Yihui Lan and Jiawei Si

Business School, The University of Western Australia

October 2017

A1. DERIVATIONS FOR THE ENHANCED BMI

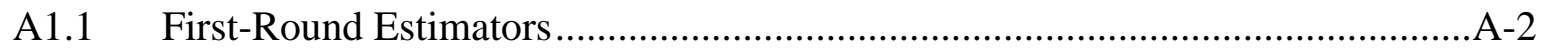

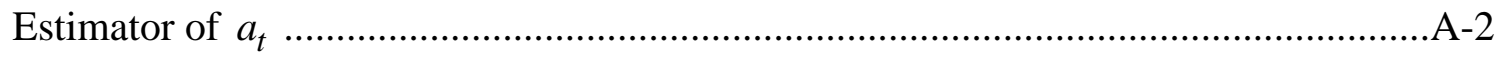

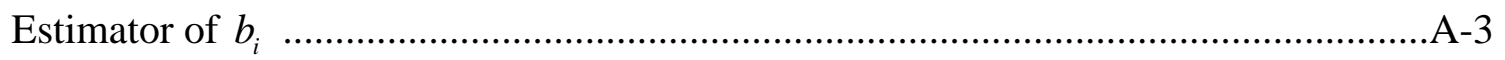

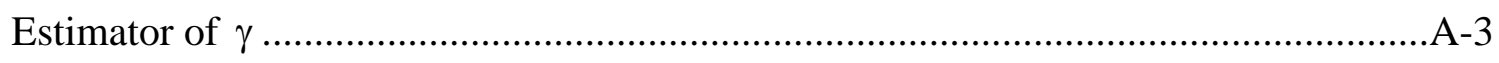

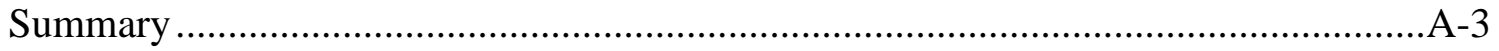

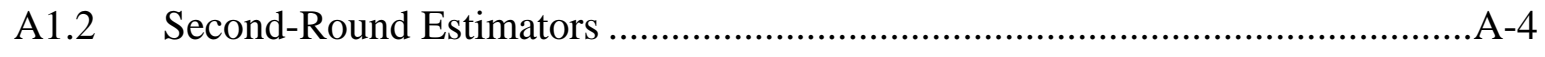

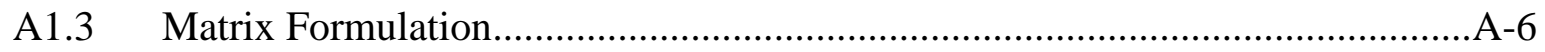

Substituting Out the Constraint..........................................................................

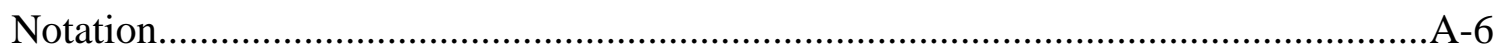

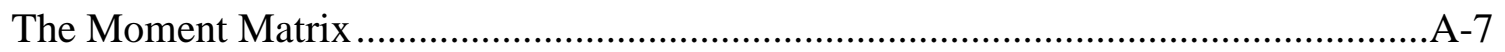

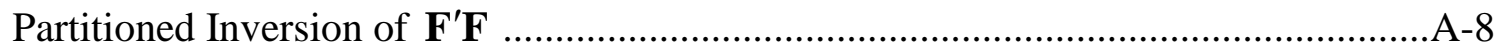

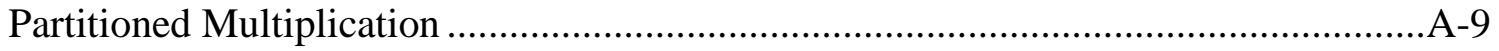

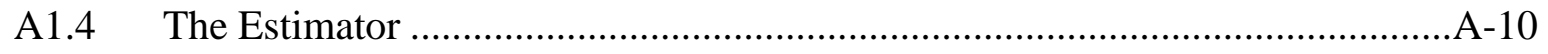

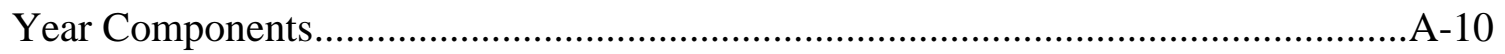

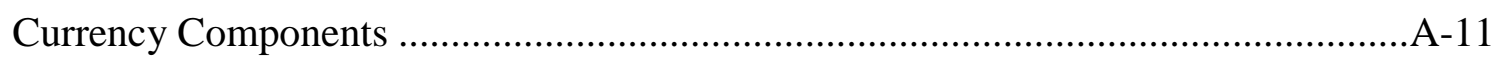

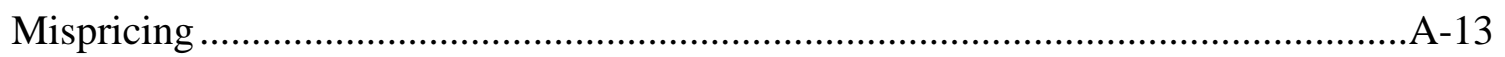

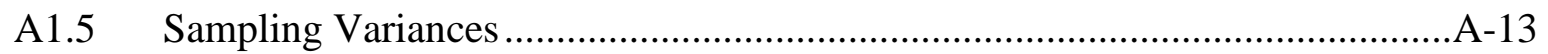

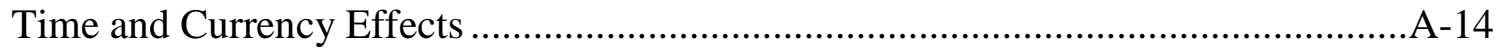

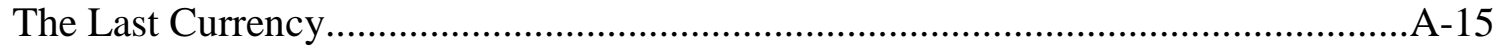

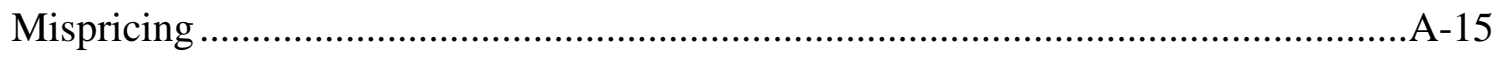

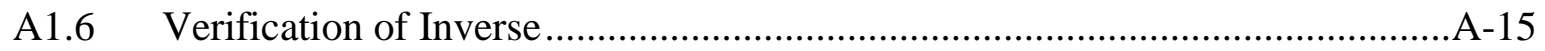

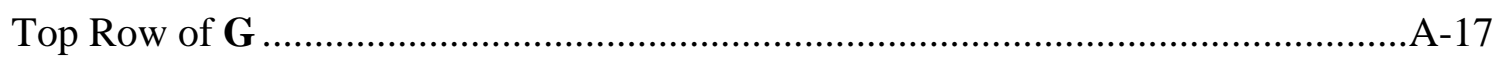

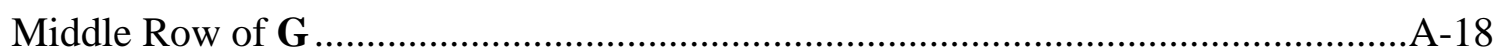

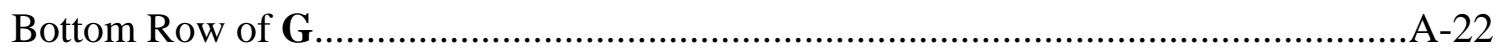

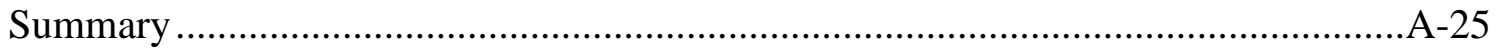

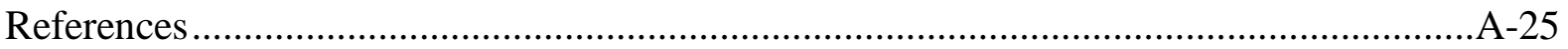

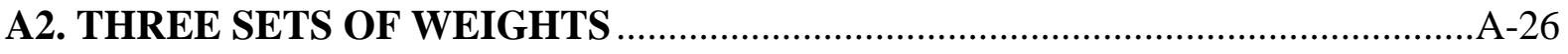

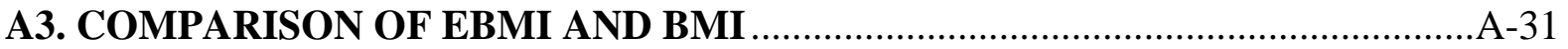




\section{A1. DERIVATIONS FOR THE ENHANCED BMI}

The enhanced Big Mac Model is equation (5) of the text:

$$
\mathrm{q}_{\mathrm{it}}=\mathrm{a}_{\mathrm{t}}+\mathrm{b}_{\mathrm{i}}+\delta_{\mathrm{ij}} \delta_{\mathrm{t \tau}} \gamma+\varepsilon_{\mathrm{it}}, \mathrm{i}=1, \ldots, \mathrm{n} \text { currencies; } \mathrm{t}=1, \ldots, \mathrm{T} \text { years. }
$$

For identification, we take the share weighted-average of the country effects to be zero,

$$
\sum_{i=1}^{n} w_{i} b_{i}=0
$$

where $\mathrm{w}_{\mathrm{i}}$ is the share of country $\mathrm{i}$ in the world economy, with $\sum_{\mathrm{i}=1}^{\mathrm{n}} \mathrm{w}_{\mathrm{i}}=1$. This appendix extends Clements and Izan (1987) to derive the expressions for the estimators of this model given as equation (6). We also derive simple scalar expressions for the corresponding standard errors. We proceed in several steps.

\section{A1.1 First-Round Estimators}

We consider estimating (A1.1) by least squares with each country weighted to reflect its relative size in the world economy, as measured by $\mathrm{w}_{\mathrm{i}}$. Initially, any heteroscedasticity is ignored. Thus, we multiple both sides of equation (A1.1) by ${\sqrt{\mathrm{w}_{i}}}_{\text {: }}$ :

$$
\mathrm{y}_{\mathrm{it}}=\mathrm{a}_{\mathrm{t}} \mathrm{x}_{\mathrm{i}}+\mathrm{b}_{\mathrm{i}} \mathrm{x}_{\mathrm{i}}+\delta_{\mathrm{ij}} \delta_{\mathrm{t} \tau} \gamma \mathrm{x}_{\mathrm{i}}+\varepsilon_{\mathrm{it}}^{\prime},
$$

where $\mathrm{y}_{\mathrm{it}}=\sqrt{\mathrm{W}}_{\mathrm{i}} \mathrm{q}_{\mathrm{it}}, \mathrm{x}_{\mathrm{i}}=\sqrt{\mathrm{W}}_{\mathrm{i}}$ and $\varepsilon_{\mathrm{it}}^{\prime}=\sqrt{\mathrm{w}}_{\mathrm{i}} \varepsilon_{\mathrm{it}}$. To minimise the sum of squared disturbances, subject to (A1.2), we form the Lagrangean function:

$\underbrace{\frac{1}{2} \sum_{i=1}^{n} \sum_{t=1}^{T}\left(y_{i t}-a_{t} x_{i}-b_{i} x_{i}\right)^{2}-\frac{1}{2}\left(y_{j \tau}-a_{\tau} x_{j}-b_{j} x_{j}\right)^{2}}_{n T-1 \text { terms }}+\underbrace{\frac{1}{2}\left(y_{j \tau}-a_{\tau} x_{j}-b_{j} x_{j}-\delta_{i j} \delta_{t \tau} \gamma x_{j}\right)^{2}}_{(j, \tau)^{\text {th }} \text { term }}-\eta \sum_{i=1}^{n} w_{i} b_{i}$,

where $\eta$ is a Lagrange multiplier.

Estimator of $a_{t}$

We differentiate the Lagrangean with respect to $a_{t}$ for $t \neq \tau$ and equate the derivative to 0 , to give $-\sum_{\mathrm{i}=1}^{\mathrm{n}} \mathrm{x}_{\mathrm{i}}\left(\mathrm{y}_{\mathrm{it}}-\mathrm{a}_{\mathrm{t}}^{*} \mathrm{x}_{\mathrm{i}}-\mathrm{b}_{\mathrm{i}} \mathrm{x}_{\mathrm{i}}\right)=0$, or $-\sum_{\mathrm{i}=1}^{\mathrm{n}} \mathrm{w}_{\mathrm{i}} \mathrm{q}_{\mathrm{it}}+\mathrm{a}_{\mathrm{t}}^{*} \sum_{\mathrm{i}=1}^{\mathrm{n}} \mathrm{w}_{\mathrm{i}}+\sum_{\mathrm{i}=1}^{\mathrm{n}} \mathrm{w}_{\mathrm{i}} \mathrm{b}_{\mathrm{i}}=0$. In view of (A1.2) and $\sum_{\mathrm{i}=1}^{\mathrm{n}} \mathrm{w}_{\mathrm{i}}=1$, this simplifies to $\mathrm{a}_{\mathrm{t}}^{*}=\sum_{\mathrm{i}=1}^{\mathrm{n}} \mathrm{w}_{\mathrm{i}} \mathrm{q}_{\mathrm{it}}, \mathrm{t} \neq \tau$. Next, we differentiate with respect to $a_{t}$ for $t=\tau$ to obtain $-\sum_{i=1}^{n} x_{i}\left(y_{i \tau}-a_{\tau}^{*} x_{i}-b_{i} x_{i}\right)+\gamma x_{j}^{2}=0$, or $\mathrm{a}_{\tau}^{*}=\sum_{\mathrm{i}=1}^{\mathrm{n}} \mathrm{w}_{\mathrm{i}} \mathrm{q}_{\mathrm{i} \tau}-\gamma \mathrm{w}_{\mathrm{j}}$. Therefore, 
(A1.4)

$$
\mathrm{a}_{\mathrm{t}}^{*}=\sum_{\mathrm{i}=1}^{\mathrm{n}} \mathrm{w}_{\mathrm{i}} \mathrm{q}_{\mathrm{it}}-\delta_{\mathrm{t \tau}} \mathrm{w}_{\mathrm{j}} \gamma
$$

where $\delta_{t \tau}$ is the Kronecker delta $\left(\delta_{t \tau}=1\right.$ if $\mathrm{t}=\tau, 0$ otherwise $)$. For future reference, we sum both sides of equation (A1.4) over $\mathrm{t}=1, \ldots, \mathrm{T}$, omit the $*$ from $\mathrm{a}_{\mathrm{t}}^{*}$ and rearrange, to obtain

$$
-\sum_{\mathrm{t}=1}^{\mathrm{T}} \sum_{\mathrm{i}=1}^{\mathrm{n}} \mathrm{w}_{\mathrm{i}} \mathrm{q}_{\mathrm{it}}+\sum_{\mathrm{t}=1}^{\mathrm{T}} \mathrm{a}_{\mathrm{t}}+\gamma \mathrm{w}_{\mathrm{j}}=0 .
$$

Estimator of $b_{i}$

Differentiating the Lagrangean with respect to $b_{i}$ and then setting the result to zero, gives

$$
-\mathrm{w}_{\mathrm{i}} \sum_{\mathrm{t}=1}^{\mathrm{T}} \mathrm{q}_{\mathrm{it}}+\mathrm{w}_{\mathrm{i}} \sum_{\mathrm{t}=1}^{\mathrm{T}} \mathrm{a}_{\mathrm{t}}+\mathrm{Tw}_{\mathrm{i}} \mathrm{b}_{\mathrm{i}}+\delta_{\mathrm{ij}} \gamma \mathrm{w}_{\mathrm{j}}=\eta \mathrm{w}_{\mathrm{i}}
$$

In view of (A1.2) and $\sum_{\mathrm{i}=1}^{\mathrm{n}} \mathrm{w}_{\mathrm{i}}=1$, summing both sides of the above over $\mathrm{t}=1, \ldots, \mathrm{T}$, yields

$$
-\sum_{\mathrm{t}=1}^{\mathrm{T}} \sum_{\mathrm{i}=1}^{\mathrm{n}} \mathrm{w}_{\mathrm{i}} \mathrm{q}_{\mathrm{it}}+\sum_{\mathrm{t}=1}^{\mathrm{T}} \mathrm{a}_{\mathrm{t}}+\gamma \mathrm{w}_{\mathrm{j}}=\eta \text {. }
$$

As the left-hand side of this equation is equivalent to that of (A1.5), the Lagrange multiplier $\eta=0$. Substituting $\eta=0$ back into (A1.6) and rearranging gives the estimator of $b_{i}$ :

$$
b_{i}^{*}=\frac{1}{T} \sum_{t=1}^{T}\left(q_{i t}-a_{t}^{*}\right)-\delta_{i j} \frac{1}{T} \gamma,
$$

or, in view of (A1.4) and using $\sum_{t=1}^{\mathrm{T}} \delta_{\mathrm{t} \tau} \gamma \mathrm{w}_{\mathrm{j}}=\gamma \mathrm{w}_{\mathrm{j}}$,

$$
\mathrm{b}_{\mathrm{i}}^{*}=\frac{1}{\mathrm{~T}} \sum_{\mathrm{t}=1}^{\mathrm{T}}\left(\mathrm{q}_{\mathrm{it}}-\sum_{\mathrm{i}=1}^{\mathrm{n}} \mathrm{w}_{\mathrm{i}} \mathrm{q}_{\mathrm{it}}\right)-\frac{1}{\mathrm{~T}}\left(\delta_{\mathrm{ij}}-\mathrm{w}_{\mathrm{j}}\right) \gamma \text {. }
$$

\section{Estimator of $\gamma$}

Finally, we differentiate the Lagrangean with respect to $\gamma$ and equate to zero to obtain $\gamma^{*}=q_{j \tau}-a_{\tau}^{*}-b_{j}^{*}$. Using equations (A1.4) for $t=\tau$ and (A1.7) for $i=j$, the estimator is

$$
\gamma^{*}=\frac{1}{\left(1-\mathrm{w}_{\mathrm{j}}\right)(1-1 / \mathrm{T})}\left[\mathrm{q}_{\mathrm{j} \tau}-\sum_{\mathrm{i}=1}^{\mathrm{n}} \mathrm{w}_{\mathrm{i}} \mathrm{q}_{\mathrm{i} \tau}-\frac{1}{\mathrm{~T}} \sum_{\mathrm{t}=1}^{\mathrm{T}}\left(\mathrm{q}_{\mathrm{jt}}-\sum_{\mathrm{i}=1}^{\mathrm{n}} \mathrm{w}_{\mathrm{i}} \mathrm{q}_{\mathrm{it}}\right)\right] .
$$

\section{Summary}

Substituting (A1.8) into (A1.4) and (A1.7) for $\gamma$ gives the first-round estimators 


\section{Supplementary Material}

$$
\begin{aligned}
& \mathrm{a}_{\mathrm{t}}^{*}=\sum_{\mathrm{i}=1}^{\mathrm{n}} \mathrm{w}_{\mathrm{i}} \mathrm{q}_{\mathrm{it}}+\delta_{\mathrm{t} \tau} \frac{1}{\left(1-1 / \mathrm{w}_{\mathrm{j}}\right)(1-1 / \mathrm{T})}\left[\mathrm{q}_{\mathrm{j} \tau}-\sum_{\mathrm{i}=1}^{\mathrm{n}} \mathrm{w}_{\mathrm{i}} \mathrm{q}_{\mathrm{i} \tau}-\frac{1}{\mathrm{~T}} \sum_{\mathrm{t}=1}^{\mathrm{T}}\left(\mathrm{q}_{\mathrm{jt}}-\sum_{\mathrm{i}=1}^{\mathrm{n}} \mathrm{w}_{\mathrm{i}} \mathrm{q}_{\mathrm{it}}\right)\right] \\
& \mathrm{b}_{\mathrm{i}}^{*}=\frac{1}{\mathrm{~T}} \sum_{\mathrm{t}=1}^{\mathrm{T}}\left(\mathrm{q}_{\mathrm{it}}-\sum_{\mathrm{i}=1}^{\mathrm{n}} \mathrm{w}_{\mathrm{i}} \mathrm{q}_{\mathrm{it}}\right)-\frac{1}{\mathrm{~T}} \frac{\delta_{\mathrm{ij}}-\mathrm{w}_{\mathrm{j}}}{\left(1-\mathrm{w}_{\mathrm{j}}\right)(1-1 / \mathrm{T})}\left[\mathrm{q}_{\mathrm{j \tau}}-\sum_{\mathrm{i}=1}^{\mathrm{n}} \mathrm{w}_{\mathrm{i}} \mathrm{q}_{\mathrm{i} \tau}-\frac{1}{\mathrm{~T}} \sum_{\mathrm{t}=1}^{\mathrm{T}}\left(\mathrm{q}_{\mathrm{jt}}-\sum_{\mathrm{i}=1}^{\mathrm{n}} \mathrm{w}_{\mathrm{i}} \mathrm{q}_{\mathrm{it}}\right)\right] \\
& \gamma^{*}=\frac{1}{\left(1-\mathrm{w}_{\mathrm{j}}\right)(1-1 / \mathrm{T})}\left[\mathrm{q}_{\mathrm{j} \tau}-\sum_{\mathrm{i}=1}^{\mathrm{n}} \mathrm{w}_{\mathrm{i}} \mathrm{q}_{\mathrm{i} \tau}-\frac{1}{\mathrm{~T}} \sum_{\mathrm{t}=1}^{\mathrm{T}}\left(\mathrm{q}_{\mathrm{jt}}-\sum_{\mathrm{i}=1}^{\mathrm{n}} \mathrm{w}_{\mathrm{i}} \mathrm{q}_{\mathrm{it}}\right)\right],
\end{aligned}
$$

where the first-round estimate of $\gamma^{*}$, equation (A1.8), has been repeated for convenience.

\section{A1.2 Second-Round Estimators}

We now allow for heteroscedasticity on the basis that currency markets are more turbulent in some years than in others. Let $\theta_{t}^{2}=\Sigma_{i=1}^{n}\left(y_{i t}-a_{t}^{*} x_{i}-b_{i}^{*} x_{i}-\delta_{i j} \delta_{t \tau} \gamma^{*} x_{i}\right)^{2}$ be the sum of squared residuals from the first-round estimators of model (A1.3). We divide both sides of (A1.3) by $\theta_{\mathrm{t}}$ to give

$$
\tilde{y}_{i t}=a_{t} \tilde{x}_{i t}+b_{i} \tilde{x}_{i t}+\delta_{i j} \delta_{t \tau} \gamma \tilde{x}_{i t}+\tilde{\varepsilon}_{i t},
$$

where $\tilde{y}_{i t}=y_{i t} / \theta_{t}, \tilde{x}_{i t}=x_{i t} / \theta_{t}$ and $\tilde{\varepsilon}_{i t}=\varepsilon_{i t}^{\prime} / \theta_{t}$. Replacing $y_{i t}$ and $x_{i t}$ in the Lagrangean function of the previous sub-section with $\tilde{y}_{i t}$ and $\tilde{x}_{i t}$, repeating the same steps for $a_{t}$, we obtain

$$
-\sum_{\mathrm{i}=1}^{\mathrm{n}} \mathrm{w}_{\mathrm{i}} \mathrm{q}_{\mathrm{it}} / \theta_{\mathrm{t}}^{2}+\mathrm{a}_{\mathrm{t}} \sum_{\mathrm{i}=1}^{\mathrm{n}} \mathrm{w}_{\mathrm{i}} / \theta_{\mathrm{t}}^{2}+\sum_{\mathrm{i}=1}^{\mathrm{n}} \mathrm{w}_{\mathrm{i}} \mathrm{b}_{\mathrm{i}} / \theta_{\mathrm{t}}^{2}+\delta_{\mathrm{t} \tau} \gamma \mathrm{w}_{\mathrm{j}} / \theta_{\tau}^{2}=0
$$

The third term disappears due to constraint (A1.2). This simplifies to yield for the secondround estimator, $\mathrm{a}_{\mathrm{t}}^{* *}$, similar to the first-round version (A1.4), $\mathrm{a}_{\mathrm{t}}^{*}$.

$$
a_{t}^{* * *}=\sum_{i=1}^{n} w_{i} q_{i t}-\delta_{t \tau} w_{j} \gamma .
$$

Differentiating the new Lagrangean function with respect to $b_{i}$ gives

$$
-\mathrm{w}_{\mathrm{i}} \sum_{\mathrm{t}=1}^{\mathrm{T}} \mathrm{q}_{\mathrm{it}} / \theta_{\mathrm{t}}^{2}+\mathrm{w}_{\mathrm{i}} \sum_{\mathrm{t}=1}^{\mathrm{T}} \mathrm{a}_{\mathrm{t}} / \theta_{\mathrm{t}}^{2}+\mathrm{w}_{\mathrm{i}} \mathrm{b}_{\mathrm{i}} \sum_{\mathrm{t}=1}^{\mathrm{T}}\left(1 / \theta_{\mathrm{t}}^{2}\right)+\delta_{\mathrm{ij}} \gamma \mathrm{w}_{\mathrm{j}} / \theta_{\tau}^{2}=\eta \mathrm{w}_{\mathrm{i}}
$$

As before, the multiplier $\eta=0$. Using (A1.10),

$$
\mathrm{b}_{\mathrm{i}}^{* *}=\sum_{\mathrm{t}=1}^{\mathrm{T}} \phi_{\mathrm{t}}\left(\mathrm{q}_{\mathrm{it}}-\sum_{\mathrm{i}=1}^{\mathrm{n}} \mathrm{w}_{\mathrm{i}} \mathrm{q}_{\mathrm{it}}\right)-\left(\delta_{\mathrm{ij}}-\mathrm{w}_{\mathrm{j}}\right) \phi_{\tau} \gamma
$$

where $\phi_{\mathrm{t}}=\left(1 / \theta_{\mathrm{t}}^{2}\right) / \Sigma_{\mathrm{t}=1}^{\mathrm{T}}\left(1 / \theta_{\mathrm{t}}^{2}\right)$ is a weight applied to the $\mathrm{t}^{\mathrm{th}}$ observation. 
Finally, differentiating the Lagrangean with respect to $\gamma$ gives $\gamma^{* *}=\mathrm{q}_{\mathrm{j \tau}}-\mathrm{a}_{\tau}^{* *}-\mathrm{b}_{\mathrm{j}}^{* *}$. Substituting the above expressions for $a_{\tau}^{* *}$ and $b_{j}^{* *}$ yields

$$
\gamma^{* *}=\frac{1}{\left(1-\mathrm{w}_{\mathrm{j}}\right)\left(1-\phi_{\tau}\right)}\left[\mathrm{q}_{\mathrm{j \tau}}-\sum_{\mathrm{i}=1}^{\mathrm{n}} \mathrm{w}_{\mathrm{i}} \mathrm{q}_{\mathrm{i} \tau}-\sum_{\mathrm{t}=1}^{\mathrm{T}} \phi_{\mathrm{t}}\left(\mathrm{q}_{\mathrm{jt}}-\sum_{\mathrm{i}=1}^{\mathrm{n}} \mathrm{w}_{\mathrm{i}} \mathrm{q}_{\mathrm{it}}\right)\right] \text {. }
$$

This expression has a simple interpretation. The right-hand side is proportional to

$$
\underbrace{\mathrm{q}_{\mathrm{j} \tau}-\sum_{\mathrm{i}=1}^{\mathrm{n}} \mathrm{w}_{\mathrm{i}} \mathrm{q}_{\mathrm{i} \tau}}_{\text {A }}-\underbrace{\sum_{\mathrm{t}=1}^{\mathrm{T}} \phi_{\mathrm{t}}\left(\mathrm{q}_{\mathrm{jt}}-\sum_{\mathrm{i}=1}^{\mathrm{n}} \mathrm{w}_{\mathrm{i}} \mathrm{q}_{\mathrm{it}}\right)}_{B} .
$$

The first term is the raw derivation from parity of currency $\mathrm{j}$ in year $\tau, \mathrm{q}_{\mathrm{i} \tau}$. This raw deviation is just the BMI. The second term is $\sum_{\mathrm{i}=1}^{\mathrm{n}} \mathrm{w}_{\mathrm{i}} \mathrm{q}_{\mathrm{i} \tau}$, which is a weighted average of the deviations of the $n$ currencies. The weight given to currency $i$ is $w_{i}$, which is the share of currency $\mathrm{i}$ in the 24-currency basket. Thus, term $\mathrm{A}$ is the deviation from raw parity of currency $\mathrm{j}$ in year $\tau$ relative to the weighted mean of all such deviations. Term $B$ is a weighted mean of the relative deviations in all $\mathrm{T}$ years. Year $\mathrm{t}$ observations receive the weight $\phi_{t}$, which is proportional to the inverse of the residual variance in that year, so that more variable years receive a lower weight. Accordingly, the difference A-B is a double-weighted mean, a mean involving both currencies and time, which reflects the two dimensional structure of the problem. In words, A-B is mispricing of $\mathrm{j}$ in $\tau$ relative to that of all currencies in that year, as compared to the weighted mean of that concept in all years. In view of equation (3) of the text, A-B is also interpreted as the residual from model (2) for $\mathrm{i}=\mathrm{j}$ and $\mathrm{t}=\tau, \mathrm{q}_{\mathrm{j \tau}}-\hat{\alpha}_{\tau}-\hat{\beta}_{\mathrm{j}}$.

The factor of proportionality for A-B in the expression for $\gamma^{* *}$ is

$$
0<\frac{1}{\left(1-\mathrm{w}_{\mathrm{j}}\right)\left(1-\phi_{\tau}\right)}<1,
$$

as $\phi_{t}$ and $\mathrm{w}_{\mathrm{i}}$ are both positive fractions. As this is increasing in $\mathrm{w}_{\mathrm{j}}$, currencies that are relatively more important receive a larger weight. Similarly for years that are less variable. If volatility in year $\tau$ is at the average value for the whole T-year period, then $\phi_{\tau}=1 / \mathrm{T}=1 / 21$; and similarly when $\mathrm{j}$ is an average-sized country, $\mathrm{w}_{\mathrm{j}}=1 / \mathrm{n}=1 / 24$. In this case,

$$
\frac{1}{\left(1-\mathrm{w}_{\mathrm{j}}\right)\left(1-\phi_{\tau}\right)}=\frac{1}{\left(1-\frac{1}{24}\right)\left(1-\frac{1}{21}\right)} \approx 1.10
$$


so $\gamma^{* * *}$ would be about 10 percent larger than the term in square brackets in (A1.12), which is the residual $\mathrm{q}_{\mathrm{j} \tau}-\hat{\alpha}_{\tau}-\hat{\beta}_{\mathrm{j}}$.

Substituting the right-hand side of equation (A1.12) for $\gamma$ in (A1.10), using $-\mathrm{w}_{\mathrm{j}} /\left[\left(1-\mathrm{w}_{\mathrm{j}}\right)\left(1-\phi_{\tau}\right)\right]=1 /\left[\left(1-1 / \mathrm{w}_{\mathrm{j}}\right)\left(1-\phi_{\tau}\right)\right]$, replacing $\quad \sum_{\mathrm{i}=1}^{\mathrm{n}} \mathrm{w}_{\mathrm{i}} \mathrm{q}_{\mathrm{it}} \quad$ with $\quad \hat{\alpha}_{\mathrm{t}}$ and $\sum_{\mathrm{t}=1}^{\mathrm{T}} \phi_{\mathrm{t}}\left(\mathrm{q}_{\mathrm{jt}}-\sum_{\mathrm{i}=1}^{\mathrm{n}} \mathrm{w}_{\mathrm{i}} \mathrm{q}_{\mathrm{it}}\right)$ with $\hat{\beta}_{\mathrm{i}}$, in accordance with equation (3) of the text, we obtain the expression for $\hat{a}_{t}$ given as the first member of equation (6) of the text. Similar substitutions confirm that $b_{i}^{* *}$ of equation (A1.11) and $\gamma^{* *}$ of (A1.12) coincide with $\hat{b}_{i}$ and $\hat{\gamma}$ of equation (6).

\section{A1.3 Matrix Formulation}

The square of the standard error of $\hat{\gamma}$, or $\gamma^{* * *}$, is given below equation (6) of the text. Our next task is to derive this equation, as well as simple scalar expressions for the other standard errors. This involves first formulating the model as a matrix equation and then deriving the weighted least-squares estimators. While these estimators are, of course, the same as those of equations (A1.10)-(A1.12) above, this serves as a check on the calculations.

\section{Substituting Out the Constraint}

Given that $\mathrm{w}_{\mathrm{i}}=\mathrm{x}_{\mathrm{it}}^{2}=\tilde{\mathrm{x}}_{\mathrm{it}}^{2} \theta_{\mathrm{t}}^{2}$, if we divide both sides of constraint (A1.2) by $\theta_{\mathrm{t}}^{2}$ we have $\sum_{\mathrm{i}=1}^{\mathrm{n}} \tilde{\mathrm{x}}_{\mathrm{it}}^{2} \mathrm{~b}_{\mathrm{i}}=0$, or

$$
\mathrm{b}_{\mathrm{n}}=\sum_{\mathrm{k}=1}^{\mathrm{n}-1}\left(-\frac{\tilde{\mathrm{x}}_{\mathrm{kt}}^{2}}{\tilde{\mathrm{x}}_{\mathrm{nt}}^{2}}\right) \mathrm{b}_{\mathrm{k}}
$$

By substituting for $b_{n}$ in (A1.9) for $i=n$, we obtain

$$
\tilde{y}_{\mathrm{nt}}=\mathrm{a}_{\mathrm{t}} \tilde{\mathrm{x}}_{\mathrm{nt}}+\sum_{\mathrm{k}=1}^{\mathrm{n}-1}\left(-\frac{\tilde{\mathrm{x}}_{\mathrm{kt}}^{2}}{\tilde{\mathrm{x}}_{\mathrm{nt}}^{2}}\right) \cdot \tilde{\mathrm{x}}_{\mathrm{nt}} \cdot \mathrm{b}_{\mathrm{k}}+\gamma_{\mathrm{j \tau}} \tilde{\mathrm{x}}_{\mathrm{it}}+\tilde{\varepsilon}_{\mathrm{it}}=\mathrm{a}_{\mathrm{t}} \tilde{\mathrm{x}}_{\mathrm{nt}}+\sum_{\mathrm{k}=1}^{\mathrm{n}-1}\left(-\frac{\tilde{\mathrm{x}}_{\mathrm{kt}}^{2}}{\tilde{\mathrm{x}}_{\mathrm{nt}}}\right) \cdot \mathrm{b}_{\mathrm{k}}+\delta_{\mathrm{ij}} \delta_{\mathrm{t} \tau} \gamma \tilde{\mathrm{x}}_{\mathrm{it}}+\tilde{\varepsilon}_{\mathrm{it}} \cdot
$$

\section{Notation}

Define the following vectors and matrices 


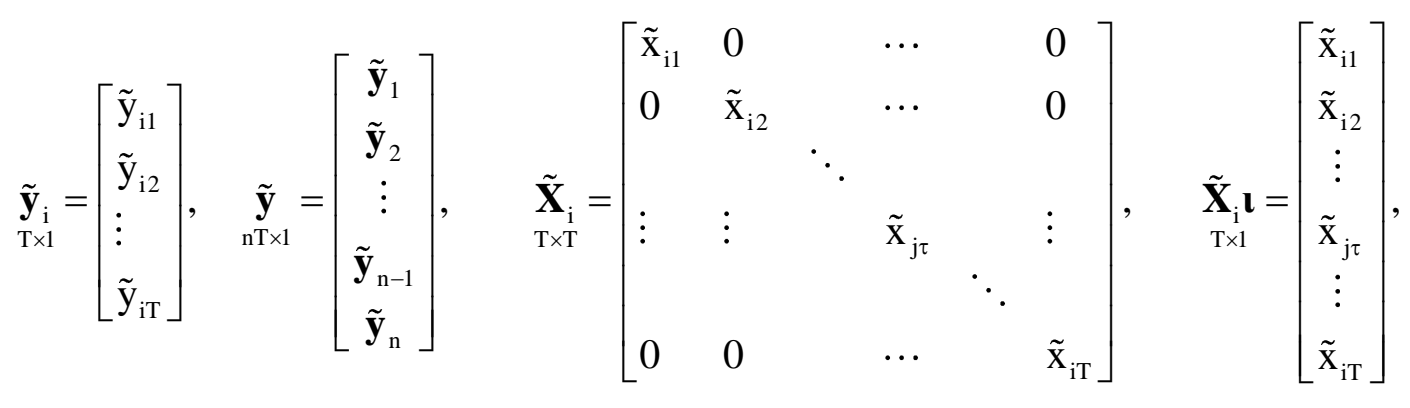

$$
\begin{aligned}
& \underset{\mathrm{T} \times 1}{\mathbf{l}}=\left[\begin{array}{c}
1 \\
1 \\
\vdots \\
1
\end{array}\right], \quad \underset{\mathrm{T} \times 1}{\tilde{\mathbf{d}}_{\mathrm{j}}}=\left[\begin{array}{c}
0 \\
\vdots \\
\tilde{\mathbf{x}}_{\mathrm{j} \tau} \\
\vdots \\
0
\end{array}\right], \quad \underset{\mathrm{nT} \times 1}{\tilde{\mathbf{d}}_{\mathbf{1}}}=\left[\begin{array}{c}
\mathbf{0} \\
\mathrm{T} \times 1 \\
\vdots \\
\tilde{\mathbf{d}}_{\mathbf{j}} \\
\vdots \\
\mathbf{0} \times 1
\end{array}\right], \quad \boldsymbol{\pi}=\left[\begin{array}{l}
\mathrm{a}_{1} \\
\vdots \\
\mathrm{a}_{\mathrm{T}} \\
\mathrm{b}_{1} \\
\vdots \\
\mathrm{b}_{\mathrm{n}-1} \\
\gamma
\end{array}\right] \\
& \underset{\mathrm{T} \times(\mathrm{n}-1)}{\mathbf{C}}=-\tilde{\mathbf{X}}_{\mathrm{n}}^{-1}\left(\tilde{\mathbf{X}}_{1} \tilde{\mathbf{X}}_{1} \mathbf{l} \quad \tilde{\mathbf{X}}_{2} \tilde{\mathbf{X}}_{2} \mathbf{l} \quad \cdots \quad \tilde{\mathbf{X}}_{\mathrm{n}-1} \tilde{\mathbf{X}}_{\mathrm{n}-1} \mathbf{l}\right)=\left[\mathrm{c}_{\mathrm{ti}}\right],
\end{aligned}
$$

where $c_{t i}=-\tilde{x}_{i t}^{2} / \tilde{x}_{n t}=-w_{i} /\left(\sqrt{\mathrm{w}_{n}} \theta_{t}\right)$,

$$
\underset{\mathrm{n} T \times(\mathrm{T}+\mathrm{n})}{\mathbf{F}}=\left[\begin{array}{lllllll:l}
\tilde{\mathbf{X}}_{1} & \tilde{\mathbf{X}}_{1} \mathbf{l} & \mathbf{0} & & \ldots & & \mathbf{0} & \mathbf{0} \\
\tilde{\mathbf{X}}_{2} & \mathbf{0} & \tilde{\mathbf{X}}_{\mathrm{p}} \mathbf{l} & & \ldots & & \mathbf{0} & \mathbf{0} \\
\vdots & & & \ddots & & & & \vdots \\
\tilde{\mathbf{X}}_{\mathrm{j}} & \vdots & \vdots & & \tilde{\mathbf{X}}_{\mathrm{j}} \mathbf{l} & & \vdots & \tilde{\mathbf{d}}_{\mathrm{j}} \\
\vdots & & & & & \ddots & & \mathbf{0} \\
\tilde{\mathbf{X}}_{\mathrm{n}-1} & \mathbf{0} & \mathbf{0} & & \ldots & & \tilde{\mathbf{X}}_{\mathrm{n}-1} & \vdots \\
\tilde{\mathbf{X}}_{\mathrm{n}} & & & \mathbf{C} & & & & \mathbf{0}
\end{array}\right] .
$$

With this notation, the model, with the constraint substituted out, can be expressed for all $\mathrm{T}$ years for the $\mathrm{n}$ currencies as $\tilde{\mathbf{y}}=\mathbf{F} \boldsymbol{\pi}+\tilde{\boldsymbol{\varepsilon}}$, where $\tilde{\boldsymbol{\varepsilon}}$ is the disturbance vector. Thus, the least-squares estimator is $\boldsymbol{\pi}^{* *}=\left(\mathbf{F}^{\prime} \mathbf{F}\right)^{-1} \mathbf{F}^{\prime} \tilde{\mathbf{y}}$ and under the assumption that weighting observations by $\phi_{\mathrm{t}}$ eliminates heteroscedasticity, the sampling variance is $\operatorname{var}\left(\boldsymbol{\pi}^{* *}\right)=\frac{1}{\mathrm{n}-1}\left(\mathbf{F}^{\prime} \mathbf{F}\right)^{-1}$. In the next several subsections, we consider the components of these expressions.

\section{The Moment Matrix}

Using the above expressions, the moment matrix is 


$$
\mathbf{F}^{\prime} \mathbf{F}=\left[\begin{array}{ccc}
\mathbf{B} & \mathbf{0} & \mathbf{D}_{1} \\
\mathbf{0} & \Theta\left[\begin{array}{c}
\mathbf{W}+\frac{1}{\mathrm{w}_{\mathrm{n}}} \mathbf{w} \mathbf{w}^{\prime} \\
\mathbf{D}_{2}^{\prime}
\end{array}\right. & \mathbf{D}_{2} \\
\mathbf{D}_{1}^{\prime} & \mathbf{w}_{\mathrm{j}} / \theta_{\tau}^{2}
\end{array}\right] .
$$

Here,

$$
\mathbf{B}=\sum_{\mathrm{i}=1}^{\mathrm{n}} \tilde{\mathbf{X}}_{\mathrm{i}} \tilde{\mathbf{X}}_{\mathrm{i}}=\left[\begin{array}{cccc}
\sum_{\mathrm{i}=1}^{\mathrm{n}} \tilde{\mathbf{x}}_{\mathrm{i} 1}^{2} & 0 & \cdots & 0 \\
0 & \sum_{\mathrm{i}=1}^{\mathrm{n}} \tilde{\mathbf{x}}_{\mathrm{i} 2}^{2} & & \vdots \\
\vdots & & \ddots & 0 \\
0 & \ldots & 0 & \sum_{\mathrm{i}=1}^{\mathrm{n}} \tilde{\mathrm{x}}_{\mathrm{iT}}^{2}
\end{array}\right]=\left[\begin{array}{cccc}
1 / \theta_{1}^{2} & \ldots & & 0 \\
\vdots & 1 / \theta_{2}^{2} & & \vdots \\
& & \ddots & \\
0 & \ldots & & 1 / \theta_{\mathrm{T}}^{2}
\end{array}\right] \text {, }
$$

$$
\Theta=\sum_{t=1}^{\mathrm{T}}\left(1 / \theta_{\mathrm{t}}^{2}\right), \mathbf{W}=\operatorname{diag}\left[\mathrm{w}_{1}, \mathrm{w}_{2}, \cdots, \mathrm{w}_{\mathrm{n}-1}\right] \text { and } \mathbf{w}=\left[\begin{array}{lllll}
\mathrm{w}_{1} & \cdots & \mathrm{w}_{\mathrm{j}} & \cdots & \mathrm{w}_{\mathrm{n}-1}
\end{array}\right]^{\prime},
$$

$$
\begin{aligned}
& \mathbf{D}_{1}=\tilde{\mathbf{X}}_{\mathrm{j}} \tilde{\mathbf{d}}_{\mathrm{j}}=\left[\begin{array}{ccccc}
\tilde{\mathbf{x}}_{\mathrm{j} 1} & 0 & \cdots & & 0 \\
0 & \ddots & & & \\
\vdots & & \tilde{\mathbf{x}}_{\mathrm{j} \tau} & & \\
& & & \ddots & \\
0 & & & & \tilde{\mathbf{x}}_{\mathrm{jT}}
\end{array}\right]\left[\begin{array}{c}
0 \\
\vdots \\
\tilde{\mathbf{x}}_{\mathrm{j} \tau} \\
\vdots \\
0
\end{array}\right]=\left[\begin{array}{c}
0 \\
\vdots \\
\tilde{\mathbf{x}}_{\mathrm{j} \tau}^{2} \\
\vdots \\
0
\end{array}\right]=\left[\begin{array}{c}
0 \\
\vdots \\
\mathrm{w}_{\mathrm{j}} / \theta_{\tau}^{2} \\
\vdots \\
0
\end{array}\right],
\end{aligned}
$$

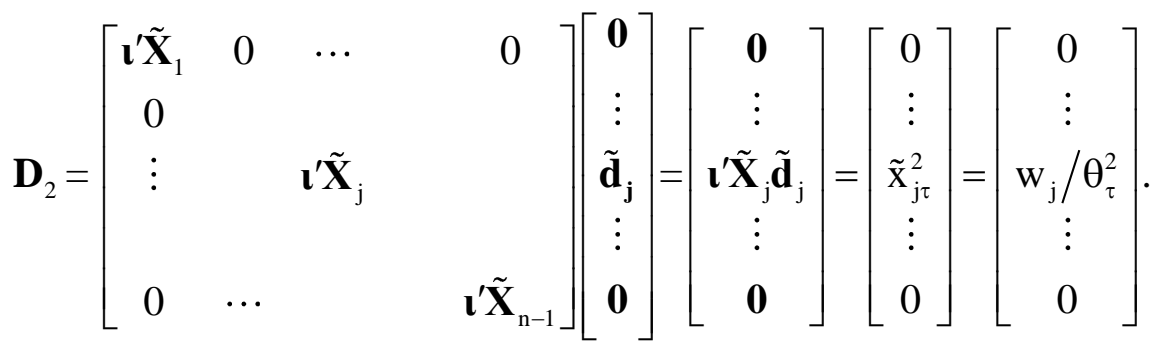

\section{Partitioned Inversion of $\mathbf{F}^{\prime} \mathbf{F}$}

If the moment matrix is partitioned as

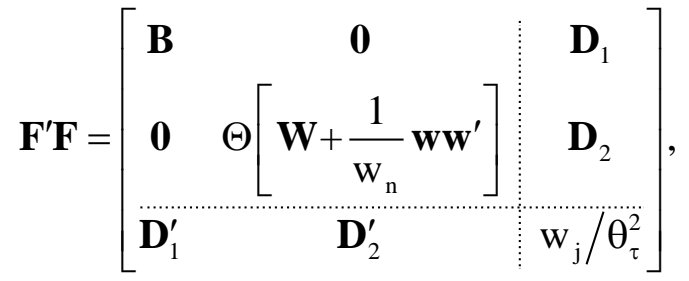

its inverse is then (Hua, 1996) 


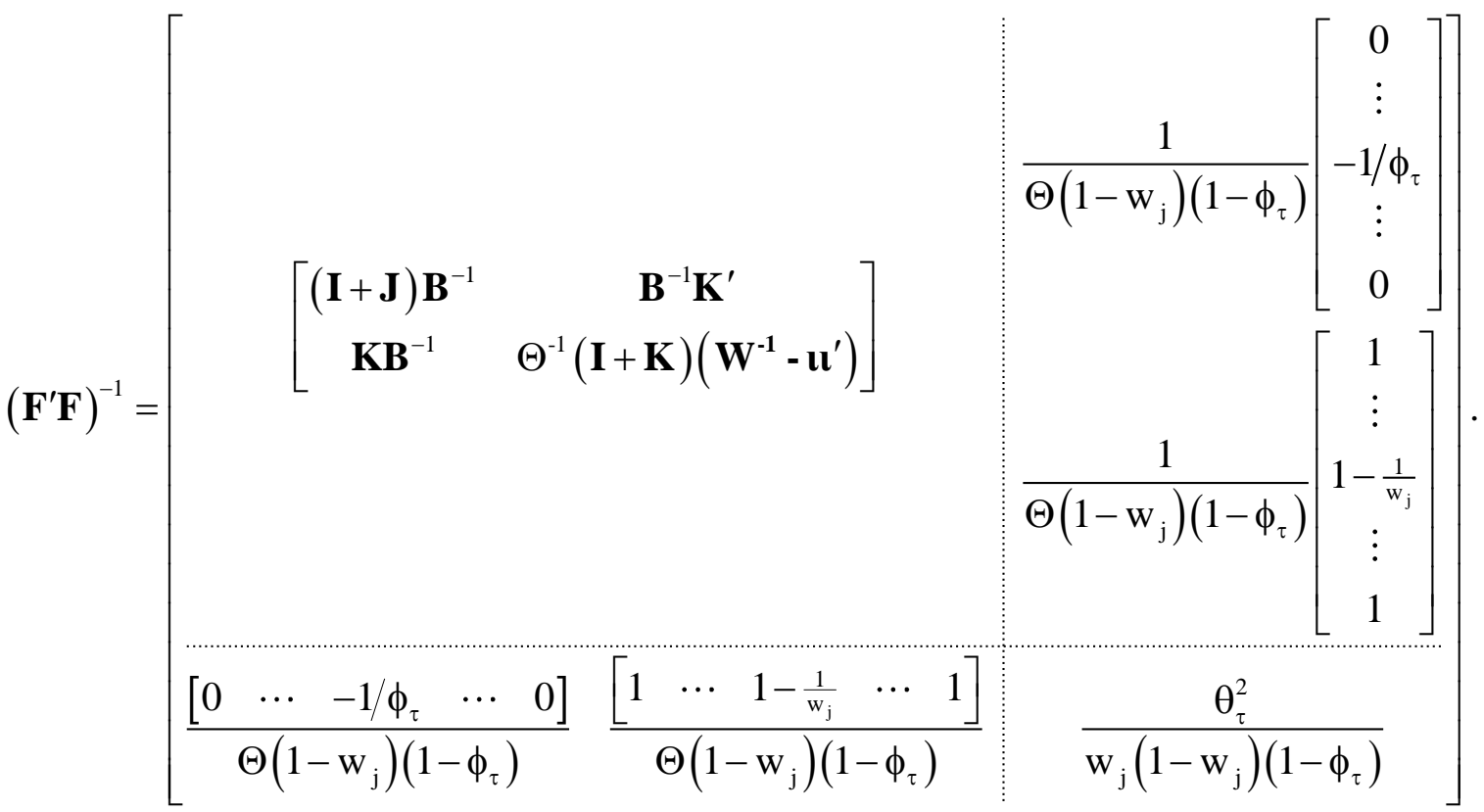

Here,

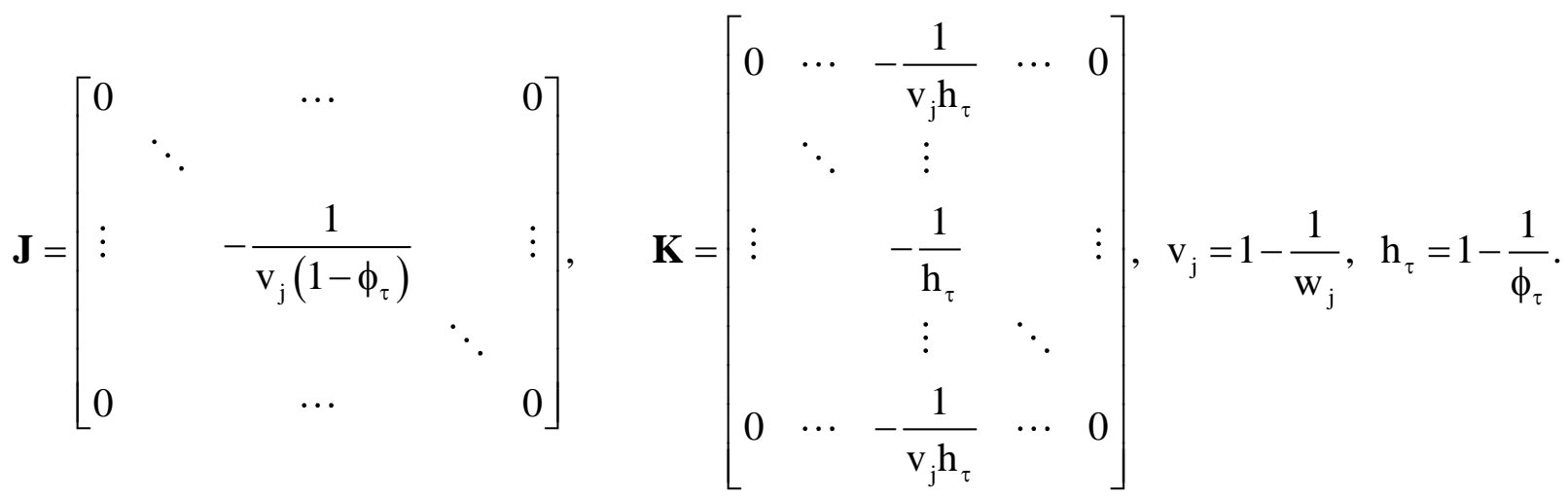

The inverse is written out in full in Table A1.1 and verified in Section A1.6.

Partitioned Multiplication

It follows from the definitions of $\mathbf{F}$ and $\tilde{\mathbf{y}}$ that 


\section{Supplementary Material}

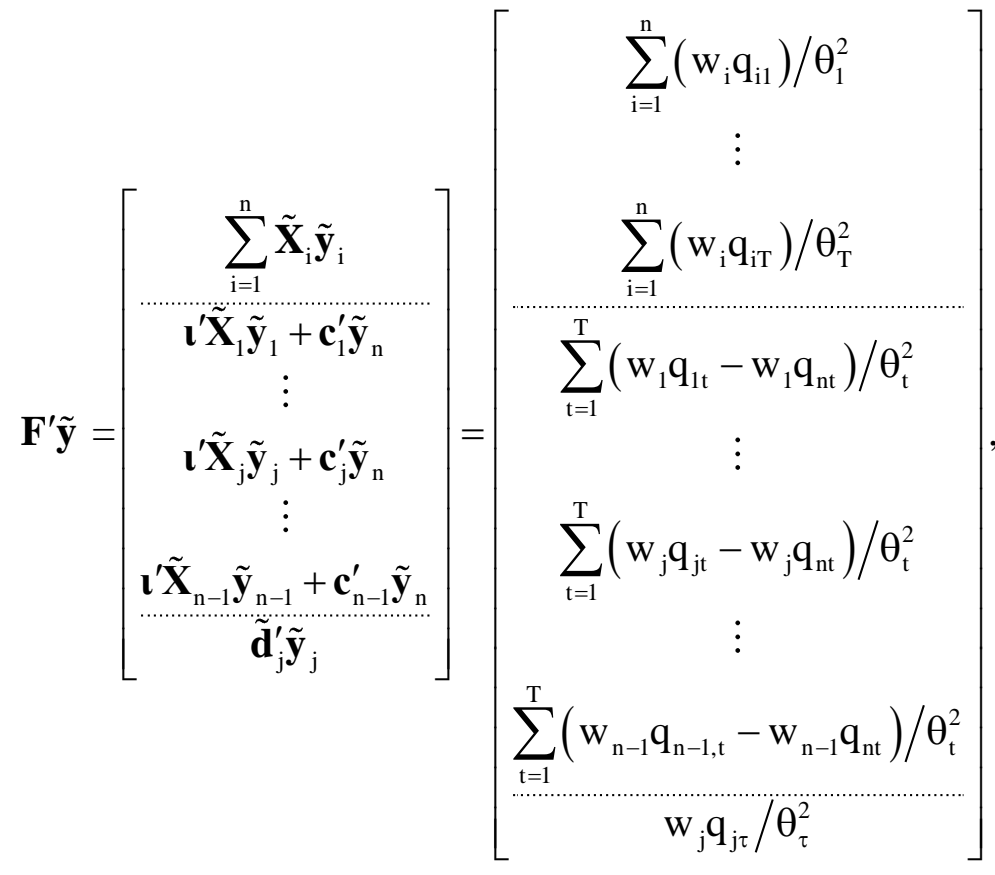

where $\mathbf{c}_{\mathrm{j}}$ is the $\mathrm{j}^{\text {th }}$ column of $\mathbf{C}$.

\section{A1.4 The Estimator}

The weighted least-squares estimator is $\boldsymbol{\pi}^{* *}=\left[\begin{array}{lllllll}\mathrm{a}_{1}^{* *} & \cdots & \mathrm{a}_{\mathrm{T}}^{* *} & \mathrm{~b}_{1}^{* *} & \cdots & \mathrm{b}_{\mathrm{n}-1}^{* *} & \gamma^{* *}\end{array}\right]^{\prime}$ $=\left(\mathbf{F}^{\prime} \mathbf{F}\right)^{-1} \mathbf{F}^{\prime} \tilde{\mathbf{y}}$. Using the above result, together with $\left(\mathbf{F}^{\prime} \mathbf{F}\right)^{-1}$ from Table A1.1 and the identities $\mathrm{v}_{\mathrm{j}}=1-1 / \mathrm{w}_{\mathrm{j}}, \mathrm{h}_{\tau}=1-1 / \phi_{\tau}, \sum_{\mathrm{i}=1}^{\mathrm{n}-1} \mathrm{w}_{\mathrm{i}}=1-\mathrm{w}_{\mathrm{n}}$, and $\phi_{\mathrm{t}}=1 / \Theta \theta_{\mathrm{t}}^{2}$, where $\Theta=\Sigma_{\mathrm{t}=1}^{\mathrm{T}}\left(1 / \theta_{\mathrm{t}}^{2}\right)$, we obtain the following scalar expressions.

\section{Year Components}

For $\mathrm{t} \neq \tau$,

$$
a_{t}^{* *}=\theta_{t}^{2} \sum_{i=1}^{n} \frac{w_{i} q_{i t}}{\theta_{t}^{2}}=\sum_{i=1}^{n} w_{i} q_{i t} .
$$

For $\mathrm{t}=\tau$,

$$
\mathrm{a}_{\tau}^{* *}=\underbrace{\left(1-\frac{1}{\mathrm{v}_{\mathrm{j}}\left(1-\phi_{\tau}\right)}\right) \sum_{\mathrm{i}=1}^{\mathrm{n}} \mathrm{w}_{\mathrm{i}} \mathrm{q}_{\mathrm{i} \tau}}_{\mathrm{c}} \underbrace{-\frac{\theta_{\tau}^{2}}{\mathrm{v}_{\mathrm{j}} \mathrm{h}_{\tau}} \sum_{\mathrm{i}=1, \mathrm{i} \neq \mathrm{j}}^{\mathrm{n}-1} \sum_{\mathrm{t}=1}^{\mathrm{T}} \frac{\mathrm{w}_{\mathrm{i}} \mathrm{q}_{\mathrm{it}}-\mathrm{w}_{\mathrm{i}} \mathrm{q}_{\mathrm{nt}}}{\theta_{\mathrm{t}}^{2}}-\frac{\theta_{\tau}^{2} \mathrm{w}_{\mathrm{j}}}{\mathrm{h}_{\tau}} \sum_{\mathrm{t}=1}^{\mathrm{T}} \frac{\left(\mathrm{q}_{\mathrm{jt}}-\mathrm{q}_{\mathrm{nt}}\right)}{\theta_{\mathrm{t}}^{2}}}_{\mathrm{d}}+\underbrace{\frac{\Theta \cdot \theta_{\tau}^{2} \mathrm{w}_{\mathrm{j}} \mathrm{q}_{\mathrm{j} \tau}}{\left(1-\mathrm{w}_{\mathrm{j}}\right) \mathrm{h}_{\tau}}}_{\mathrm{e}}
$$

We shall consider separately each of the three terms. The first is

$$
\mathrm{c}=\sum_{\mathrm{i}=1}^{\mathrm{n}} \mathrm{w}_{\mathrm{i}} \mathrm{q}_{\mathrm{i} \tau}-\frac{1}{\left(1-\phi_{\tau}\right)\left(1-1 / \mathrm{w}_{\mathrm{j}}\right)} \sum_{\mathrm{i}=1}^{\mathrm{n}} \mathrm{w}_{\mathrm{i}} \mathrm{q}_{\mathrm{i} \tau}
$$


The second term is

$$
\begin{aligned}
\mathrm{d} & =-\frac{1}{\Theta \phi_{\tau} \mathrm{v}_{\mathrm{j}} \mathrm{h}_{\tau}}\left[\sum_{\mathrm{i}=1, \mathrm{i} \neq \mathrm{j}}^{\mathrm{n}-1} \sum_{\mathrm{t}=1}^{\mathrm{T}} \Theta \phi_{\mathrm{t}}\left(\mathrm{w}_{\mathrm{i}} \mathrm{q}_{\mathrm{it}}-\mathrm{w}_{\mathrm{i}} \mathrm{q}_{\mathrm{nt}}\right)+\mathrm{w}_{\mathrm{j}}\left(1-\frac{1}{\mathrm{w}_{\mathrm{j}}}\right) \sum_{\mathrm{t}=1}^{\mathrm{T}} \Theta \phi_{\mathrm{t}}\left(\mathrm{q}_{\mathrm{jt}}-\mathrm{q}_{\mathrm{nt}}\right)\right] \\
& =\frac{1}{\left(1-\phi_{\tau}\right)\left(1-1 / \mathrm{w}_{\mathrm{j}}\right)}\left[\sum_{\mathrm{t}=1}^{\mathrm{T}} \phi_{\mathrm{t}} \sum_{\mathrm{i}=1}^{\mathrm{n}-1}\left(\mathrm{w}_{\mathrm{i}} \mathrm{q}_{\mathrm{it}}-\mathrm{w}_{\mathrm{i}} \mathrm{q}_{\mathrm{nt}}\right)-\sum_{\mathrm{t}=1}^{\mathrm{T}} \phi_{\mathrm{t}}\left(\mathrm{q}_{\mathrm{jt}}-\mathrm{q}_{\mathrm{nt}}\right)\right] \\
& =\frac{1}{\left(1-\phi_{\tau}\right)\left(1-1 / \mathrm{w}_{\mathrm{j}}\right)}\left\{\sum_{\mathrm{t}=1}^{\mathrm{T}} \phi_{\mathrm{t}}\left[\sum_{\mathrm{i}=1}^{\mathrm{n}-1}\left(\mathrm{w}_{\mathrm{i}} \mathrm{q}_{\mathrm{it}}\right)-\mathrm{q}_{\mathrm{nt}}\left(1-\mathrm{w}_{\mathrm{n}}\right)-\left(\mathrm{q}_{\mathrm{jt}}-\mathrm{q}_{\mathrm{nt}}\right)\right]\right\} \\
& =-\frac{1}{\left(1-\phi_{\tau}\right)\left(1-1 / \mathrm{w}_{\mathrm{j}}\right)}\left[\sum_{\mathrm{t}=1}^{\mathrm{T}} \phi_{\mathrm{t}}\left(\mathrm{q}_{\mathrm{jt}}-\sum_{\mathrm{i}=1}^{\mathrm{n}} \mathrm{w}_{\mathrm{i}} \mathrm{q}_{\mathrm{it}}\right)\right] .
\end{aligned}
$$

The third term can be expressed as

$$
\mathrm{e}=\frac{\Theta \cdot \theta_{\tau}^{2} \mathrm{w}_{\mathrm{j}} \mathrm{q}_{\mathrm{j} \tau}}{\left(1-\mathrm{w}_{\mathrm{j}}\right) \mathrm{h}_{\tau}}=\frac{\mathrm{w}_{\mathrm{j}} \mathrm{q}_{\mathrm{j} \tau}}{\phi_{\tau}\left(1-\mathrm{w}_{\mathrm{j}}\right) \mathrm{h}_{\tau}}=\frac{\mathrm{q}_{\mathrm{j} \tau}}{\left(1-\phi_{\tau}\right)\left(1-1 / \mathrm{w}_{\mathrm{j}}\right)} .
$$

Putting the three components together, we have

$$
\mathrm{a}_{\tau}^{* *}=\sum_{\mathrm{i}=1}^{\mathrm{n}} \mathrm{w}_{\mathrm{i}} \mathrm{q}_{\mathrm{i} \tau}+\frac{1}{\left(1-\phi_{\tau}\right)\left(1-1 / \mathrm{w}_{\mathrm{j}}\right)}\left[\mathrm{q}_{\mathrm{j} \tau}-\sum_{\mathrm{i}=1}^{\mathrm{n}} \mathrm{w}_{\mathrm{i}} \mathrm{q}_{\mathrm{i} \tau}-\sum_{\mathrm{t}=1}^{\mathrm{T}} \phi_{\mathrm{t}}\left(\mathrm{q}_{\mathrm{jt}}-\sum_{\mathrm{i}=1}^{\mathrm{n}} \mathrm{w}_{\mathrm{i}} \mathrm{q}_{\mathrm{it}}\right)\right] \text {. }
$$

This coincides with equation (A1.10), the estimator derived from the scalar formulation of the problem.

\section{Currency Components}

Using similar steps to the above, for $\mathrm{i} \neq \mathrm{j}$, we have

$$
\begin{aligned}
\mathrm{b}_{\mathrm{i}}^{* * *}= & \underbrace{-\frac{1}{\mathrm{v}_{\mathrm{j}} \mathrm{h}_{\tau}} \sum_{\mathrm{i}=1}^{\mathrm{n}} \mathrm{w}_{\mathrm{i}} \mathrm{q}_{\mathrm{i} \tau}}_{\mathrm{c}}-\underbrace{-\frac{\mathrm{w}_{\mathrm{j}} \mathrm{q}_{\mathrm{j} \tau}}{\left(1-\mathrm{w}_{\mathrm{j}}\right) \mathrm{h}_{\tau}}}_{\mathrm{e}} \\
& \underbrace{\frac{1}{\Theta}\left[\left(\frac{1}{\mathrm{v}_{\mathrm{j}} \mathrm{h}_{\tau}}-1\right) \sum_{\mathrm{t}=1}^{\mathrm{T}} \sum_{\mathrm{i}=1}^{\mathrm{n}-1} \frac{\mathrm{w}_{\mathrm{i}} \mathrm{q}_{\mathrm{it}}-\mathrm{w}_{\mathrm{i}} \mathrm{q}_{\mathrm{nt}}}{\theta_{\mathrm{t}}^{2}}+\mathrm{w}_{\mathrm{i}}\left(1-\mathrm{v}_{\mathrm{i}}\right) \sum_{\mathrm{t}=1}^{\mathrm{T}} \frac{\mathrm{q}_{\mathrm{it}}-\mathrm{q}_{\mathrm{nt}}}{\theta_{\mathrm{t}}^{2}}+\frac{\mathrm{w}_{\mathrm{j}}}{\mathrm{h}_{\tau}}\left(1-\frac{1}{\mathrm{v}_{\mathrm{j}}}\right) \sum_{\mathrm{t}=1}^{\mathrm{T}} \frac{\mathrm{q}_{\mathrm{jt}}-\mathrm{q}_{\mathrm{nt}}}{\theta_{\mathrm{t}}^{2}}\right]}_{\mathrm{d}} .
\end{aligned}
$$

The three terms here can be simplified as follows:

$$
\begin{aligned}
& c=-\frac{1}{\left(1-1 / \phi_{\tau}\right)\left(1-1 / w_{j}\right)} \sum_{i=1}^{n} w_{i} q_{i \tau}, \\
& e=-\frac{w_{j} q_{j \tau}}{\left(1-w_{j}\right) h_{\tau}}=\frac{q_{j \tau}}{\left(1-1 / \phi_{\tau}\right)\left(1-1 / w_{j}\right)},
\end{aligned}
$$




\section{Supplementary Material}

$$
\begin{aligned}
\mathrm{d} & =\left(\frac{1}{\mathrm{v}_{\mathrm{j}} \mathrm{h}_{\tau}}-1\right) \sum_{\mathrm{t}=1}^{\mathrm{T}} \phi_{\mathrm{t}} \sum_{\mathrm{i}=1}^{\mathrm{n}-1}\left(\mathrm{w}_{\mathrm{i}} \mathrm{q}_{\mathrm{it}}-\mathrm{w}_{\mathrm{i}} \mathrm{q}_{\mathrm{nt}}\right)+\sum_{\mathrm{t}=1}^{\mathrm{T}} \phi_{\mathrm{t}}\left(\mathrm{q}_{\mathrm{it}}-\mathrm{q}_{\mathrm{nt}}\right)+\frac{\mathrm{w}_{\mathrm{j}}}{\mathrm{h}_{\tau}}\left(\frac{1}{\mathrm{w}_{\mathrm{j}}-1}\right) \sum_{\mathrm{t}=1}^{\mathrm{T}} \phi_{\mathrm{t}}\left(\mathrm{q}_{\mathrm{jt}}-\mathrm{q}_{\mathrm{nt}}\right) \\
& =\left(\frac{1}{\mathrm{v}_{\mathrm{j}} \mathrm{h}_{\tau}}-1\right) \sum_{\mathrm{t}=1}^{\mathrm{T}} \phi_{\mathrm{t}}\left[\sum_{\mathrm{i}=1}^{\mathrm{n}-1}\left(\mathrm{w}_{\mathrm{i}} \mathrm{q}_{\mathrm{it}}\right)-\mathrm{q}_{\mathrm{nt}}\left(1-\mathrm{w}_{\mathrm{n}}\right)\right]+\sum_{\mathrm{t}=1}^{\mathrm{T}} \phi_{\mathrm{t}}\left(\mathrm{q}_{\mathrm{it}}-\mathrm{q}_{\mathrm{nt}}\right)-\frac{1}{\mathrm{v}_{\mathrm{j}} \mathrm{h}_{\tau}} \sum_{\mathrm{t}=1}^{\mathrm{T}} \phi_{\mathrm{t}}\left(\mathrm{q}_{\mathrm{jt}}-\mathrm{q}_{\mathrm{nt}}\right) \\
& =\sum_{\mathrm{t}=1}^{\mathrm{T}} \phi_{\mathrm{t}}\left[\mathrm{q}_{\mathrm{it}}-\mathrm{q}_{\mathrm{nt}}-\sum_{\mathrm{i}=1}^{\mathrm{n}}\left(\mathrm{w}_{\mathrm{i}} \mathrm{q}_{\mathrm{it}}\right)+\mathrm{q}_{\mathrm{nt}}\right]+\frac{1}{\mathrm{v}_{\mathrm{j}} \mathrm{h}_{\tau}} \sum_{\mathrm{t}=1}^{\mathrm{T}} \phi_{\mathrm{t}}\left[\sum_{\mathrm{i}=1}^{\mathrm{n}}\left(\mathrm{w}_{\mathrm{i}} \mathrm{q}_{\mathrm{it}}\right)-\mathrm{q}_{\mathrm{nt}}-\left(\mathrm{q}_{\mathrm{jt}}-\mathrm{q}_{\mathrm{nt}}\right)\right] \\
& =\sum_{\mathrm{t}=1}^{\mathrm{T}} \phi_{\mathrm{t}}\left[\mathrm{q}_{\mathrm{it}}-\sum_{\mathrm{i}=1}^{\mathrm{n}} \mathrm{w}_{\mathrm{i}} \mathrm{q}_{\mathrm{it}}\right]-\frac{1}{\left(1-1 / \phi_{\tau}\right)\left(1-1 / \mathrm{w}_{\mathrm{j}}\right)} \sum_{\mathrm{t}=1}^{\mathrm{T}} \phi_{\mathrm{t}}\left[\mathrm{q}_{\mathrm{jt}}-\sum_{\mathrm{i}=1}^{\mathrm{n}}\left(\mathrm{w}_{\mathrm{i}} \mathrm{q}_{\mathrm{it}}\right)\right] .
\end{aligned}
$$

Therefore,

$$
\mathrm{b}_{\mathrm{i}}^{* *}=\sum_{\mathrm{t}=1}^{\mathrm{T}} \phi_{\mathrm{t}}\left(\mathrm{q}_{\mathrm{it}}-\sum_{\mathrm{i}=1}^{\mathrm{n}} \mathrm{w}_{\mathrm{i}} \mathrm{q}_{\mathrm{it}}\right)+\frac{1}{\left(1-1 / \phi_{\tau}\right)\left(1-1 / \mathrm{w}_{\mathrm{j}}\right)}\left[\mathrm{q}_{\mathrm{j \tau}}-\sum_{\mathrm{i}=1}^{\mathrm{n}} \mathrm{w}_{\mathrm{i}} \mathrm{q}_{\mathrm{i} \tau}-\sum_{\mathrm{t}=1}^{\mathrm{T}} \phi_{\mathrm{t}}\left(\mathrm{q}_{\mathrm{jt}}-\sum_{\mathrm{i}=1}^{\mathrm{n}} \mathrm{w}_{\mathrm{i}} \mathrm{q}_{\mathrm{it}}\right)\right] .
$$

For $\mathrm{i}=\mathrm{j}$, we have

$$
\mathrm{b}_{\mathrm{j}}^{* *}=\underbrace{-\frac{1}{\mathrm{~h}_{\tau}} \sum_{\mathrm{i}=1}^{\mathrm{n}} \mathrm{w}_{\mathrm{i}} \mathrm{q}_{\mathrm{i \tau}}}_{\mathrm{c}} \underbrace{+\frac{1}{\Theta}\left[\left(\frac{1}{\mathrm{~h}_{\tau}}-1\right) \sum_{\mathrm{t}=1}^{\mathrm{T}} \sum_{\mathrm{i}=1}^{\mathrm{n}-1} \frac{\mathrm{w}_{\mathrm{i}} \mathrm{q}_{\mathrm{it}}-\mathrm{w}_{\mathrm{i}} \mathrm{q}_{\mathrm{nt}}}{\theta_{\mathrm{t}}^{2}}+\mathrm{w}_{\mathrm{j}}\left(\frac{1}{\mathrm{~h}_{\tau}}-1\right)\left(\mathrm{v}_{\mathrm{j}}-1\right) \sum_{\mathrm{t}=1}^{\mathrm{T}} \frac{\mathrm{q}_{\mathrm{jt}}-\mathrm{q}_{\mathrm{nt}}}{\theta_{\mathrm{t}}^{2}}\right]}_{\mathrm{d}}+\underbrace{+\frac{\mathrm{q}_{\mathrm{j} \tau}}{\mathrm{h}_{\tau}},}_{\mathrm{c}}
$$

with

$$
\begin{aligned}
\mathrm{c} & =-\frac{1}{\left(1-1 / \phi_{\tau}\right)} \sum_{\mathrm{i}=1}^{\mathrm{n}} \mathrm{w}_{\mathrm{i}} \mathrm{q}_{\mathrm{i} \tau}, \\
\mathrm{d} & =\left(\frac{1}{\mathrm{~h}_{\tau}}-1\right) \sum_{\mathrm{t}=1}^{\mathrm{T}} \phi_{\mathrm{t}} \sum_{\mathrm{i}=1}^{\mathrm{n}-1}\left(\mathrm{w}_{\mathrm{i}} \mathrm{q}_{\mathrm{it}}-\mathrm{w}_{\mathrm{i}} \mathrm{q}_{\mathrm{nt}}\right)+\mathrm{w}_{\mathrm{j}}\left(\frac{1}{\mathrm{~h}_{\tau}}-1\right)\left(\mathrm{v}_{\mathrm{j}}-1\right) \sum_{\mathrm{t}=1}^{\mathrm{T}} \phi_{\mathrm{t}}\left(\mathrm{q}_{\mathrm{jt}}-\mathrm{q}_{\mathrm{nt}}\right) \\
& =\left(\frac{1}{\mathrm{~h}_{\tau}}-1\right) \sum_{\mathrm{t}=1}^{\mathrm{T}} \phi_{\mathrm{t}}\left[\sum_{\mathrm{i}=1}^{\mathrm{n}-1}\left(\mathrm{w}_{\mathrm{i}} \mathrm{q}_{\mathrm{it}}\right)-\mathrm{q}_{\mathrm{nt}}\left(1-\mathrm{w}_{\mathrm{n}}\right)-\left(\mathrm{q}_{\mathrm{jt}}-\mathrm{q}_{\mathrm{nt}}\right)\right] \\
& =\left(\frac{1}{\mathrm{~h}_{\tau}}-1\right) \sum_{\mathrm{t}=1}^{\mathrm{T}} \phi_{\mathrm{t}}\left[\sum_{\mathrm{i}=1}^{\mathrm{n}}\left(\mathrm{w}_{\mathrm{i}} \mathrm{q}_{\mathrm{it}}\right)-\mathrm{q}_{\mathrm{jt}}\right] \\
& =\sum_{\mathrm{t}=1}^{\mathrm{T}} \phi_{\mathrm{t}}\left[\mathrm{q}_{\mathrm{jt}}-\sum_{\mathrm{i}=1}^{\mathrm{n}} \mathrm{w}_{\mathrm{i}} \mathrm{q}_{\mathrm{it}}\right]-\frac{1}{\left(1-1 / \phi_{\tau}\right)} \sum_{\mathrm{t}=1}^{\mathrm{T}} \phi_{\mathrm{t}}\left[\mathrm{q}_{\mathrm{jt}}-\sum_{\mathrm{i}=1}^{\mathrm{n}} \mathrm{w}_{\mathrm{i}} \mathrm{q}_{\mathrm{it}}\right], \text { and } \\
\mathrm{e} & =\frac{\mathrm{q}_{\mathrm{j} \tau}}{\left(1-1 / \phi_{\tau}\right)} .
\end{aligned}
$$

Therefore,

$$
\mathrm{b}_{\mathrm{j}}^{* *}=\sum_{\mathrm{t}=1}^{\mathrm{T}} \phi_{\mathrm{t}}\left(\mathrm{q}_{\mathrm{jt}}-\sum_{\mathrm{i}=1}^{\mathrm{n}} \mathrm{w}_{\mathrm{i}} \mathrm{q}_{\mathrm{it}}\right)+\frac{1}{\left(1-1 / \phi_{\tau}\right)}\left[\mathrm{q}_{\mathrm{j} \tau}-\sum_{\mathrm{i}=1}^{\mathrm{n}} \mathrm{w}_{\mathrm{i}} \mathrm{q}_{\mathrm{i \tau}}-\sum_{\mathrm{t}=1}^{\mathrm{T}} \phi_{\mathrm{t}}\left(\mathrm{q}_{\mathrm{jt}}-\sum_{\mathrm{i}=1}^{\mathrm{n}} \mathrm{w}_{\mathrm{i}} \mathrm{q}_{\mathrm{it}}\right)\right] .
$$


These expressions coincide with equation (A1.11) above.

\section{Mispricing}

Lastly, $\gamma^{* *}$ can be written as

$$
\gamma^{* * *}=\underbrace{\frac{\Theta \cdot \theta_{\tau}^{2}}{\left(1-\mathrm{w}_{\mathrm{j}}\right) \mathrm{h}_{\tau}} \sum_{\mathrm{i}=1}^{\mathrm{n}} \mathrm{w}_{\mathrm{i}} \mathrm{q}_{\mathrm{i} \tau}}_{\mathrm{c}} \underbrace{-\frac{\theta_{\tau}^{2}}{\left(1-\mathrm{w}_{\mathrm{j}}\right) \mathrm{h}_{\tau}} \sum_{\mathrm{t}=1}^{\mathrm{T}} \sum_{\mathrm{i}=1, \mathrm{i} \neq \mathrm{j}}^{\mathrm{n}-1} \frac{\mathrm{w}_{\mathrm{i}} \mathrm{q}_{\mathrm{it}}-\mathrm{w}_{\mathrm{i}} \mathrm{q}_{\mathrm{nt}}}{\theta_{\mathrm{t}}^{2}}+\frac{\theta_{\tau}^{2}}{\mathrm{~h}_{\tau}} \sum_{\mathrm{t}=1}^{\mathrm{T}} \frac{\mathrm{q}_{\mathrm{jt}}-\mathrm{q}_{\mathrm{nt}}}{\theta_{\mathrm{t}}^{2}}}_{\mathrm{d}}+\underbrace{\frac{\mathrm{q}_{\mathrm{j} \tau}}{\left(1-\mathrm{w}_{\mathrm{j}}\right)\left(1-\phi_{\tau}\right)}}_{\mathrm{e}},
$$

with

$$
\begin{aligned}
\mathrm{c} & =\frac{1}{\phi_{\tau}\left(1-\mathrm{w}_{\mathrm{j}}\right) \mathrm{h}_{\tau}} \sum_{\mathrm{i}=1}^{\mathrm{n}} \mathrm{w}_{\mathrm{i}} \mathrm{q}_{\mathrm{i} \tau}=-\frac{1}{\left(1-\mathrm{w}_{\mathrm{j}}\right)\left(1-\phi_{\tau}\right)} \sum_{\mathrm{i}=1}^{\mathrm{n}} \mathrm{w}_{\mathrm{i}} \mathrm{q}_{\mathrm{i} \tau}, \\
\mathrm{d} & =-\frac{1}{\phi_{\tau}\left(1-\mathrm{w}_{\mathrm{j}}\right) \mathrm{h}_{\tau}} \sum_{\mathrm{t}=1}^{\mathrm{T}} \phi_{\mathrm{t}} \sum_{\mathrm{i}=1, \mathrm{i} \neq \mathrm{j}}^{\mathrm{n}-1}\left(\mathrm{w}_{\mathrm{i}} \mathrm{q}_{\mathrm{it}}-\mathrm{w}_{\mathrm{i}} \mathrm{q}_{\mathrm{nt}}\right)+\frac{1}{\phi_{\tau} \mathrm{h}_{\tau}} \sum_{\mathrm{t}=1}^{\mathrm{T}} \phi_{\mathrm{t}}\left(\mathrm{q}_{\mathrm{jt}}-\mathrm{q}_{\mathrm{nt}}\right) \\
& =\frac{1}{\left(1-\mathrm{w}_{\mathrm{j}}\right)\left(1-\phi_{\tau}\right)} \sum_{\mathrm{t}=1}^{\mathrm{T}} \phi_{\mathrm{t}}\left[\sum_{\mathrm{i}=1, \mathrm{i} \neq \mathrm{j}}^{\mathrm{n}-1}\left(\mathrm{w}_{\mathrm{i}} \mathrm{q}_{\mathrm{it}}-\mathrm{w}_{\mathrm{i}} \mathrm{q}_{\mathrm{nt}}\right)-\left(1-\mathrm{w}_{\mathrm{j}}\right)\left(\mathrm{q}_{\mathrm{jt}}-\mathrm{q}_{\mathrm{nt}}\right)\right] \\
& =\frac{1}{\left(1-\mathrm{w}_{\mathrm{j}}\right)\left(1-\phi_{\tau}\right)} \sum_{\mathrm{t}=1}^{\mathrm{T}} \phi_{\mathrm{t}}\left[\sum_{\mathrm{i}=1}^{\mathrm{n}-1}\left(\mathrm{w}_{\mathrm{i}} \mathrm{q}_{\mathrm{it}}\right)-\mathrm{q}_{\mathrm{nt}}\left(1-\mathrm{w}_{\mathrm{n}}\right)-\left(\mathrm{q}_{\mathrm{jt}}-\mathrm{q}_{\mathrm{nt}}\right)\right] \\
& =-\frac{1}{\left(1-\mathrm{w}_{\mathrm{j}}\right)\left(1-\phi_{\tau}\right)} \sum_{\mathrm{t}=1}^{\mathrm{T}} \phi_{\mathrm{t}}\left(\mathrm{q}_{\mathrm{jt}}-\sum_{\mathrm{i}=1}^{\mathrm{n}} \mathrm{w}_{\mathrm{i}} \mathrm{q}_{\mathrm{it}}\right), \text { and } \\
\mathrm{e} & =\frac{\mathrm{q}_{\mathrm{j} \tau}}{\left(1-\mathrm{w}_{\mathrm{j}}\right)\left(1-\phi_{\tau}\right)} .
\end{aligned}
$$

Therefore,

$$
\gamma^{* *}=\frac{1}{\left(1-\mathrm{w}_{\mathrm{j}}\right)\left(1-\phi_{\tau}\right)}\left[\mathrm{q}_{\mathrm{j} \tau}-\sum_{\mathrm{i}=1}^{\mathrm{n}} \mathrm{w}_{\mathrm{i}} \mathrm{q}_{\mathrm{i} \tau}-\sum_{\mathrm{t}=1}^{\mathrm{T}} \phi_{\mathrm{t}}\left(\mathrm{q}_{\mathrm{jt}}-\sum_{\mathrm{i}=1}^{\mathrm{n}} \mathrm{w}_{\mathrm{i}} \mathrm{q}_{\mathrm{it}}\right)\right],
$$

which is identical to equation (A1.12).

In summary, this sub-section has confirmed the previous expressions for the weighted least-squares estimators given in equations (A1.10)-(A1.12).

\section{A1.5 Sampling Variances}

Using the above results, we can derive scalar expressions for the variance of the estimator, $\operatorname{var}\left(\boldsymbol{\pi}^{* * *}\right)=\frac{1}{\mathrm{n}-1}\left(\mathbf{F}^{\prime} \mathbf{F}\right)^{-1}$. 
A-14

\section{Time and Currency Effects}

Using the block in the top right-hand corner of the inverse $\left(\mathbf{F}^{\prime} \mathbf{F}\right)^{-1}$ given in Table A1.1, we have

$$
\operatorname{var}\left[\begin{array}{c}
\mathrm{a}_{1}^{* *} \\
\mathrm{a}_{2}^{* *} \\
\vdots \\
\mathrm{a}_{\tau}^{* *} \\
\vdots \\
\mathrm{a}_{\mathrm{T}}^{* *}
\end{array}\right]=\frac{1}{\mathrm{n}-1}\left[\begin{array}{ccccc}
\theta_{1}^{2} & & \cdots & & 0 \\
& \ddots & & \\
\vdots & & \theta_{\tau}^{2}\left[1-\frac{1}{\mathrm{v}_{\mathrm{j}}\left(1-\phi_{\tau}\right)}\right] & & \vdots \\
& & & \ddots & \\
0 & & \ldots & & \theta_{\mathrm{T}}^{2}
\end{array}\right] .
$$

So,

$$
\operatorname{var}\left(\mathrm{a}_{\mathrm{t}}^{* *}\right)=\frac{\theta_{\mathrm{t}}^{2}}{\mathrm{n}-1}\left[1-\delta_{\mathrm{t \tau}} \frac{1}{\left(1-1 / \mathrm{w}_{\mathrm{j}}\right)\left(1-\phi_{\tau}\right)}\right],
$$

where $\delta_{t \tau}$ is the Kronecker delta, and

$$
\operatorname{cov}\left(a_{t}^{* *}, a_{s}^{* *}\right)=0, \operatorname{cov}\left(a_{\tau}^{* *}, a_{s}^{* *}\right)=0, \text { where } t \neq \tau \neq s .
$$

Next, defining $k=\Theta^{-1} /(n-1)$, we have

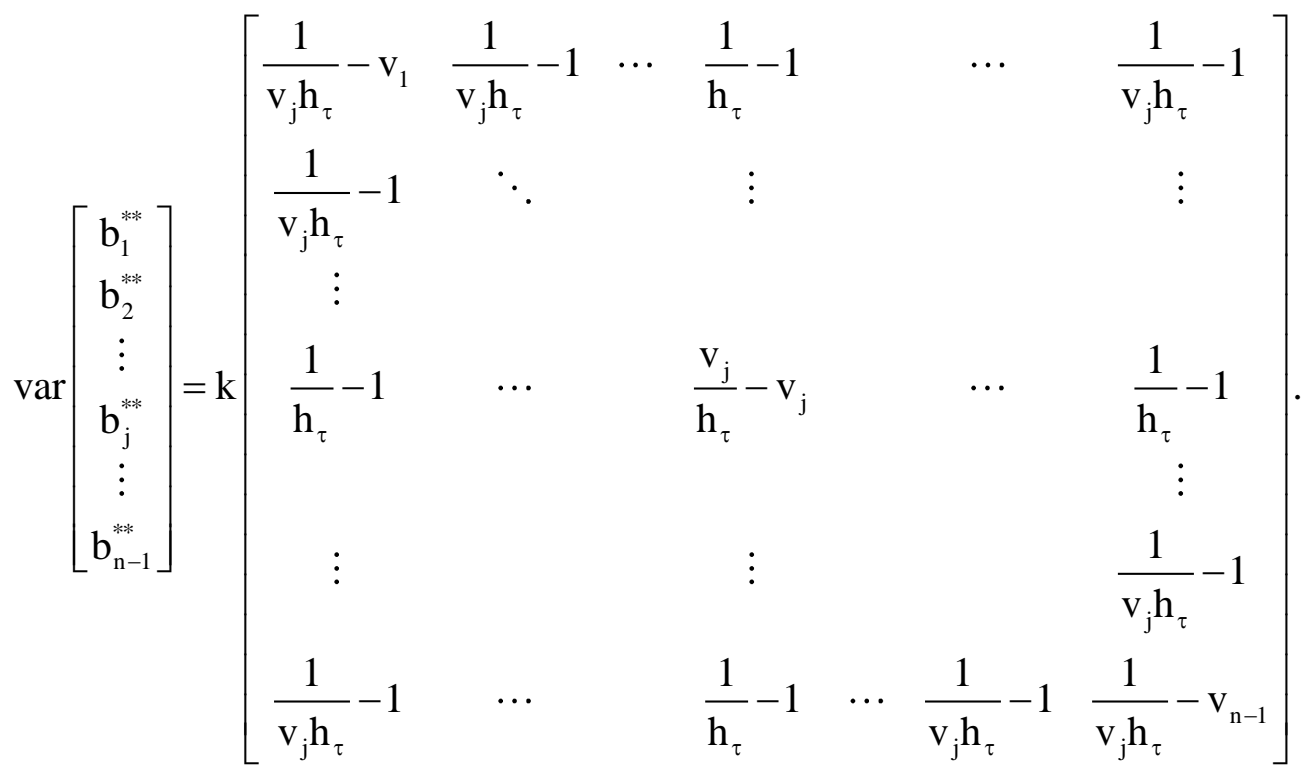

Thus,

$$
\begin{gathered}
\operatorname{var}\left(b_{i}^{* *}\right)=k\left[\frac{\left(1-1 / w_{j}\right)^{2 \delta_{i j}}}{\left(1-1 / w_{j}\right)\left(1-1 / \phi_{\tau}\right)}+\frac{1}{w_{i}}-1\right], \\
\operatorname{cov}\left(b_{i}^{* *}, b_{i^{\prime}}^{* *}\right)=k\left[\frac{1}{\left(1-1 / w_{j}\right)\left(1-1 / \phi_{\tau}\right)}-1\right], \operatorname{cov}\left(b_{i}^{* *}, b_{j}^{* *}\right)=k\left[\frac{1}{\left(1-1 / \phi_{\tau}\right)}-1\right], \text { for } i \neq i^{\prime} \neq j .
\end{gathered}
$$




\section{The Last Currency}

The currency factor for the last currency, $\mathrm{b}_{\mathrm{n}}^{* *}$, was omitted from the above analysis as the identification constraint equation (A1.2) was used to substitute it out. The variance of $b_{n}^{* * *}$, can be obtained from going back to the constraint (A1.2), which we expressed in the form $\mathrm{b}_{\mathrm{n}}=-\sum_{\mathrm{k}=1}^{\mathrm{n}-1}\left(\tilde{\mathrm{x}}_{\mathrm{kt}}^{2} / \tilde{\mathrm{x}}_{\mathrm{nt}}^{2}\right) \mathrm{b}_{\mathrm{k}}$. If we write this as $\mu=\zeta^{\prime} \boldsymbol{\psi}$, where $\zeta$ is a vector of $\mathrm{n}-1$ constants and $\psi$ is a random vector with covariance matrix $\operatorname{var}(\psi)$, then $\operatorname{var}(\mu)=\zeta^{\prime} \operatorname{var}(\psi) \zeta$. After some algebra, application of this approach yields

$$
\operatorname{var}\left(b_{\mathrm{n}}^{* *}\right)=\mathrm{k}\left[\frac{1}{\left(1-1 / \mathrm{w}_{\mathrm{j}}\right)\left(1-1 / \phi_{\tau}\right)}+\frac{1}{\mathrm{w}_{\mathrm{n}}}-1\right],
$$

which is the same form as $\operatorname{var}\left(b_{i}^{* *}\right)$ above with $\delta_{i j}=0$.

\section{Mispricing}

Lastly, the variance of $\gamma^{* *}$ is

$$
\operatorname{var}\left(\gamma^{* *}\right)=\frac{\theta_{\tau}^{2}}{\mathrm{w}_{\mathrm{j}}\left(1-\mathrm{w}_{\mathrm{j}}\right)\left(1-\phi_{\tau}\right)(\mathrm{n}-1)},
$$

which is given below expression (6) of the text.

\section{A1.6 Verification of Inverse}

The fourth subsection of Section A1.3 contains the partitioned inverse of the moment matrix $\mathbf{F}^{\prime} \mathbf{F}$. The form of this inverse can be verified by establishing that $\left(\mathbf{F}^{\prime} \mathbf{F}\right)\left(\mathbf{F}^{\prime} \mathbf{F}\right)^{-1}=\mathbf{I}$, the identity matrix.

Using the expressions given above, $\mathbf{F}^{\prime} \mathbf{F}\left(\mathbf{F}^{\prime} \mathbf{F}\right)^{-1}$ can be written as 


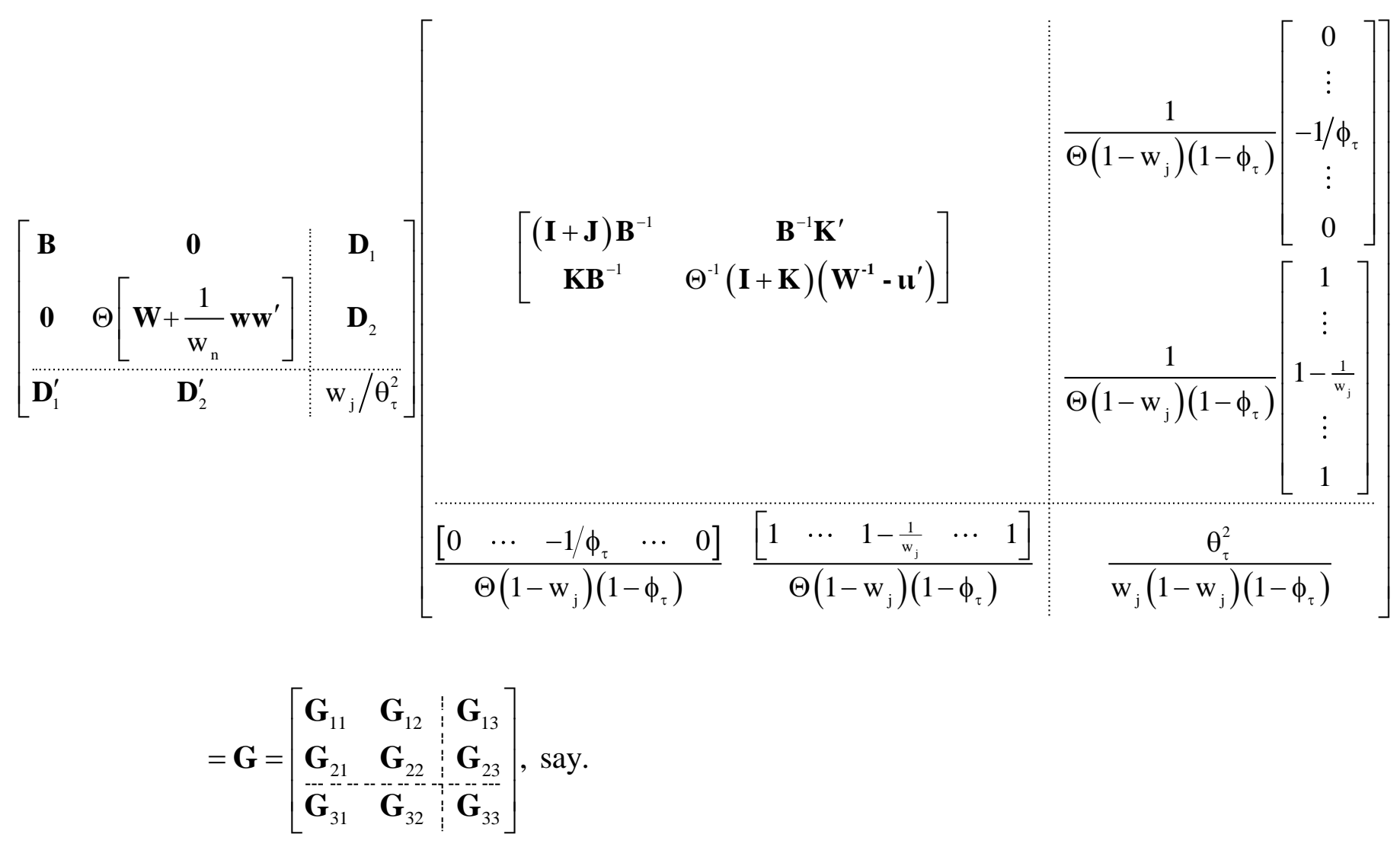

The inverse is confirmed by establishing that $\mathbf{G}=\mathbf{I}$. To do that, we shall consider separately each of the three blocks of "rows" of $\mathbf{G}$ to show

$$
\left[\begin{array}{ll:l}
\mathbf{G}_{11} & \mathbf{G}_{12} & \mathbf{G}_{13} \\
\mathbf{G}_{21} & \mathbf{G}_{22} & \mathbf{G}_{23} \\
\hdashline \mathbf{G}_{31} & \mathbf{G}_{32} & \mathbf{G}_{33}
\end{array}\right]=\left[\begin{array}{cc:c}
\mathbf{I} & \mathbf{0} & \mathbf{0} \\
\mathbf{0} & \mathbf{I} & \mathbf{0} \\
\hdashline \mathbf{0} & \mathbf{0} & \mathbf{I}
\end{array}\right]=\mathbf{I} .
$$

For what is to follow, it is useful to recall the definitions:

$$
\begin{aligned}
& \mathbf{J}=\left[\begin{array}{ccccc}
0 & & & & \\
& \ddots & & & \\
\vdots & -\frac{1}{\mathrm{v}_{\mathrm{j}}\left(1-\phi_{\tau}\right)} & & \vdots \\
& & & \ddots & \\
0 & & & & 0
\end{array}\right], \mathbf{K}=\left[\begin{array}{ccccc}
0 & \cdots & -\frac{1}{\mathrm{v}_{\mathrm{j}} \mathrm{h}_{\tau}} & \cdots & 0 \\
& \ddots & \vdots & & \\
\vdots & & -\frac{1}{\mathrm{~h}_{\tau}} & & \vdots \\
& & \vdots & \ddots & \\
0 & \cdots & -\frac{1}{\mathrm{v}_{\mathrm{j}} \mathrm{h}_{\tau}} & \cdots & 0
\end{array}\right], \mathrm{v}_{\mathrm{j}}=1-\frac{1}{\mathrm{w}_{\mathrm{j}}}, \mathrm{h}_{\tau}=1-\frac{1}{\phi_{\tau}}, \\
& \mathbf{D}_{1}=\left[\begin{array}{c}
0 \\
\vdots \\
\mathrm{w}_{\mathrm{j}} / \theta_{\tau}^{2} \\
\vdots \\
0
\end{array}\right], \mathbf{D}_{2}=\left[\begin{array}{c}
0 \\
\vdots \\
\mathrm{w}_{\mathrm{j}} / \theta_{\tau}^{2} \\
\vdots \\
0
\end{array}\right] \text {. }
\end{aligned}
$$


Top Row of $\boldsymbol{G}$

We need to establish that the first row of $\mathbf{G}$ takes the form $\left[\mathbf{G}_{11} \mathbf{G}_{12} \mathbf{G}_{13}\right]=[\mathbf{I} \mathbf{0 0} 0]$. Thus,

$$
\begin{aligned}
& \mathbf{G}_{11}=\mathbf{B}(\mathbf{I}+\mathbf{J}) \mathbf{B}^{-1}+\mathbf{D}_{1}\left[\begin{array}{lllll}
0 & \cdots & \frac{\Theta \cdot \theta_{\tau}^{4}}{\left(1-\mathrm{w}_{\mathrm{j}}\right) \mathrm{h}_{\tau}} & \cdots & 0
\end{array}\right]
\end{aligned}
$$

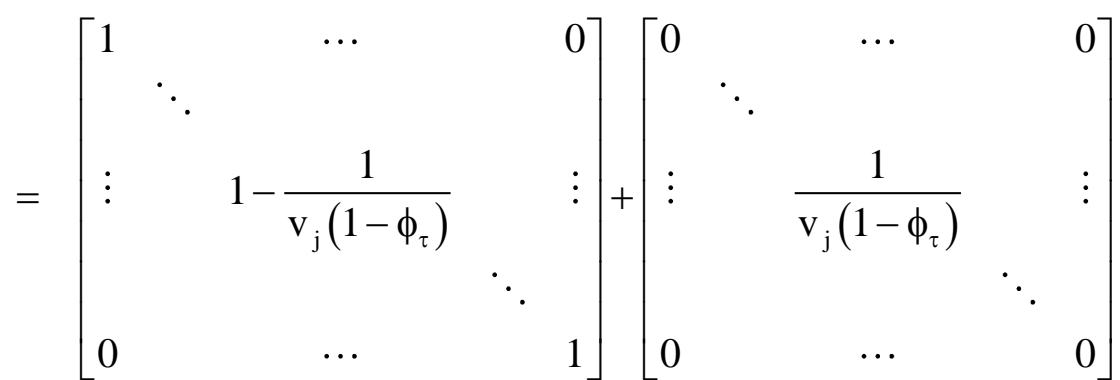

$=\mathbf{I}$.

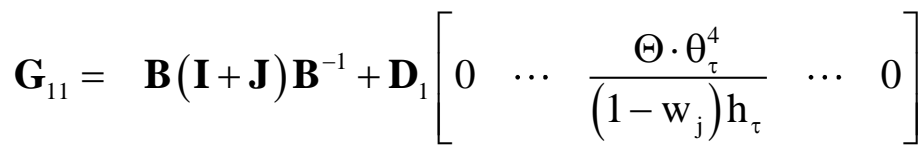

$=\left[\begin{array}{ccccc}1 & & \cdots & & 0 \\ & \ddots & & & \\ \vdots & 1-\frac{1}{\mathrm{v}_{\mathrm{j}}\left(1-\phi_{\tau}\right)} & & \vdots \\ & & & \ddots & \\ 0 & & \cdots & & 1\end{array}\right]+\left[\begin{array}{ccccc}0 & & \cdots & & 0 \\ & \ddots & & & \\ \vdots & & \frac{1}{\mathrm{v}_{\mathrm{j}}\left(1-\phi_{\tau}\right)} & & \vdots \\ & & & \ddots & \\ 0 & & \cdots & & 0\end{array}\right]$

$=\mathbf{I}$.

$\mathbf{G}_{12}=\mathbf{B B}^{-1} \mathbf{K}^{\prime}+\mathbf{D}_{1}\left[\begin{array}{ccccc}\frac{-\theta_{\tau}^{2}}{\left(1-\mathrm{w}_{\mathrm{j}}\right) \mathrm{h}_{\tau}} & \cdots & \frac{\theta_{\tau}^{2}}{\mathrm{w}_{\mathrm{j}} \mathrm{h}_{\tau}} & \cdots & \frac{-\theta_{\tau}^{2}}{\left(1-\mathrm{w}_{\mathrm{j}}\right) \mathrm{h}_{\tau}}\end{array}\right]$

$=\mathbf{K}^{\prime}+\left[\begin{array}{ccccc}0 & \cdots & 0 & \cdots & 0 \\ & \ddots & \vdots & & \\ \frac{1}{\mathrm{v}_{\mathrm{j}} \mathrm{h}_{\tau}} & & \frac{1}{\mathrm{~h}_{\tau}} & & \frac{1}{\mathrm{v}_{\mathrm{j}} \mathrm{h}_{\tau}} \\ & & \vdots & \ddots & \\ 0 & \cdots & 0 & \cdots & 0\end{array}\right]$

$=[\mathbf{0}]$. 


$$
\mathbf{G}_{13}=\left[\begin{array}{c}
0 \\
\vdots \\
\frac{-1}{\left(1-\mathrm{w}_{\mathrm{j}}\right)\left(1-\phi_{\tau}\right)} \\
\vdots \\
0
\end{array}\right]+\left[\begin{array}{c}
0 \\
\vdots \\
1 \\
\left(1-\mathrm{w}_{\mathrm{j}}\right)\left(1-\phi_{\tau}\right) \\
\vdots \\
0
\end{array}\right]=[\mathbf{0}] \text {. }
$$

Middle Row of $\boldsymbol{G}$

The second row of $\mathbf{G}$ needs to be of the form $\left[\mathbf{G}_{21} \mathbf{G}_{22} \mathbf{G}_{23}\right]=[\mathbf{0} \mathbf{I} \mathbf{0}]$. We proceed as before:

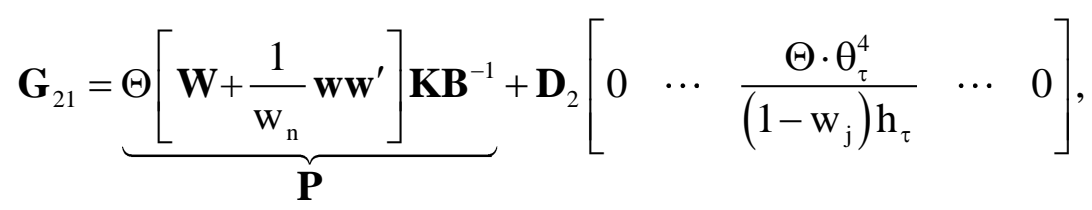

Let the $(\mathrm{i}, \mathrm{k})^{\text {th }}$ element of the matrix $\mathbf{P}$ be $\mathrm{p}_{\mathrm{ik}}$, which can be denoted by $\mathbf{P}=\left[\mathrm{p}_{\mathrm{ik}}\right]$. Two cases need to be considered for $\mathbf{P}$.

Case 1: For columns where $\mathrm{k} \neq \mathrm{j}, \mathrm{p}_{\mathrm{ik}}=0$.

Case 2: When column $\mathrm{k}=\mathrm{j}$ and row $\mathrm{i} \neq \mathrm{j}$,

$$
\begin{aligned}
\mathrm{p}_{\mathrm{ik}} & =\frac{1}{\mathrm{v}_{\mathrm{j}}\left(1-\phi_{\tau}\right)}\left(\mathrm{w}_{\mathrm{i}}+\frac{\mathrm{w}_{\mathrm{i}}}{\mathrm{w}_{\mathrm{n}}} \sum_{\mathrm{k}=1, \mathrm{k} \neq \mathrm{j}}^{\mathrm{n}-1} \mathrm{w}_{\mathrm{k}}\right)+\frac{1}{\left(1-\phi_{\tau}\right)}\left(\frac{\mathrm{w}_{\mathrm{i}} \mathrm{w}_{\mathrm{j}}}{\mathrm{w}_{\mathrm{n}}}\right) \\
& =\frac{1}{\mathrm{v}_{\mathrm{j}}\left(1-\phi_{\tau}\right)}\left[\mathrm{w}_{\mathrm{i}}+\frac{\mathrm{w}_{\mathrm{i}}}{\mathrm{w}_{\mathrm{n}}} \sum_{\mathrm{k}=1, \mathrm{k} \neq \mathrm{j}}^{\mathrm{n}-1}\left(\mathrm{w}_{\mathrm{k}}\right)+\left(\mathrm{w}_{\mathrm{j}}-1\right) \frac{\mathrm{w}_{\mathrm{i}}}{\mathrm{w}_{\mathrm{n}}}\right] \\
& =\frac{1}{\mathrm{v}_{\mathrm{j}}\left(1-\phi_{\tau}\right)}\left[\mathrm{w}_{\mathrm{i}}+\frac{\mathrm{w}_{\mathrm{i}}}{\mathrm{w}_{\mathrm{n}}}\left(1-\mathrm{w}_{\mathrm{n}}\right)-\frac{\mathrm{w}_{\mathrm{i}}}{\mathrm{w}_{\mathrm{n}}}\right] \\
& =0 .
\end{aligned}
$$

The next part of case 2 is when column $\mathrm{k}=\mathrm{j}$ and row $\mathrm{i}=\mathrm{j}$,

$$
\begin{aligned}
\mathrm{p}_{\mathrm{jj}} & =\frac{1}{\mathrm{v}_{\mathrm{j}}\left(1-\phi_{\tau}\right)}\left(\frac{\mathrm{w}_{\mathrm{j}}}{\mathrm{w}_{\mathrm{n}}} \sum_{\mathrm{k}=1, \mathrm{k} \neq \mathrm{j}}^{\mathrm{n}-1} \mathrm{w}_{\mathrm{k}}\right)+\frac{1}{\left(1-\phi_{\tau}\right)}\left(\mathrm{w}_{\mathrm{j}}+\frac{\mathrm{w}_{\mathrm{j}} \mathrm{w}_{\mathrm{j}}}{\mathrm{w}_{\mathrm{n}}}\right) \\
& =\frac{1}{\mathrm{v}_{\mathrm{j}}\left(1-\phi_{\tau}\right)}\left[\frac{\mathrm{w}_{\mathrm{j}}}{\mathrm{w}_{\mathrm{n}}} \sum_{\mathrm{k}=1, \mathrm{k} \neq \mathrm{j}}^{\mathrm{n}-1}\left(\mathrm{w}_{\mathrm{k}}\right)+\mathrm{w}_{\mathrm{j}}\left(\frac{\mathrm{w}_{\mathrm{j}}-1}{\mathrm{w}_{\mathrm{j}}}\right)\left(1+\frac{\mathrm{w}_{\mathrm{j}}}{\mathrm{w}_{\mathrm{n}}}\right)\right] \\
& =\frac{1}{\mathrm{v}_{\mathrm{j}}\left(1-\phi_{\tau}\right)}\left[\frac{\mathrm{w}_{\mathrm{j}}}{\mathrm{w}_{\mathrm{n}}}\left(1-\mathrm{w}_{\mathrm{n}}\right)+\mathrm{w}_{\mathrm{j}}-1-\frac{\mathrm{w}_{\mathrm{j}}}{\mathrm{w}_{\mathrm{n}}}\right] \\
& =-\frac{1}{\mathrm{v}_{j}\left(1-\phi_{\tau}\right)} .
\end{aligned}
$$


Combining these results, we obtain

$$
\begin{aligned}
& \mathbf{G}_{21}=\left[\begin{array}{ccccc}
0 & & \cdots & & 0 \\
& \ddots & & & \\
\vdots & -\frac{1}{\mathrm{v}_{\mathrm{j}}\left(1-\phi_{\tau}\right)} & & \vdots \\
& & \ddots & \\
0 & \cdots & & 0
\end{array}\right]+\mathbf{D}_{2}\left[\begin{array}{lllll}
0 & \cdots & \frac{\Theta \cdot \theta_{\tau}^{4}}{\left(1-\mathrm{w}_{\mathrm{j}}\right) \mathrm{h}_{\tau}} & \cdots & 0
\end{array}\right]
\end{aligned}
$$

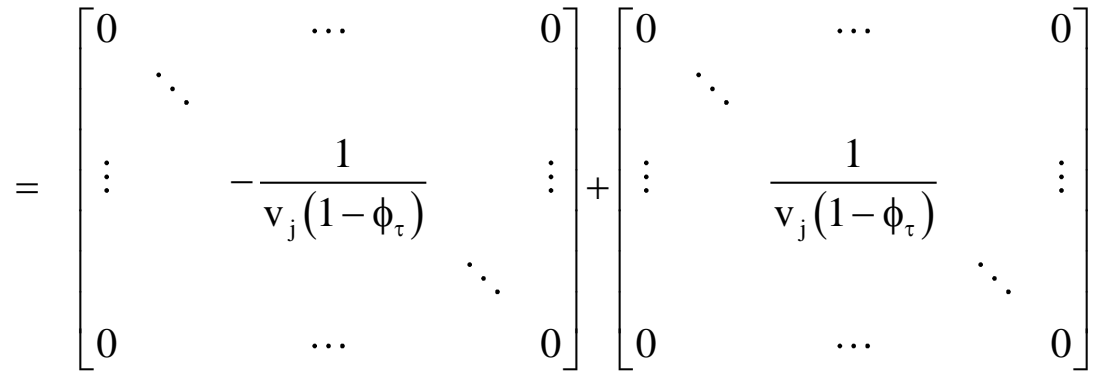

$$
\begin{aligned}
& =[\mathbf{0}] \text {. }
\end{aligned}
$$

Next,

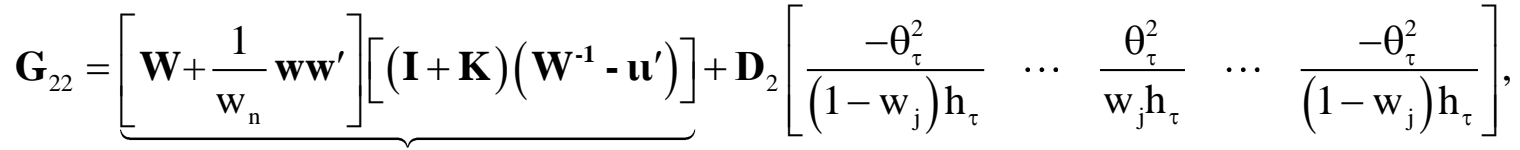

with $\mathbf{A}=\left[\mathrm{a}_{\mathrm{ik}}\right]$. Three cases need to be considered.

Case 1: The main diagonal, where $\mathrm{i}=\mathrm{k}, \mathrm{i} \neq \mathrm{j}$

$$
\begin{aligned}
a_{i i} & =\left(\frac{1}{v_{j} h_{\tau}}-1\right)\left[w_{i}+\frac{w_{i}}{w_{n}} \sum_{k=1, k \neq j}^{n-1} w_{k}\right]+\left(1-v_{i}\right)\left(w_{i}+\frac{w_{i} w_{i}}{w_{n}}\right)+\left(\frac{1}{h_{\tau}}-1\right) \frac{w_{i} w_{j}}{w_{n}} \\
& =\frac{1}{v_{j} h_{\tau}}\left[w_{i}+\frac{w_{i}}{w_{n}} \sum_{k=1, k \neq j}^{n-1}\left(w_{k}\right)\right]-w_{i}-\frac{w_{i}}{w_{n}} \sum_{k=1, k \neq j}^{n-1}\left(w_{k}\right)+1+\frac{w_{i}}{w_{n}}+\frac{1}{v_{j} h_{\tau}}\left(v_{j} \frac{w_{i} w_{j}}{w_{n}}\right)-\frac{w_{i} w_{j}}{w_{n}} \\
& =1+\frac{w_{i}}{w_{n}}-w_{i}-\frac{w_{i}}{w_{n}} \sum_{k=1}^{n-1}\left(w_{k}\right)+\frac{1}{v_{j} h_{\tau}}\left[w_{i}+\frac{w_{i}}{w_{n}} \sum_{k=1}^{n-1}\left(w_{k}\right)-\frac{w_{i}}{w_{n}}\right] \\
& =1+\frac{w_{i}}{w_{n}}-w_{i}-\frac{w_{i}}{w_{n}}\left(1-w_{n}\right)+\frac{1}{v_{j} h_{\tau}}\left[w_{i}+\frac{w_{i}}{w_{n}}\left(1-w_{n}\right)-\frac{w_{i}}{w_{n}}\right] \\
& =1 .
\end{aligned}
$$

The next part of case 1 refers to the main diagonal with $\mathrm{i}=\mathrm{k}=\mathrm{j}$ : 


$$
\begin{aligned}
a_{j j} & =\left(\frac{1}{h_{\tau}}-1\right)\left[\frac{w_{j}}{w_{n}} \sum_{k=1, k \neq j}^{n-1} w_{k}\right]+\left(v_{j}\right)\left(\frac{1}{h_{\tau}}-1\right)\left(w_{j}+\frac{w_{j} w_{j}}{w_{n}}\right) \\
& =\left(\frac{1}{h_{\tau}}-1\right)\left[\frac{w_{j}}{w_{n}} \sum_{k=1, k \neq j}^{n-1}\left(w_{k}\right)+w_{j}-1+\frac{w_{j} w_{j}}{w_{n}}-\frac{w_{j}}{w_{n}}\right] \\
& =\left(\frac{1}{h_{\tau}}-1\right)\left[\frac{w_{j}}{w_{n}}\left(1-w_{n}\right)+w_{j}-1-\frac{w_{j}}{w_{n}}\right] \\
& =1-\frac{1}{h_{\tau}} .
\end{aligned}
$$

Case 2: For off-diagonals, where $\mathrm{i} \neq \mathrm{j}$ :

$$
\begin{aligned}
\mathrm{a}_{\mathrm{ik}} & =\left(\frac{1}{\mathrm{v}_{\mathrm{j}} \mathrm{h}_{\tau}}-1\right)\left[\mathrm{w}_{\mathrm{i}}+\frac{\mathrm{w}_{\mathrm{i}}}{\mathrm{w}_{\mathrm{n}}} \sum_{\mathrm{k}=1, \mathrm{k} \neq \mathrm{j}}^{\mathrm{n}-1} \mathrm{w}_{\mathrm{k}}\right]+\left(1-\mathrm{v}_{\mathrm{k}}\right)\left(\frac{\mathrm{w}_{\mathrm{i}} \mathrm{w}_{\mathrm{k}}}{\mathrm{w}_{\mathrm{n}}}\right)+\left(\frac{1}{\mathrm{~h}_{\tau}}-1\right) \frac{\mathrm{w}_{\mathrm{i}} \mathrm{w}_{\mathrm{j}}}{\mathrm{w}_{\mathrm{n}}} \\
& =\frac{1}{\mathrm{v}_{\mathrm{j}} \mathrm{h}_{\tau}}\left[\mathrm{w}_{\mathrm{i}}+\frac{\mathrm{w}_{\mathrm{i}}}{\mathrm{w}_{\mathrm{n}}} \sum_{\mathrm{k}=1, \mathrm{k} \neq \mathrm{j}}^{\mathrm{n}-1}\left(\mathrm{w}_{\mathrm{k}}\right)\right]-\mathrm{w}_{\mathrm{i}}-\frac{\mathrm{w}_{\mathrm{i}}}{\mathrm{w}_{\mathrm{n}}} \sum_{\mathrm{k}=1, \mathrm{k} \neq \mathrm{j}}^{\mathrm{n}-1}\left(\mathrm{w}_{\mathrm{k}}\right)+\frac{\mathrm{w}_{\mathrm{i}}}{\mathrm{w}_{\mathrm{n}}}+\frac{1}{\mathrm{v}_{\mathrm{j}} \mathrm{h}_{\tau}}\left(\mathrm{v}_{\mathrm{j}} \frac{\mathrm{w}_{\mathrm{i}} \mathrm{w}_{\mathrm{j}}}{\mathrm{w}_{\mathrm{n}}}\right)-\frac{\mathrm{w}_{\mathrm{i}} \mathrm{w}_{j}}{\mathrm{w}_{\mathrm{n}}} \\
& =-\mathrm{w}_{\mathrm{i}}-\frac{\mathrm{w}_{\mathrm{i}}}{\mathrm{w}_{\mathrm{n}}} \sum_{\mathrm{k}=1}^{\mathrm{n}-1}\left(\mathrm{w}_{\mathrm{k}}\right)+\frac{\mathrm{w}_{\mathrm{i}}}{\mathrm{w}_{\mathrm{n}}}+\frac{1}{\mathrm{v}_{\mathrm{j}} \mathrm{h}_{\tau}}\left[\mathrm{w}_{\mathrm{i}}+\frac{\mathrm{w}_{\mathrm{i}}}{\mathrm{w}_{\mathrm{n}}} \sum_{\mathrm{k}=1, \mathrm{k} \neq \mathrm{j}}^{\mathrm{n}-1}\left(\mathrm{w}_{\mathrm{k}}\right)-\frac{\mathrm{w}_{\mathrm{i}}}{\mathrm{w}_{\mathrm{n}}}\right] \\
& =\frac{\mathrm{w}_{\mathrm{i}}}{\mathrm{w}_{\mathrm{n}}}-\mathrm{w}_{\mathrm{i}}-\frac{\mathrm{w}_{\mathrm{i}}}{\mathrm{w}_{\mathrm{n}}}\left(1-\mathrm{w}_{\mathrm{n}}\right)+\frac{1}{\mathrm{v}_{\mathrm{j}} \mathrm{h}_{\tau}}\left[\mathrm{w}_{\mathrm{i}}+\frac{\mathrm{w}_{\mathrm{i}}}{\mathrm{w}_{\mathrm{n}}}\left(1-\mathrm{w}_{\mathrm{n}}\right)-\frac{\mathrm{w}_{\mathrm{i}}}{\mathrm{w}_{\mathrm{n}}}\right] \\
& =0 .
\end{aligned}
$$

Case 3: For off-diagonal, when $\mathrm{i}=\mathrm{j}$ :

$$
\begin{aligned}
a_{j k} & =\left(\frac{1}{v_{j} h_{\tau}}-1\right)\left[\frac{w_{j}}{w_{n}} \sum_{k=1, k \neq j}^{n-1} w_{k}\right]+\left(1-v_{k}\right)\left(\frac{w_{j} w_{k}}{w_{n}}\right)+\left(\frac{1}{h_{\tau}}-1\right)\left(w_{j}+\frac{w_{j} w_{j}}{w_{n}}\right) \\
& =\frac{1}{v_{j} h_{\tau}}\left[\frac{w_{j}}{w_{n}} \sum_{k=1, k \neq j}^{n-1}\left(w_{k}\right)\right]-\frac{w_{j}}{w_{n}} \sum_{k=1, k \neq j}^{n-1}\left(w_{k}\right)+\frac{w_{j}}{w_{n}}+\frac{1}{v_{j} h_{\tau}}\left[v_{j} w_{j}\left(1+\frac{w_{j}}{w_{n}}\right)\right]-w_{j}-\frac{w_{j} w_{j}}{w_{n}} \\
& =-\frac{w_{j}}{w_{n}} \sum_{k=1}^{n-1}\left(w_{k}\right)+\frac{w_{j}}{w_{n}}-w_{j}+\frac{1}{v_{j} h_{\tau}}\left[\frac{w_{j}}{w_{n}} \sum_{k=1}^{n-1}\left(w_{k}\right)+w_{j}-1-\frac{w_{j}}{w_{n}}\right] \\
& =-\frac{w_{j}}{w_{n}}\left(1-w_{n}\right)+\frac{w_{j}}{w_{n}}-w_{j}+\frac{1}{v_{j} h_{\tau}}\left[\frac{w_{j}}{w_{n}}\left(1-w_{n}\right)+w_{j}-1-\frac{w_{j}}{w_{n}}\right] \\
& =-\frac{1}{v_{j} h_{\tau}} .
\end{aligned}
$$

Combining, we obtain 


$$
\begin{aligned}
& \mathbf{G}_{22}=\mathbf{A}+\mathbf{D}_{2}\left[\begin{array}{lllll}
\frac{-\theta_{\tau}^{2}}{\left(1-\mathrm{w}_{\mathrm{j}}\right) \mathrm{h}_{\tau}} & \cdots & \frac{\theta_{\tau}^{2}}{\mathrm{w}_{\mathrm{j}} \mathrm{h}_{\tau}} & \cdots & \frac{-\theta_{\tau}^{2}}{\left(1-\mathrm{w}_{\mathrm{j}}\right) \mathrm{h}_{\tau}}
\end{array}\right] \\
& =\left[\begin{array}{lllll}
1 & \cdots & & & 0 \\
\vdots & \ddots & & & \vdots \\
-\frac{1}{\mathrm{v}_{\mathrm{j}} \mathrm{h}_{\tau}} & \cdots & 1-\frac{1}{\mathrm{~h}_{\tau}} & \cdots & -\frac{1}{\mathrm{v}_{\mathrm{j}} \mathrm{h}_{\tau}} \\
\vdots & & & \ddots & \vdots \\
0 & \cdots & & \cdots & 1
\end{array}\right]+\left[\begin{array}{lllll}
0 & \cdots & & 0 \\
\vdots & \ddots & & \vdots \\
\frac{1}{\mathrm{v}_{\mathrm{j}} \mathrm{h}_{\tau}} & \cdots & \frac{1}{\mathrm{~h}_{\tau}} & \cdots & \frac{1}{\mathrm{v}_{\mathrm{j}} \mathrm{h}_{\tau}} \\
\vdots & & & \ddots & \vdots \\
0 & \cdots & & \cdots & 0
\end{array}\right] \\
& =\mathbf{I} \text {. }
\end{aligned}
$$

The last block of the middle row is

$$
\mathbf{G}_{23}=\underbrace{\frac{1}{\left(1-\mathrm{w}_{\mathrm{j}}\right)\left(1-\phi_{\tau}\right)}\left[\mathbf{W}+\frac{1}{\mathrm{w}_{\mathrm{n}}} \mathbf{w} \mathbf{w}^{\prime}\right]\left[\begin{array}{c}
1 \\
\vdots \\
1-\frac{1}{\mathrm{w}_{\mathrm{j}}} \\
\vdots \\
1
\end{array}\right]}_{\mathbf{m}}+\frac{\theta_{\tau}^{2}}{\mathrm{w}_{\mathrm{j}}\left(1-\mathrm{w}_{\mathrm{j}}\right)\left(1-\phi_{\tau}\right)}\left[\begin{array}{c}
0 \\
\vdots \\
\frac{\mathrm{w}_{\mathrm{j}}}{\theta_{\tau}^{2}} \\
\vdots \\
0
\end{array}\right],
$$

where $\mathbf{m}=\left[\mathrm{m}_{\mathrm{i}}\right]$ is a column vector. For $\mathrm{i} \neq \mathrm{j}$,

$$
\begin{aligned}
\mathrm{m}_{\mathrm{i}} & =\frac{1}{\left(1-\mathrm{w}_{\mathrm{j}}\right)\left(1-\phi_{\tau}\right)}\left[\mathrm{w}_{\mathrm{i}}+\frac{\mathrm{w}_{\mathrm{i}}}{\mathrm{w}_{\mathrm{n}}} \sum_{\mathrm{k}=1, \mathrm{k} \neq \mathrm{j}}^{\mathrm{n}-1} \mathrm{w}_{\mathrm{k}}+\left(1-\frac{1}{\mathrm{w}_{\mathrm{j}}}\right)\left(\frac{\mathrm{w}_{\mathrm{i}} \mathrm{w}_{\mathrm{j}}}{\mathrm{w}_{\mathrm{n}}}\right)\right] \\
& =\frac{1}{\left(1-\mathrm{w}_{\mathrm{j}}\right)\left(1-\phi_{\tau}\right)}\left[\mathrm{w}_{\mathrm{i}}+\frac{\mathrm{w}_{\mathrm{i}}}{\mathrm{w}_{\mathrm{n}}} \sum_{\mathrm{k}=1}^{\mathrm{n}-1} \mathrm{w}_{\mathrm{k}}-\frac{\mathrm{w}_{\mathrm{i}}}{\mathrm{w}_{\mathrm{n}}}\right] \\
& =\frac{1}{\left(1-\mathrm{w}_{\mathrm{j}}\right)\left(1-\phi_{\tau}\right)}\left[\mathrm{w}_{\mathrm{i}}+\frac{\mathrm{w}_{\mathrm{i}}}{\mathrm{w}_{\mathrm{n}}}\left(1-\mathrm{w}_{\mathrm{n}}\right)-\frac{\mathrm{w}_{\mathrm{i}}}{\mathrm{w}_{\mathrm{n}}}\right] \\
& =0 .
\end{aligned}
$$

For $\mathrm{i}=\mathrm{j}$,

$$
\begin{aligned}
\mathrm{m}_{\mathrm{j}} & =\frac{1}{\left(1-\mathrm{w}_{\mathrm{j}}\right)\left(1-\phi_{\tau}\right)}\left[\frac{\mathrm{w}_{\mathrm{j}}}{\mathrm{w}_{\mathrm{n}}} \sum_{\mathrm{k}=1, \mathrm{k} \neq \mathrm{j}}^{\mathrm{n}-1} \mathrm{w}_{\mathrm{k}}+\left(1-\frac{1}{\mathrm{w}_{\mathrm{j}}}\right)\left(\mathrm{w}_{\mathrm{j}}+\frac{\mathrm{w}_{\mathrm{j}} \mathrm{w}_{\mathrm{j}}}{\mathrm{w}_{\mathrm{n}}}\right)\right] \\
& =\frac{1}{\left(1-\mathrm{w}_{\mathrm{j}}\right)\left(1-\phi_{\tau}\right)}\left[\frac{\mathrm{w}_{\mathrm{j}}}{\mathrm{w}_{\mathrm{n}}} \sum_{\mathrm{k}=1}^{\mathrm{n}-1} \mathrm{w}_{\mathrm{k}}+\mathrm{w}_{\mathrm{j}}-1-\frac{\mathrm{w}_{\mathrm{j}}}{\mathrm{w}_{\mathrm{n}}}\right] \\
& =\frac{1}{\left(1-\mathrm{w}_{\mathrm{j}}\right)\left(1-\phi_{\tau}\right)}\left[\frac{\mathrm{w}_{\mathrm{j}}}{\mathrm{w}_{\mathrm{n}}}\left(1-\mathrm{w}_{\mathrm{n}}\right)+\mathrm{w}_{\mathrm{j}}-1-\frac{\mathrm{w}_{\mathrm{j}}}{\mathrm{w}_{\mathrm{n}}}\right] \\
& =-\frac{1}{\left(1-\mathrm{w}_{\mathrm{j}}\right)\left(1-\phi_{\tau}\right)} .
\end{aligned}
$$

Therefore, 


$$
\mathbf{G}_{23}=\left[\begin{array}{c}
0 \\
\vdots \\
1 \\
-\frac{\left.1-\mathrm{w}_{\mathrm{j}}\right)\left(1-\phi_{\tau}\right)}{\vdots} \\
0
\end{array}\right]+\left[\begin{array}{c}
0 \\
\vdots \\
1 \\
\left(1-\mathrm{w}_{\mathrm{j}}\right)\left(1-\phi_{\tau}\right) \\
\vdots \\
0
\end{array}\right]=[\mathbf{0}] \text {. }
$$

\section{Bottom Row of $\boldsymbol{G}$}

The first two blocks of the bottom row, $\mathbf{G}_{31}$ and $\mathbf{G}_{32}$, are row vectors whilst $\mathbf{G}_{33}$ is a scalar. We need to confirm that $\left[\mathbf{G}_{31} \mathbf{G}_{32} \mathbf{G}_{33}\right]=\left[\begin{array}{lll}\mathbf{0} & \mathbf{0} & 1\end{array}\right]$.

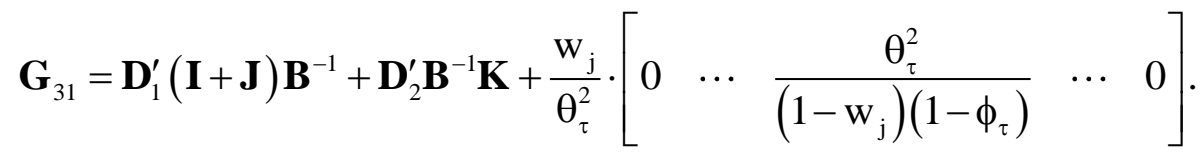

Each of the three terms, the only non-zero element is $\mathrm{j}^{\text {th }}$, which we add to give

$$
\begin{aligned}
\mathrm{w}_{\mathrm{j}}\left[1-\frac{1}{\mathrm{v}_{\mathrm{j}}\left(1-\phi_{\tau}\right)}\right]-\frac{\mathrm{w}_{\mathrm{j}}}{\mathrm{h}_{\tau}}-\frac{\mathrm{w}}{\left(1-\mathrm{w}_{\mathrm{j}}\right)\left(1-\phi_{\tau}\right)} & =\mathrm{w}_{\mathrm{j}}+\frac{\mathrm{w}_{\mathrm{j}}^{2}}{\left(1-\mathrm{w}_{\mathrm{j}}\right)\left(1-\phi_{\tau}\right)}+\frac{\mathrm{w}_{\mathrm{j}} \phi_{\tau}}{\left(1-\phi_{\tau}\right)}-\frac{\mathrm{w}_{\mathrm{j}}}{\left(1-\mathrm{w}_{\mathrm{j}}\right)\left(1-\phi_{\tau}\right)} \\
& =\frac{\mathrm{w}_{\mathrm{j}}\left(1-\mathrm{w}_{\mathrm{j}}\right)\left(1-\phi_{\tau}\right)+\mathrm{w}_{\mathrm{j}}^{2}+\mathrm{w}_{\mathrm{j}} \phi_{\tau}\left(1-\mathrm{w}_{\mathrm{j}}\right)-\mathrm{w}_{\mathrm{j}}}{\left(1-\mathrm{w}_{\mathrm{j}}\right)\left(1-\phi_{\tau}\right)} \\
& =0 .
\end{aligned}
$$

Therefore, $\mathbf{G}_{31}=[\mathbf{0}]$.

Next,

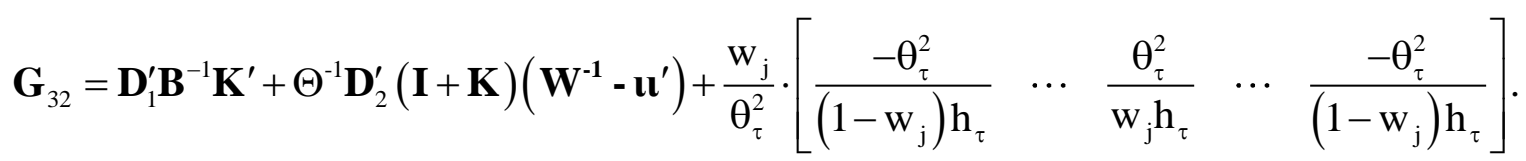

Considering each term separately, 


$$
\begin{aligned}
& \mathbf{D}_{1}^{\prime} \mathbf{B}^{-1} \mathbf{K}^{\prime}=\left[\begin{array}{lllll}
0 & \cdots & \frac{\mathrm{w}_{\mathrm{j}}}{\theta_{\tau}^{2}} & \cdots & 0
\end{array}\right]\left[\begin{array}{cccc}
\theta_{1}^{2} & \cdots & & 0 \\
\vdots & \theta_{2}^{2} & & \vdots \\
& & \ddots & \\
0 & \cdots & & \theta_{\mathrm{T}}^{2}
\end{array}\right]\left[\begin{array}{ccccc}
0 & & \cdots & & 0 \\
& \ddots & \vdots & & \\
-\frac{1}{\mathrm{v}_{\mathrm{j}} \mathrm{h}_{\tau}} & \cdots & -\frac{1}{\mathrm{~h}_{\tau}} & \cdots & -\frac{1}{\mathrm{v}_{\mathrm{j}} \mathrm{h}_{\tau}} \\
& & \vdots & \ddots & \\
0 & & \cdots & & 0
\end{array}\right] \\
& =\left[\begin{array}{lllll}
0 & \cdots & \mathrm{w}_{\mathrm{j}} & \cdots & 0
\end{array}\right]\left[\begin{array}{ccccc}
0 & & \cdots & & 0 \\
& \ddots & \vdots & & \\
-\frac{1}{\mathrm{v}_{\mathrm{j}} \mathrm{h}_{\tau}} & \cdots & -\frac{1}{\mathrm{~h}_{\tau}} & \cdots & -\frac{1}{\mathrm{v}_{\mathrm{j}} \mathrm{h}_{\tau}} \\
& & \vdots & \ddots & \\
0 & & \cdots & & 0
\end{array}\right] \\
& =\left[\begin{array}{lllll}
-\frac{w_{j}}{v_{j} h_{\tau}} & \cdots & -\frac{w_{j}}{h_{\tau}} & \cdots & -\frac{w_{j}}{v_{j} h_{\tau}}
\end{array}\right] .
\end{aligned}
$$

Using the central block matrix in Table A1.1 for $\Theta^{-1}(\mathbf{I}+\mathbf{K})\left(\mathbf{W}^{-1}-\mathbf{u}^{\prime}\right)$, we obtain

$$
\begin{aligned}
& \Theta^{-1} \mathbf{D}_{2}^{\prime}(\mathbf{I}+\mathbf{K})\left(\mathbf{W}^{-1}-\mathbf{u}^{\prime}\right)=\left[\begin{array}{lllll}
0 & \cdots & \phi_{\tau} \mathbf{W}_{j} & \cdots & 0
\end{array}\right](\mathbf{I}+\mathbf{K})\left(\mathbf{W}^{-1}-\mathbf{u}^{\prime}\right) \\
& =\left[\left(\frac{1}{\mathrm{~h}_{\tau}}-1\right) \phi_{\tau} \mathrm{w}_{\mathrm{j}} \quad \cdots \quad \mathrm{v}_{\mathrm{j}}\left(\frac{1}{\mathrm{~h}_{\tau}}-1\right) \phi_{\tau} \mathrm{w}_{\mathrm{j}} \quad \cdots\left(\frac{1}{\mathrm{~h}_{\tau}}-1\right) \phi_{\tau} \mathrm{w}_{\mathrm{j}}\right] .
\end{aligned}
$$

The elements here are

$$
\begin{aligned}
& \left(\frac{1}{h_{\tau}}-1\right) \phi_{\tau} \mathrm{w}_{j}=\frac{1}{\mathrm{~h}_{\tau}}\left(\phi_{\tau} \mathrm{w}_{\mathrm{j}}-\phi_{\tau} \mathrm{w}_{\mathrm{j}} \mathrm{h}_{\tau}\right)=\frac{1}{\mathrm{~h}_{\tau}}\left[\phi_{\tau} \mathrm{w}_{\mathrm{j}}-\mathrm{w}_{\mathrm{j}}\left(\phi_{\tau}-1\right)\right]=\frac{\mathrm{w}_{\mathrm{j}}}{\mathrm{h}_{\tau}}=\frac{\mathrm{w}_{\mathrm{j}}-1}{\mathrm{v}_{\mathrm{j}} \mathrm{h}_{\tau}}, \text { and } \\
& \mathrm{v}_{\mathrm{j}}\left(\frac{1}{\mathrm{~h}_{\tau}}-1\right) \phi_{\tau} \mathrm{w}_{\mathrm{j}}=\mathrm{v}_{\mathrm{j}}\left(\frac{\phi_{\tau}}{\phi_{\tau}-1}\right) \mathrm{w}_{\mathrm{j}}=\mathrm{v}_{\mathrm{j}}\left(\frac{\mathrm{w}_{\mathrm{j}}}{\mathrm{h}_{\tau}}\right)=\frac{\mathrm{w}_{\mathrm{j}}-1}{\mathrm{~h}_{\tau}} .
\end{aligned}
$$

Therefore,

$$
\Theta^{-1} \mathbf{D}_{2}^{\prime}(\mathbf{I}+\mathbf{K})\left(\mathbf{W}^{-1}-\mathbf{u l}^{\prime}\right)=\left[\begin{array}{lllll}
\frac{w_{j}-1}{v_{j} h_{\tau}} & \cdots & \frac{w_{j}-1}{h_{\tau}} & \cdots & \frac{w_{j}-1}{v_{j} h_{\tau}}
\end{array}\right] .
$$

Lastly, the final term of $\mathbf{G}_{32}$ is

$$
\frac{\mathrm{w}_{\mathrm{j}}}{\theta_{\tau}^{2}} \cdot\left[\begin{array}{lllll}
\frac{-\theta_{\tau}^{2}}{\left(1-\mathrm{w}_{\mathrm{j}}\right) \mathrm{h}_{\tau}} & \cdots & \frac{\theta_{\tau}^{2}}{\mathrm{w}_{\mathrm{j}} \mathrm{h}_{\tau}} & \cdots & \frac{-\theta_{\tau}^{2}}{\left(1-\mathrm{w}_{\mathrm{j}}\right) \mathrm{h}_{\tau}}
\end{array}\right]=\left[\begin{array}{lllll}
\frac{1}{\mathrm{v}_{\mathrm{j}} \mathrm{h}_{\tau}} & \cdots & \frac{1}{\mathrm{~h}_{\tau}} & \cdots & \frac{1}{\mathrm{v}_{\mathrm{j}} \mathrm{h}_{\tau}}
\end{array}\right] .
$$

Combining these gives 


$$
\begin{aligned}
\mathbf{G}_{32} & =\left[\frac{-w_{j}}{v_{j} h_{\tau}}+\frac{w_{j}-1}{v_{j} h_{\tau}}+\frac{1}{v_{j} h_{\tau}} \cdots \frac{-w_{j}}{h_{\tau}}+\frac{w_{j}-1}{h_{\tau}}+\frac{1}{h_{\tau}} \quad \cdots \frac{-w_{j}}{v_{j} h_{\tau}}+\frac{w_{j}-1}{v_{j} h_{\tau}}+\frac{1}{v_{j} h_{\tau}}\right] \\
& =[0] .
\end{aligned}
$$

The final block is $\mathbf{G}_{33}$, a scalar made up of the sum of three terms:

$$
\mathbf{G}_{33}=\frac{1}{\Theta\left(1-\mathrm{w}_{\mathrm{j}}\right)\left(1-\phi_{\tau}\right)} \mathbf{D}_{1}^{\prime}\left[\begin{array}{c}
0 \\
\vdots \\
-1 / \phi_{\tau} \\
\vdots \\
0
\end{array}\right]+\frac{\theta_{\tau}^{2}}{\mathrm{w}_{\mathrm{j}}\left(1-\mathrm{w}_{\mathrm{j}}\right)\left(1-\phi_{\tau}\right)} \mathbf{D}_{2}^{\prime}\left[\begin{array}{c}
1 \\
\vdots \\
1-\frac{1}{\mathrm{w}_{\mathrm{j}}} \\
\vdots \\
1
\end{array}\right]+\frac{\mathrm{w}_{\mathrm{j}}}{\theta_{\tau}^{2}} \cdot \frac{\theta_{\tau}^{2}}{\mathrm{w}_{\mathrm{j}}\left(1-\mathrm{w}_{\mathrm{j}}\right)\left(1-\phi_{\tau}\right)}
$$

The first term is

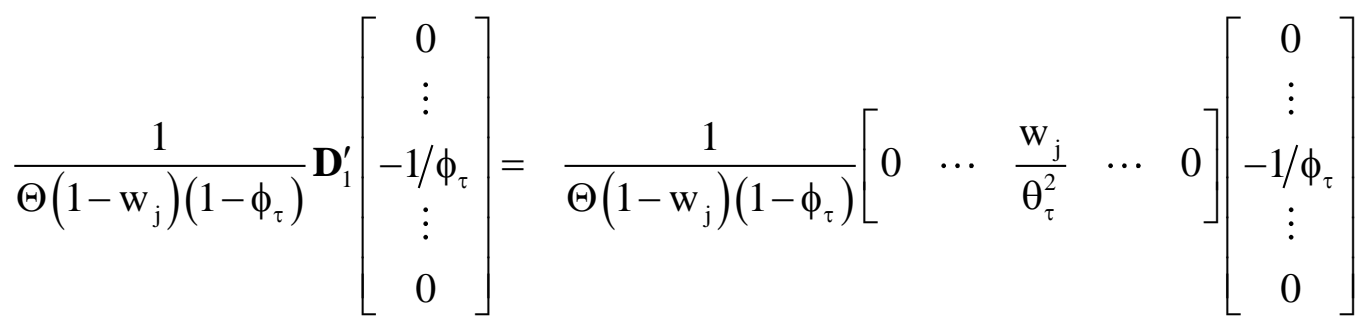

$$
\begin{aligned}
& =\frac{1}{\Theta\left(1-\mathrm{w}_{\mathrm{j}}\right)\left(1-\phi_{\tau}\right)} \cdot \frac{-\mathrm{w}_{\mathrm{j}}}{\theta_{\tau}^{2}} \cdot \frac{1}{\phi_{\tau}} \\
& =\frac{-w_{j} \Theta}{\Theta\left(1-w_{j}\right)\left(1-\phi_{\tau}\right)} \\
& =\frac{-\mathrm{w}_{\mathrm{j}}}{\left(1-\mathrm{w}_{\mathrm{j}}\right)\left(1-\phi_{\tau}\right)} \text {. }
\end{aligned}
$$

Next,

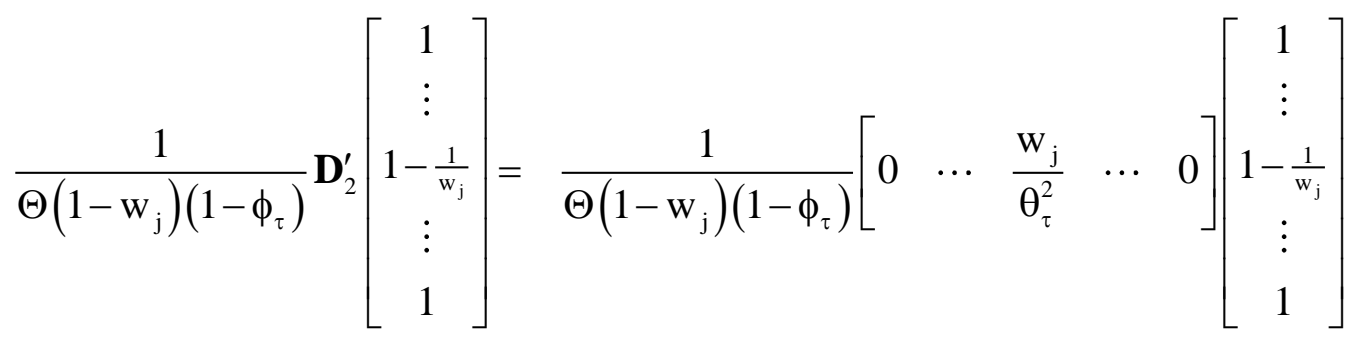

$$
\begin{aligned}
& =\frac{1}{\Theta\left(1-\mathrm{w}_{\mathrm{j}}\right)\left(1-\phi_{\tau}\right)} \cdot \frac{-\left(1-\mathrm{w}_{\mathrm{j}}\right)}{\theta_{\tau}^{2}} \\
& =\frac{-1}{\Theta \theta_{\tau}^{2}\left(1-\phi_{\tau}\right)} \\
& =\frac{-\phi_{\tau}}{\left(1-\phi_{\tau}\right)} \text {. }
\end{aligned}
$$

Lastly, 


$$
\frac{\mathrm{w}_{\mathrm{j}}}{\theta_{\tau}^{2}} \cdot \frac{\theta_{\tau}^{2}}{\mathrm{w}_{\mathrm{j}}\left(1-\mathrm{w}_{\mathrm{j}}\right)\left(1-\phi_{\tau}\right)}=\frac{1}{\left(1-\mathrm{w}_{\mathrm{j}}\right)\left(1-\phi_{\tau}\right)} .
$$

Combining gives

$$
\mathbf{G}_{33}=\frac{-\mathrm{w}_{\mathrm{j}}}{\left(1-\mathrm{w}_{\mathrm{j}}\right)\left(1-\phi_{\tau}\right)}-\frac{\phi_{\tau}}{\left(1-\phi_{\tau}\right)}+\frac{1}{\left(1-\mathrm{w}_{\mathrm{j}}\right)\left(1-\phi_{\tau}\right)}=1 .
$$

\section{Summary}

The analysis above establishes that

$$
\mathbf{F}^{\prime} \mathbf{F}\left(\mathbf{F}^{\prime} \mathbf{F}\right)^{-1}=\left[\begin{array}{ll:l}
\mathbf{G}_{11} & \mathbf{G}_{12} & \mathbf{G}_{13} \\
\mathbf{G}_{21} & \mathbf{G}_{22} & \mathbf{G}_{23} \\
\hdashline \mathbf{G}_{31} & \mathbf{G}_{32} & \mathbf{G}_{33}
\end{array}\right]=\left[\begin{array}{cc:c}
\mathbf{I} & \mathbf{0} & \mathbf{0} \\
\mathbf{0} & \mathbf{I} & \mathbf{0} \\
\hdashline \mathbf{0} & \mathbf{0} & \mathbf{I}
\end{array}\right]=\mathbf{I},
$$

which serves to confirm the form of the inverse.

\section{$\underline{\text { References }}$}

Clements, K. W., and H. Y. Izan (1987). "The Measurement of Inflation: A Stochastic Approach." Journal of Business \& Economic Statistics 5: 339-50.

Hua, D. (1996). "Completing a Symmetric $2 \times 2$ Block Matrix and its Inverse." Linear Algebra and its Applications 235: 235-45. 


\section{Supplementary Material}

\section{A2. THREE SETS OF WEIGHTS}

For robustness, we have used two additional sets of weights -- PPP-based GDP and nominal GDP -- in addition to trade weights reported in the text. This Appendix gives the details for the calculation of these three sets of weights and the corresponding estimates.

Trade Weights

The value of imports and exports in \$US for the 24 countries/areas from 1994 to 2014 are downloaded from the IMF International Financial Statistics website. The data for the Euro member countries are only available starting from 1999, the inception year. The country weights are computed as follows:

- For each year over the 16-year period from 1999 to 2014 , we first calculate the weights for each of 24 countries, and then the 15-year average for the Euro area, $\overline{\mathrm{w}}_{\text {euro }}$.

- For each year from 1994 to 1998, we replace the missing value for the euro area with its average $\overline{\mathrm{w}}_{\text {euro }}$. The weights for the remaining 23 countries from 1994 to 1998 are normalised such that $\sum_{\mathrm{i}=1}^{23} \mathrm{w}_{\mathrm{i}}=1-\overline{\mathrm{w}}_{\text {euro }}$.

- Finally, the mean weight for each country is calculated as the average of the weights for the relevant sub-sample.

\section{GDP, PPP}

GDP based on PPP exchange rates for the 24 countries are downloaded from IMF World Economic Outlook (WEO). Since data for the Czech Republic are unavailable for 1994 from the WEO, we use instead data from the World Bank (http://data.worldbank.org/). The Euro Area as a whole is not reported by the WEO so for each year, we calculate this as the sum of GDP of constituent countries adopting the Euro dollar as the official currency. ${ }^{1}$ The corresponding weights are constructed following similar steps to those above for the missing pre-1999 Euro Area data.

\section{$\underline{\text { GDP, Market Exchange Rates }}$}

A third set of weights using GDP with market exchange rates (MER) are also constructed using data from the WEO. As before, data are only available up to 2014. We use the same approach to missing values and the calculation of weights as above.

\footnotetext{
${ }^{1}$ The constituent countries making up the Euro Area are as follows: Starting from its inception in 1999, there countries are Austria, Belgium, Finland, France, Germany, Ireland, Italy, Luxembourg, Netherlands, Portugal and Spain. Later additions to the Euro Area are Greece (2001), Slovenia (2007), Cyprus (2008), Malta (2008), Slovakia (2009), Estonia (2011) and Latvia (2014).
} 


\section{The Estimates}

Table A2.1 gives the three sets of weights for the four sub-periods. Model (5) of the text is $\mathrm{q}_{\mathrm{it}}=\mathrm{a}_{\mathrm{t}}+\mathrm{b}_{\mathrm{i}}+\delta_{\mathrm{ij}} \delta_{\mathrm{t} \tau} \gamma+\varepsilon_{\mathrm{it}}$, which we estimate without specifying a country and year for which mispricing is examined; that is, for $\mathrm{i} \neq \mathrm{j}$ and $\mathrm{t} \neq \tau, \delta_{\mathrm{ij}}=\delta_{\mathrm{t} \tau}=0$, so that the model to be estimated takes the form $\mathrm{q}_{\mathrm{it}}=\mathrm{a}_{\mathrm{t}}+\mathrm{b}_{\mathrm{i}}+\varepsilon_{\mathrm{it}}$. The estimates are presented in Table A2.2. Panel A shows for the estimated year effects $\hat{a}_{t}$, the ranking is GDP-MER > Trade > GDP-PPP. Recall that $-\hat{a}_{t}$ is interpreted as the mispricing of the dollar, that is, the dollar is over-valued if $\hat{a}_{t}<0$. Thus, these results show that PPP-converted GDP leads to the dollar being overvalued by more than it is under the two other weighting schemes. In most cases, the standard errors of the $\hat{a}_{t}{ }^{\prime} s$ from three weights are of similar magnitude.

Panel B shows the country-specific estimates $\hat{b}_{i}$ associated with the three sets of weights. In all years, when the GDP-PPP weights are used, these estimates are larger than those with when trade weights are used; and the trade-based estimates always exceed the ones with GDP-MER weights. However, for the majority of cases, the differences are not large. Generally speaking, the standard errors associated with the trade and MER weights are lower than those with the PPP weights.

\section{Summary}

When the weights change, only very seldomly do the signs of the estimates change; and when they do, the change is usually not substantial. When trade weights are used (the case reported in the text), the overvaluation of the US dollar is somewhat larger relative to the case when GDP's at market exchange rates are used, but lower than when PPP GDP's are used. Regarding the estimates of the country effects, the choice of the weights has only modest effects. 
Table A1.1 Inverse of Moment Matrix $\mathbf{F}^{\prime} \mathbf{F}$

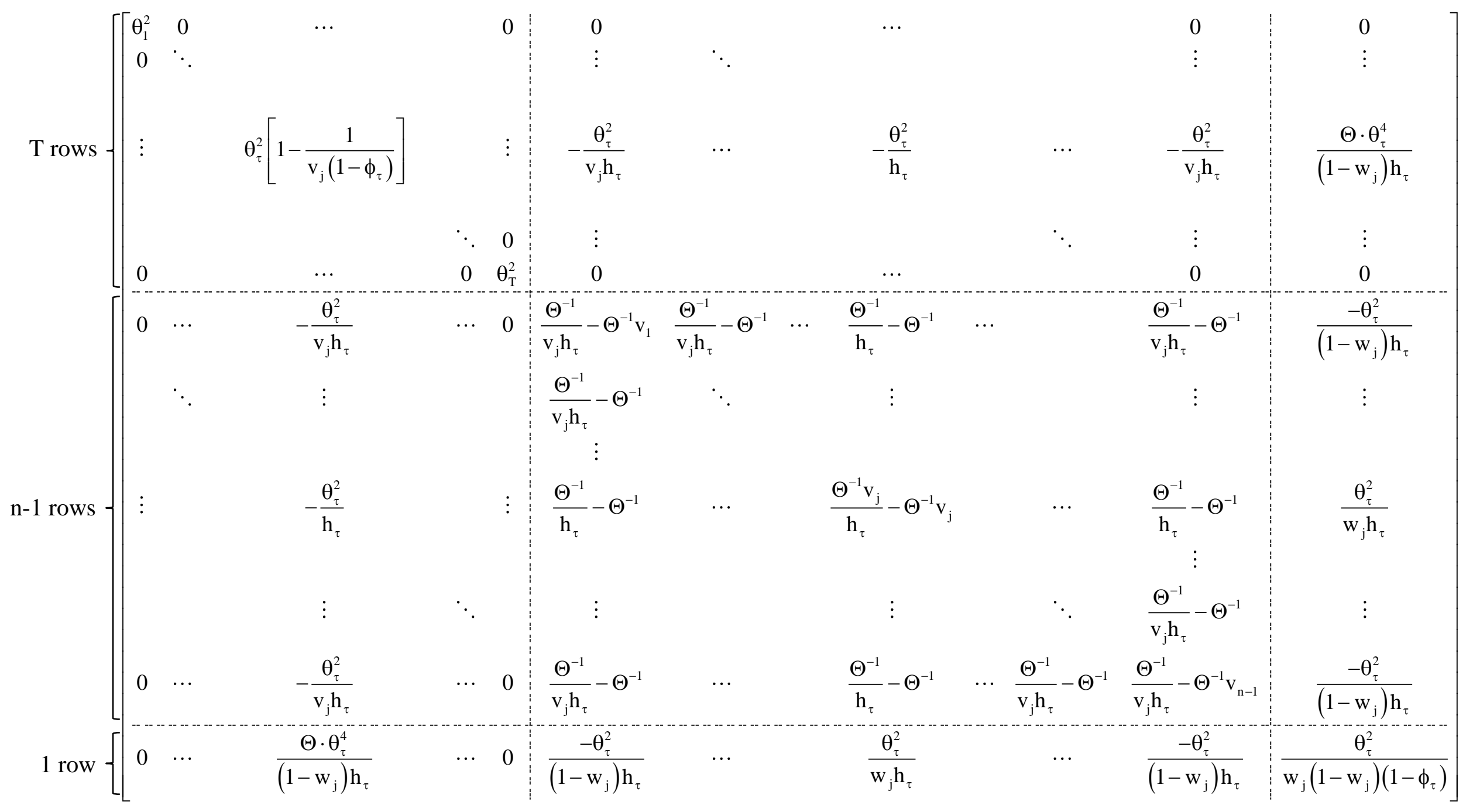


A-29

Supplementary Material

Table A2.1 Country Weights

\begin{tabular}{|c|c|c|c|c|c|c|c|c|c|c|c|c|}
\hline \multirow{2}{*}{ Country/Weight } & \multicolumn{3}{|c|}{ 1994-1999 } & \multicolumn{3}{|c|}{$2000-2004$} & \multicolumn{3}{|c|}{$2005-2009$} & \multicolumn{3}{|c|}{$2010-2014$} \\
\hline & Trade & GDP-PPP & GDP-MER & Trade & GDP-PPP & GDP-MER & Trade & GDP-PPP & GDP-MER & Trade & GDP-PPP & GDP-MER \\
\hline 1. Argentina & 0.0079 & 0.0176 & 0.0175 & 0.0057 & 0.0143 & 0.0108 & 0.0062 & 0.0152 & 0.0094 & 0.0068 & 0.0162 & 0.0125 \\
\hline 2. Australia & 0.0196 & 0.0202 & 0.0208 & 0.0183 & 0.0203 & 0.0221 & 0.0199 & 0.0194 & 0.0266 & 0.0231 & 0.0185 & 0.0325 \\
\hline 3. Brazil & 0.0168 & 0.0615 & 0.0399 & 0.0152 & 0.0573 & 0.0279 & 0.0181 & 0.0558 & 0.0397 & 0.0220 & 0.0563 & 0.0539 \\
\hline 4. Britain & 0.0883 & 0.0572 & 0.0722 & 0.0814 & 0.0557 & 0.0836 & 0.0661 & 0.0509 & 0.0785 & 0.0523 & 0.0438 & 0.0595 \\
\hline 5. Canada & 0.0642 & 0.0329 & 0.0331 & 0.0634 & 0.0328 & 0.0385 & 0.0502 & 0.0298 & 0.0409 & 0.0432 & 0.0271 & 0.0398 \\
\hline 6. Chile & 0.0054 & 0.0065 & 0.0039 & 0.0050 & 0.0065 & 0.0037 & 0.0067 & 0.0066 & 0.0048 & 0.0071 & 0.0068 & 0.0057 \\
\hline 7. China & 0.0495 & 0.1169 & 0.0459 & 0.0849 & 0.1520 & 0.0705 & 0.1333 & 0.2081 & 0.1060 & 0.1803 & 0.2772 & 0.1868 \\
\hline 8. Czech Rep. & 0.0081 & 0.0066 & 0.0032 & 0.0108 & 0.0062 & 0.0039 & 0.0143 & 0.0063 & 0.0054 & 0.0144 & 0.0055 & 0.0048 \\
\hline 9. Denmark & 0.0153 & 0.0066 & 0.0093 & 0.0135 & 0.0061 & 0.0091 & 0.0123 & 0.0054 & 0.0092 & 0.0096 & 0.0044 & 0.0075 \\
\hline 10. Euro Area & 0.2627 & 0.3099 & 0.3596 & 0.2589 & 0.3018 & 0.3580 & 0.2515 & 0.2686 & 0.3629 & 0.2245 & 0.2317 & 0.2941 \\
\hline 11. Hong Kong & 0.0594 & 0.0069 & 0.0084 & 0.0535 & 0.0065 & 0.0079 & 0.0450 & 0.0068 & 0.0061 & 0.0447 & 0.0067 & 0.0059 \\
\hline 12. Hungary & 0.0062 & 0.0054 & 0.0025 & 0.0096 & 0.0054 & 0.0033 & 0.0111 & 0.0051 & 0.0039 & 0.0097 & 0.0042 & 0.0030 \\
\hline 13. Japan & 0.1200 & 0.1325 & 0.2424 & 0.1032 & 0.1138 & 0.2062 & 0.0844 & 0.0976 & 0.1394 & 0.0754 & 0.0834 & 0.1215 \\
\hline 14. Malaysia & 0.0237 & 0.0107 & 0.0049 & 0.0225 & 0.0112 & 0.0052 & 0.0200 & 0.0117 & 0.0057 & 0.0199 & 0.0123 & 0.0069 \\
\hline 15. Mexico & 0.0338 & 0.0439 & 0.0250 & 0.0431 & 0.0423 & 0.0343 & 0.0349 & 0.0389 & 0.0292 & 0.0352 & 0.0363 & 0.0268 \\
\hline 16. N. Zealand & 0.0045 & 0.0032 & 0.0032 & 0.0039 & 0.0031 & 0.0032 & 0.0036 & 0.0030 & 0.0037 & 0.0036 & 0.0027 & 0.0039 \\
\hline 17. Poland & 0.0099 & 0.0156 & 0.0079 & 0.0130 & 0.0160 & 0.0096 & 0.0181 & 0.0160 & 0.0121 & 0.0187 & 0.0161 & 0.0116 \\
\hline 18. Russia & 0.0237 & 0.0585 & 0.0163 & 0.0238 & 0.0591 & 0.0177 & 0.0362 & 0.0649 & 0.0348 & 0.0398 & 0.0613 & 0.0421 \\
\hline 19. Singapore & 0.0382 & 0.0057 & 0.0047 & 0.0335 & 0.0060 & 0.0046 & 0.0355 & 0.0067 & 0.0050 & 0.0362 & 0.0075 & 0.0063 \\
\hline 20. S. Korea & 0.0411 & 0.0265 & 0.0265 & 0.0431 & 0.0295 & 0.0294 & 0.0458 & 0.0298 & 0.0297 & 0.0498 & 0.0298 & 0.0280 \\
\hline 21. Sweden & 0.0236 & 0.0095 & 0.0139 & 0.0209 & 0.0094 & 0.0137 & 0.0191 & 0.0087 & 0.0134 & 0.0159 & 0.0078 & 0.0123 \\
\hline 22. Switzerland & 0.0242 & 0.0107 & 0.0161 & 0.0217 & 0.0098 & 0.0149 & 0.0201 & 0.0089 & 0.0143 & 0.0192 & 0.0081 & 0.0150 \\
\hline 23. Taiwan & 0.0354 & 0.0165 & 0.0151 & 0.0334 & 0.0175 & 0.0152 & 0.0286 & 0.0178 & 0.0119 & 0.0273 & 0.0181 & 0.0111 \\
\hline 24. Thailand & 0.0187 & 0.0185 & 0.0078 & 0.0178 & 0.0176 & 0.0066 & 0.0189 & 0.0181 & 0.0074 & 0.0213 & 0.0180 & 0.0087 \\
\hline
\end{tabular}

Note: GDP-PPP (MER) refers to the share of a country's GDP in the total when PPP (market) exchange rates are used to convert to US dollars. 
A-30

Supplementary Material

Table A2.2 Estimates of Currency Pricing Model with Three Sets of Weights, $q_{i t}=a_{t}+b_{i}+\varepsilon_{i t}$

\begin{tabular}{l|r} 
Sub-period 1 & Sub-period 2
\end{tabular}

A. The time component $\hat{a}_{\mathrm{t}} \times 100$

\begin{tabular}{|c|c|c|c|c|c|c|c|c|c|c|c|c|c|c|c|c|c|c|c|c|c|}
\hline Weight/Year & 1994 & 1995 & 1996 & 1997 & 1998 & 1999 & 2000 & 2001 & 2002 & 2003 & 2004 & 2005 & 2006 & 2007 & 2008 & 2009 & 2010 & 2011 & 2012 & 2013 & 2014 \\
\hline Trade & $\begin{array}{c}0.03 \\
(0.03)\end{array}$ & $\begin{array}{c}0.12 \\
(0.03)\end{array}$ & $\begin{array}{c}0.04 \\
(0.01)\end{array}$ & $\begin{array}{c}-0.04 \\
(0.02)\end{array}$ & $\begin{array}{l}-0.18 \\
(0.03)\end{array}$ & $\begin{array}{c}-0.10 \\
(0.02)\end{array}$ & $\begin{array}{c}-0.19 \\
(0.02)\end{array}$ & $\begin{array}{l}-0.24 \\
(0.02)\end{array}$ & $\begin{array}{c}-0.21 \\
(0.02)\end{array}$ & $\begin{array}{c}-0.19 \\
(0.02)\end{array}$ & $\begin{array}{c}-0.19 \\
(0.02)\end{array}$ & $\begin{array}{c}-0.23 \\
(0.02)\end{array}$ & $\begin{array}{c}-0.19 \\
(0.01)\end{array}$ & $\begin{array}{c}-0.19 \\
(0.01)\end{array}$ & $\begin{array}{l}-0.05 \\
(0.02)\end{array}$ & $\begin{array}{l}-0.14 \\
(0.02)\end{array}$ & $\begin{array}{c}-0.19 \\
(0.01)\end{array}$ & $\begin{array}{c}-0.13 \\
(0.01)\end{array}$ & $\begin{array}{c}-0.23 \\
(0.01)\end{array}$ & $\begin{array}{l}-0.25 \\
(0.01)\end{array}$ & $\begin{array}{c}-0.24 \\
(0.02)\end{array}$ \\
\hline GDP-PPP & $\begin{array}{c}-0.01 \\
(0.03)\end{array}$ & $\begin{array}{c}0.10 \\
(0.04)\end{array}$ & $\begin{array}{c}0.02 \\
(0.02)\end{array}$ & $\begin{array}{c}-0.07 \\
(0.02)\end{array}$ & $\begin{array}{l}-0.18 \\
(0.03)\end{array}$ & $\begin{array}{c}-0.14 \\
(0.02)\end{array}$ & $\begin{array}{c}-0.23 \\
(0.02)\end{array}$ & $\begin{array}{c}-0.29 \\
(0.02)\end{array}$ & $\begin{array}{l}-0.27 \\
(0.02)\end{array}$ & $\begin{array}{c}-0.26 \\
(0.02)\end{array}$ & $\begin{array}{c}-0.25 \\
(0.02)\end{array}$ & $\begin{array}{c}-0.29 \\
(0.02)\end{array}$ & $\begin{array}{c}-0.25 \\
(0.01)\end{array}$ & $\begin{array}{c}-0.24 \\
(0.01)\end{array}$ & $\begin{array}{l}-0.08 \\
(0.02)\end{array}$ & $\begin{array}{c}-0.16 \\
(0.02)\end{array}$ & $\begin{array}{c}-0.21 \\
(0.01)\end{array}$ & $\begin{array}{c}-0.15 \\
(0.01)\end{array}$ & $\begin{array}{l}-0.25 \\
(0.01)\end{array}$ & $\begin{array}{c}-0.27 \\
(0.01)\end{array}$ & $\begin{array}{l}-0.27 \\
(0.02)\end{array}$ \\
\hline GDP-MER & $\begin{array}{c}0.15 \\
(0.03)\end{array}$ & $\begin{array}{c}0.29 \\
(0.04)\end{array}$ & $\begin{array}{c}0.13 \\
(0.02)\end{array}$ & $\begin{array}{c}0.02 \\
(0.02)\end{array}$ & $\begin{array}{l}-0.11 \\
(0.03)\end{array}$ & $\begin{array}{c}-0.03 \\
(0.02)\end{array}$ & $\begin{array}{c}-0.10 \\
(0.03)\end{array}$ & $\begin{array}{c}-0.17 \\
(0.02)\end{array}$ & $\begin{array}{l}-0.17 \\
(0.02)\end{array}$ & $\begin{array}{c}-0.13 \\
(0.02)\end{array}$ & $\begin{array}{c}-0.12 \\
(0.02)\end{array}$ & $\begin{array}{c}-0.14 \\
(0.02)\end{array}$ & $\begin{array}{c}-0.11 \\
(0.01)\end{array}$ & $\begin{array}{c}-0.10 \\
(0.01)\end{array}$ & $\begin{array}{c}0.05 \\
(0.02)\end{array}$ & $\begin{array}{c}-0.03 \\
(0.02)\end{array}$ & $\begin{array}{c}-0.11 \\
(0.01)\end{array}$ & $\begin{array}{c}-0.05 \\
(0.01)\end{array}$ & $\begin{array}{l}-0.17 \\
(0.01)\end{array}$ & $\begin{array}{c}-0.20 \\
(0.01)\end{array}$ & $\begin{array}{c}-0.18 \\
(0.02)\end{array}$ \\
\hline
\end{tabular}

B. The country component $\hat{b}_{i} \times 100$

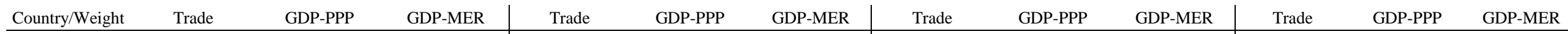

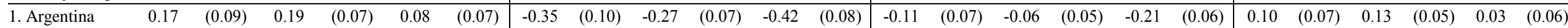

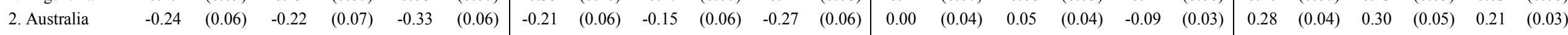

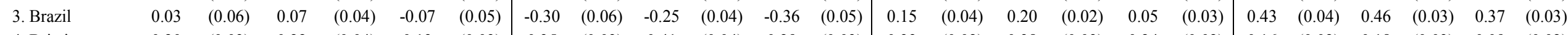

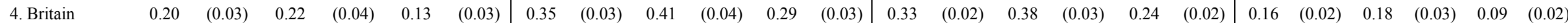

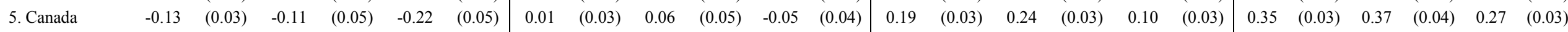

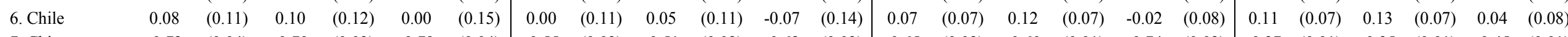

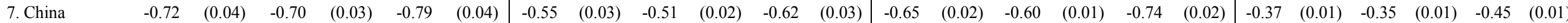

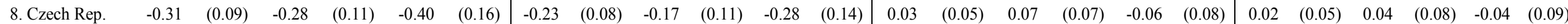

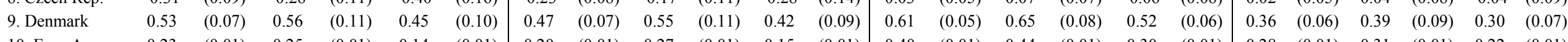

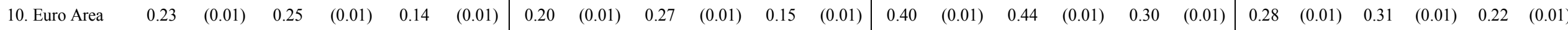

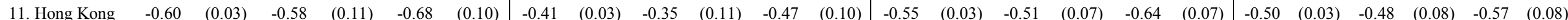

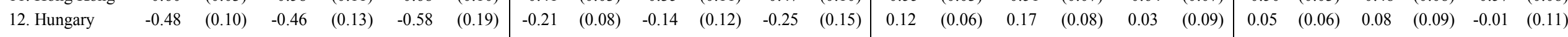

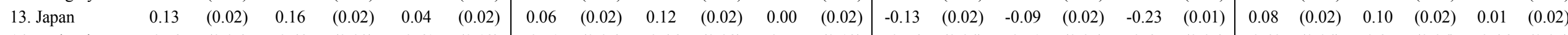

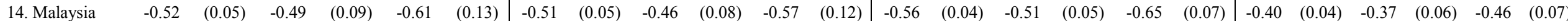

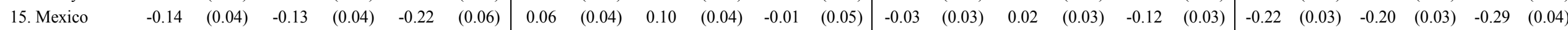

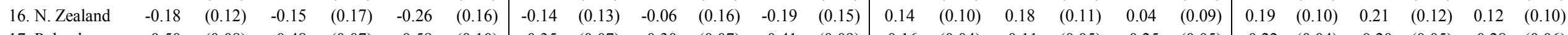

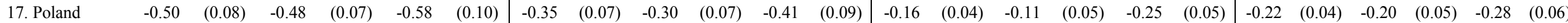

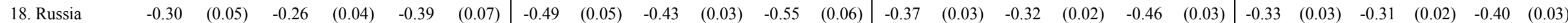

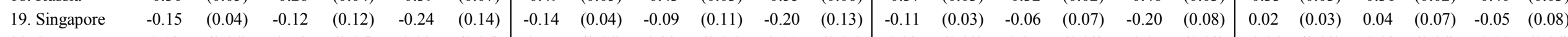

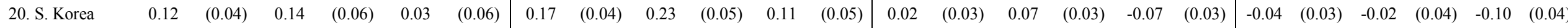

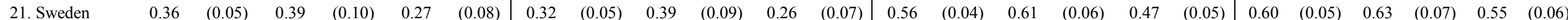

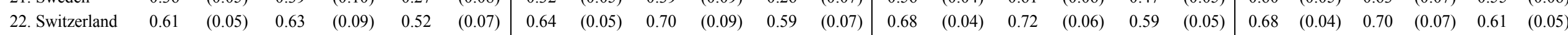

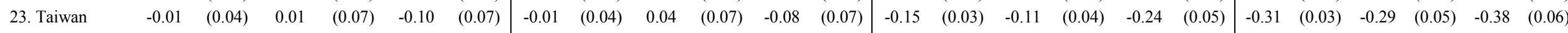

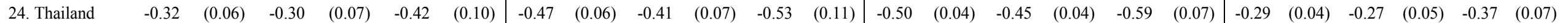

Note: Standard errors in parentheses. 


\section{A3. COMPARISON OF EBMI AND BMI}

Figure A3.1 EBMI vs. BMI, 24 Currencies, 1994-2014, All values ×100

$\underline{\text { Argentina }}$

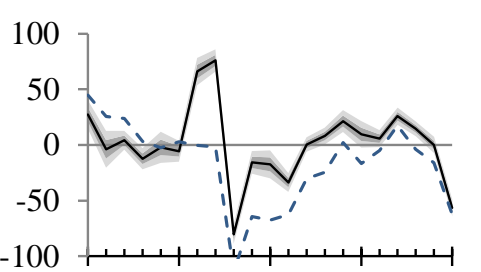

19941999200420092014

Canada
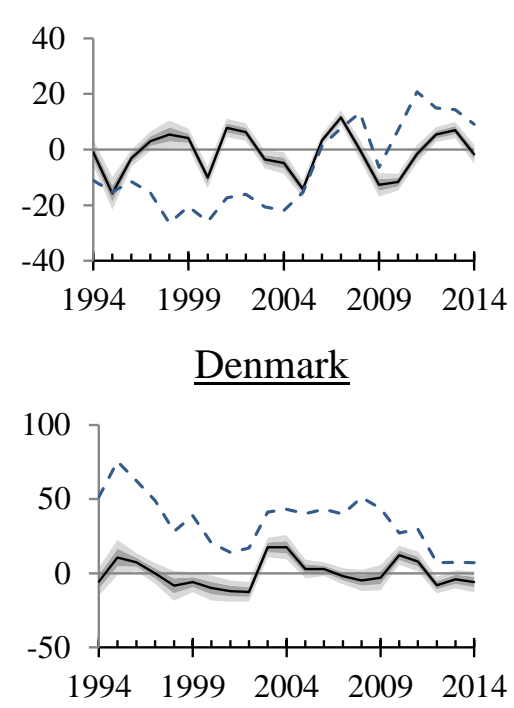

$\underline{\text { Australia }}$

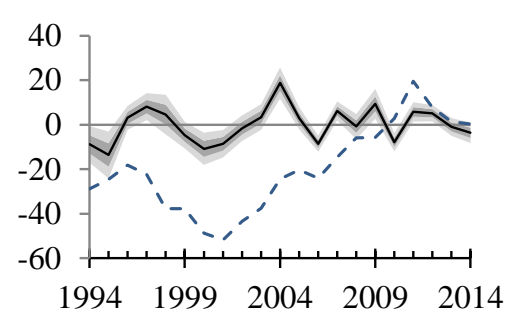

$\underline{\text { Chile }}$
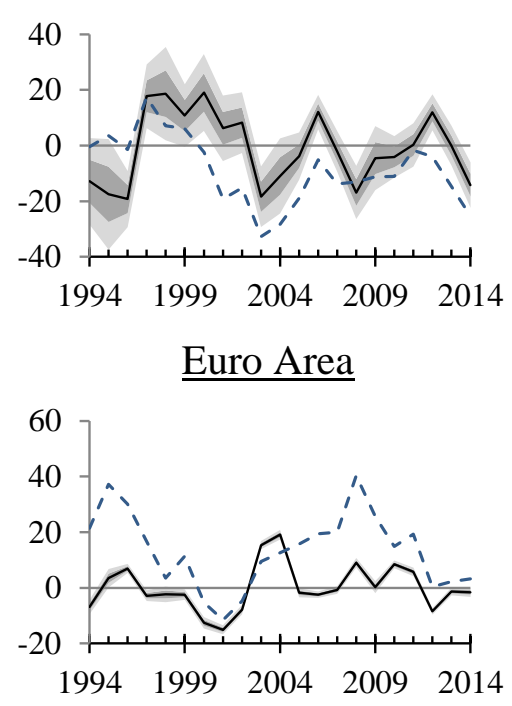

Brazil

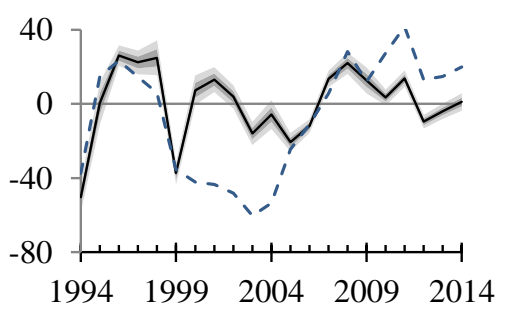

China
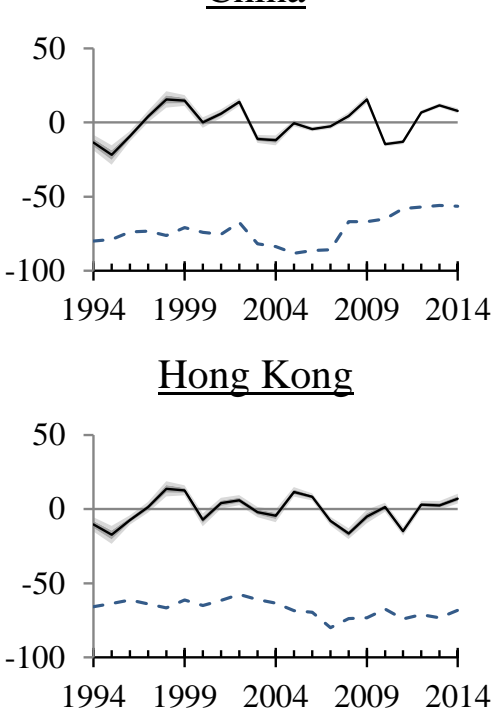

$\underline{\text { Britain }}$

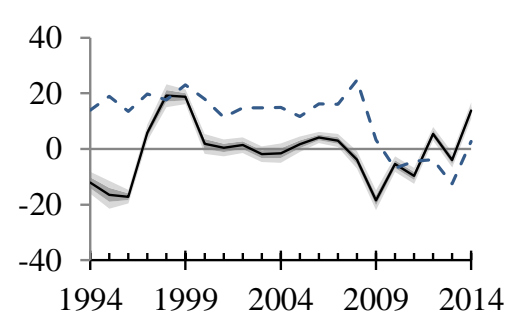

Czech Republic
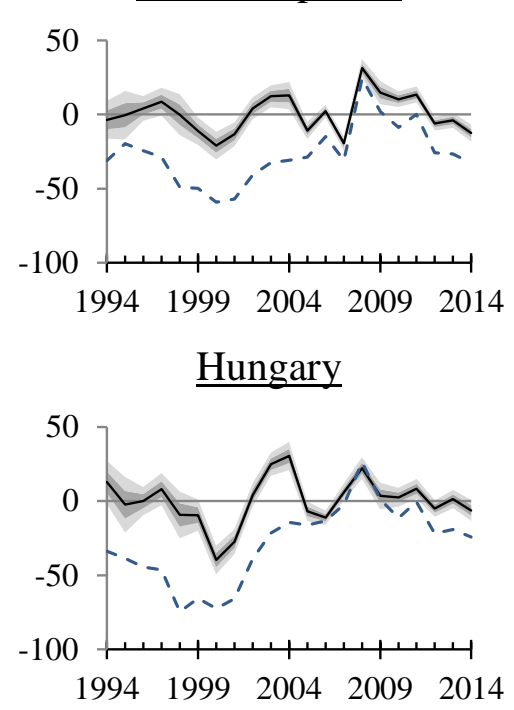

(continued on next page) 
Figure A3.1 EBMI vs. BMI, 24 Currencies, 1994-2014, All values $\times 100$ (continued)

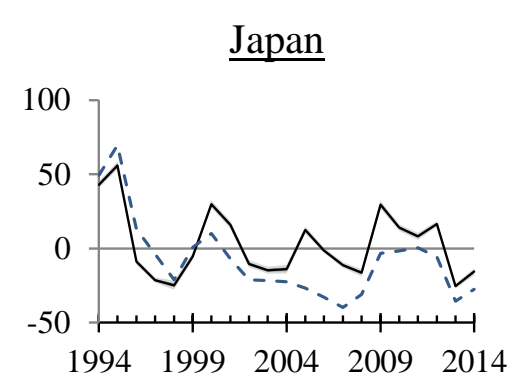

$\underline{\text { Poland }}$

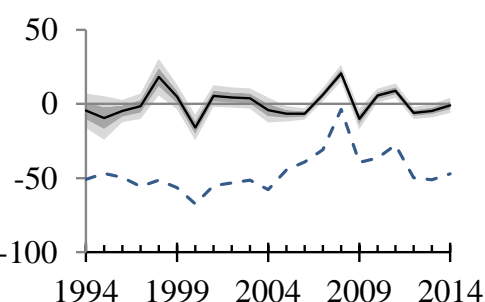

$\underline{\text { Sweden }}$

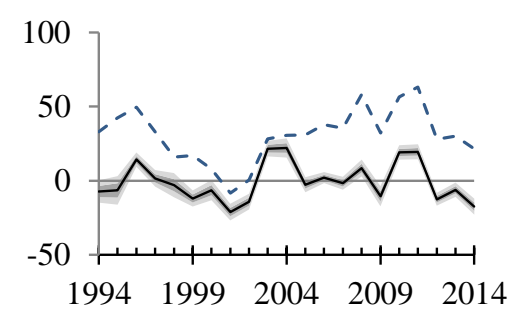

Malaysia

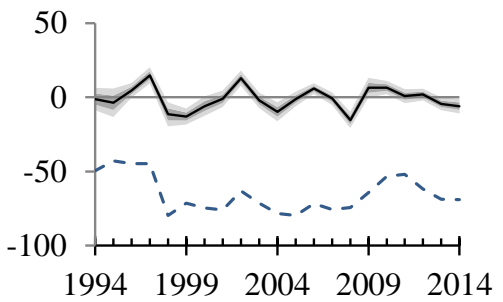

$\underline{\text { Russia }}$

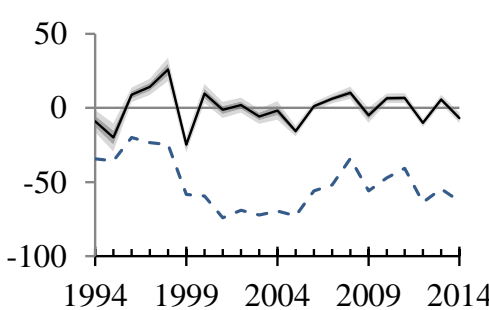

Switzerland

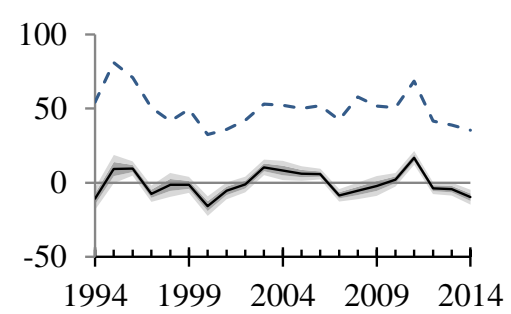

Mexico

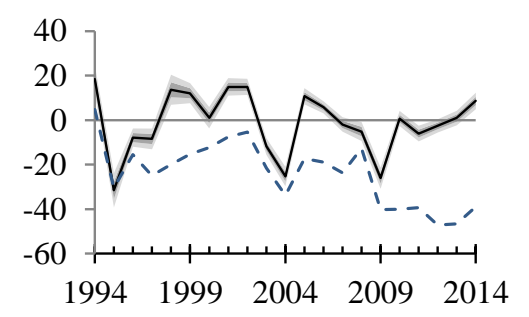

Singapore
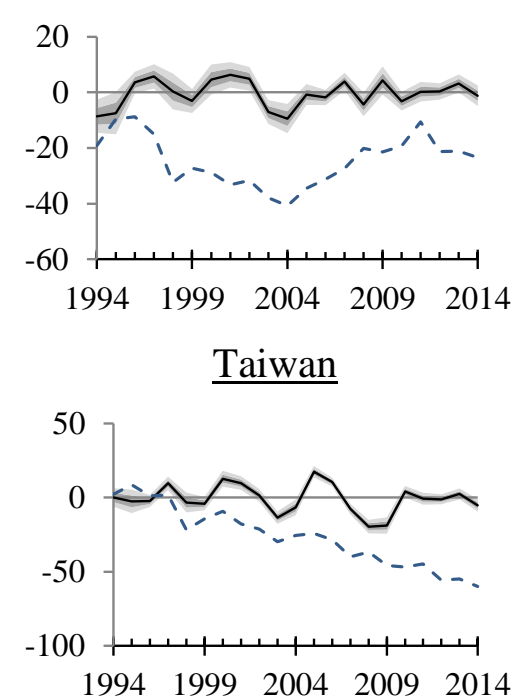

New Zealand

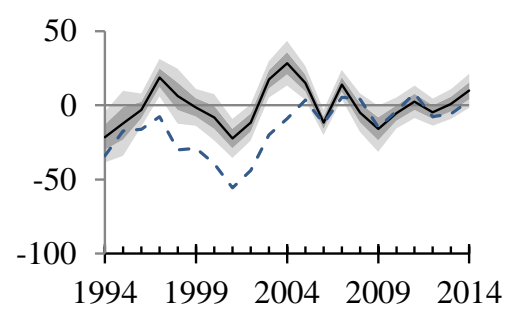

South Korea

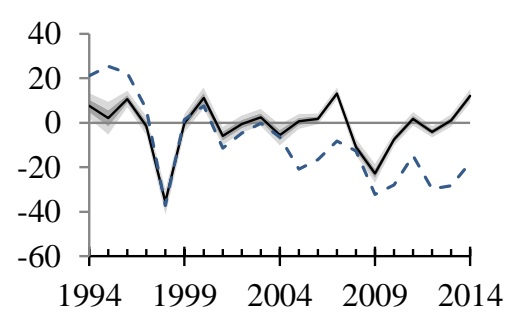

Thailand

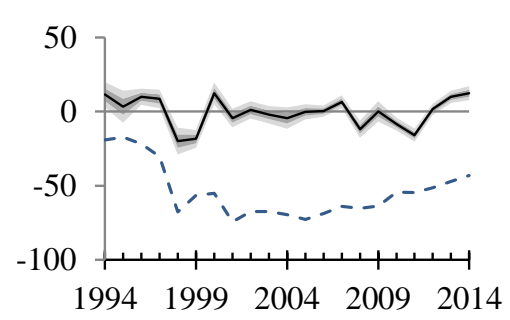

Notes:

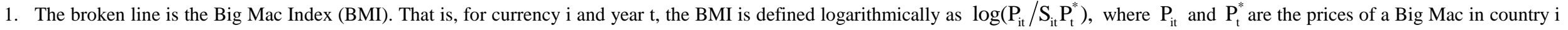
and the US; and $\mathrm{S}_{\mathrm{it}}$ is the exchange rate. According to the BMI, the currency is overvalued if $\log \left(\mathrm{P}_{\mathrm{it}} / \mathrm{S}_{\mathrm{it}} \mathrm{P}_{\mathrm{t}}^{*}\right)>0$ and vice versa.

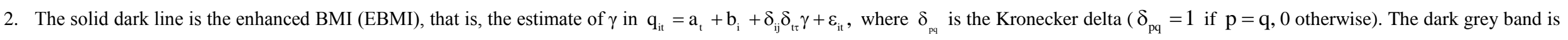
the EBMI +/- one standard error, and the light grey band is $+/$ - two standard errors. When the light grey band includes 0 , we are unable to reject $\mathrm{H}_{0}$ : $\gamma=0$; and when the band includes the $\mathrm{BMI}$, we are unable to reject $\mathrm{H}_{0}: \gamma=$ BMI. The model is estimated separately for each of the four sub-periods. 